\title{
Aging and its impact on sociality in Barbary macaques (Macaca sylvanus)
}

\author{
Dissertation \\ zur Erlangung des mathematisch-naturwissenschaftlichen Doktorgrades \\ „Doctor rerum naturalium“ \\ der Georg-August-Universität Göttingen \\ im Promotionsprogramm Behavior and Cognition (BeCog) \\ der Georg-August University School of Science (GAUSS) \\ vorgelegt von \\ Laura Almeling \\ aus Hannover \\ Göttingen 2017
}




\section{Betreuungsausschuss}

Julia Fischer, Kognitive Ethologie, Deutsches Primatenzentrum - Leibniz-Institut für Primatenforschung, Göttingen

Julia Ostner, Verhaltensökologie, Universität Göttingen

Margarete Boos, Sozial- und Kommunikationspsychologie, Universität Göttingen

\section{Mitglieder der Prüfungskommission}

Referentin: Julia Fischer, Kognitive Ethologie, Deutsches

Primatenzentrum - Leibniz-Institut für Primatenforschung, Göttingen

Korreferentin: Julia Ostner, Verhaltensökologie, Universität Göttingen

\section{Weitere Mitglieder der Prüfungskommission}

Margarete Boos, Sozial- und Kommunikationspsychologie, Universität Göttingen

Claudia Fichtel, Soziobiologie \& Verhaltensökologie, Deutsches

Primatenzentrum, Göttingen

Tanya Behne, Kognitive Entwicklungspsychologie, Universität Göttingen

Bernhard Fink, Biologische Persönlichkeitspsychologie, Universität Göttingen

Tag der mündlichen Prüfung: 9. Mai 2017 
"No one can avoid aging, but aging productively is something else" Katharine Graham (1917-2001)

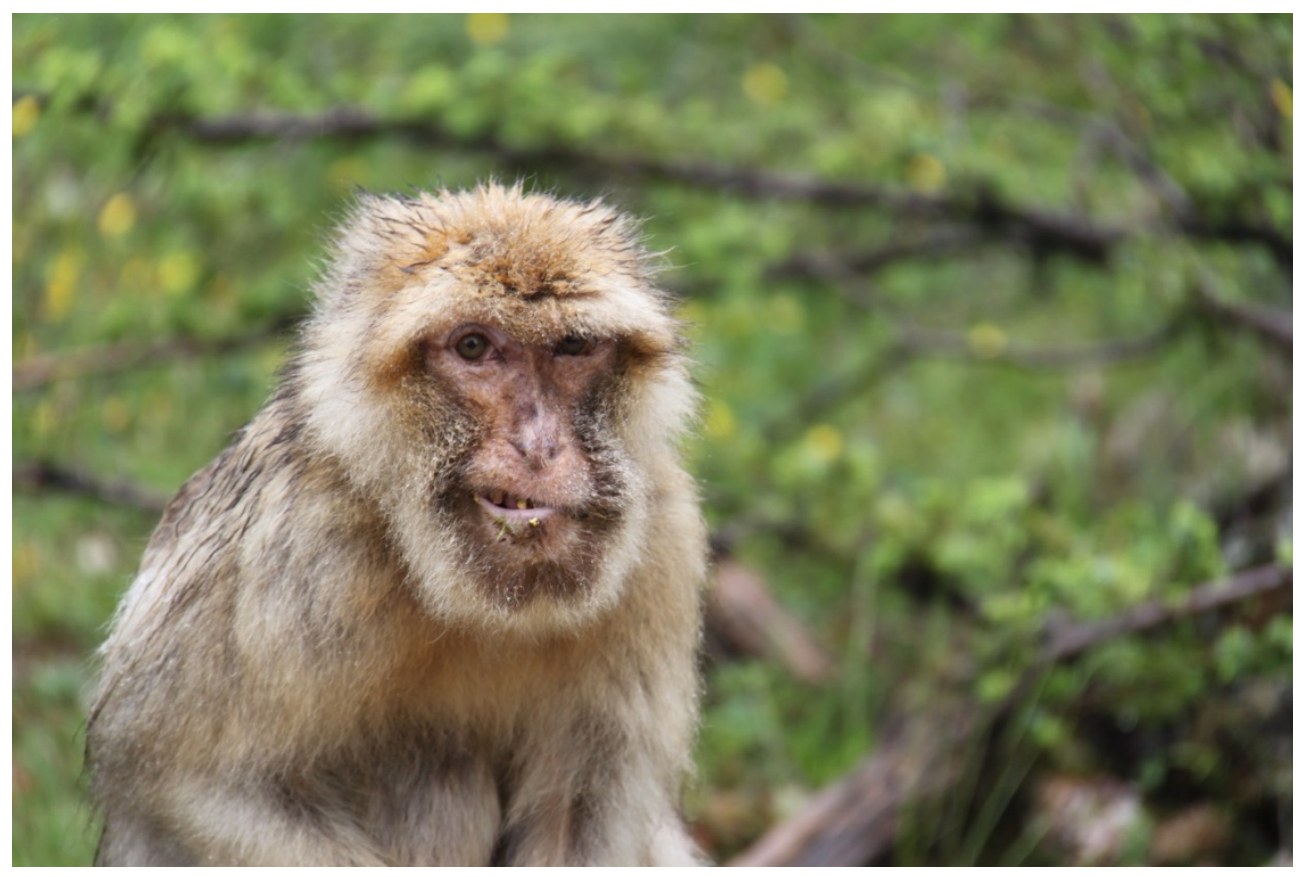




\section{Content}

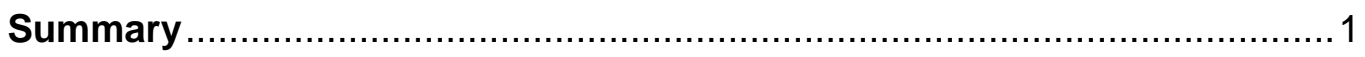

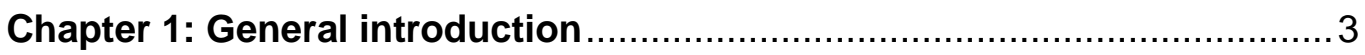

1.1 Aging and its characteristics ...................................................... 4

1.2 Sociality: Measures and associated benefits ................................... 8

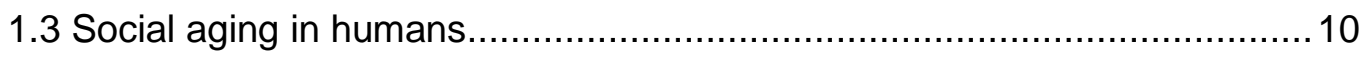

1.4 Social aging in (other) primates .................................................. 15

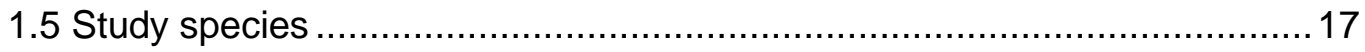

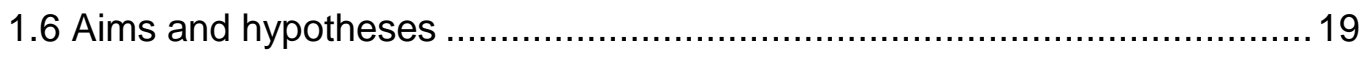

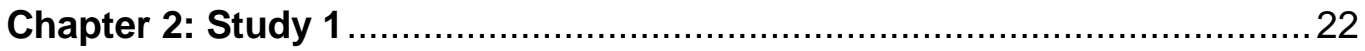

Motivational shifts in aging monkeys and the origins of social selectivity

with Kurt Hammerschmidt, Holger Sennhenn-Reulen, Alexandra M. Freund and Julia Fischer

Chapter 3: Study 2

Social interactions and activity patterns of old Barbary macaques: further insights into the foundations of social selectivity

with Holger Sennhenn-Reulen, Kurt Hammerschmidt, Alexandra M. Freund and Julia Fischer

Chapter 4: General discussion 69

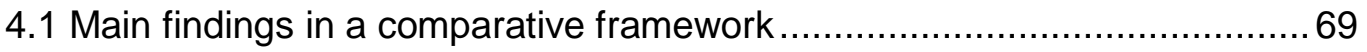

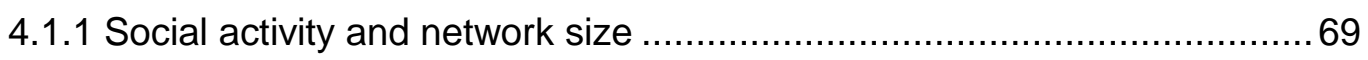

4.1.2 Interest in social and non-social information .................................... 71 


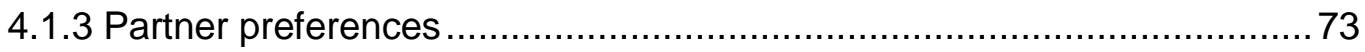

4.1.4 Avoidance of potentially stressful situations ..................................... 75

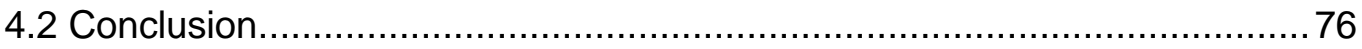

4.3 Limitations and further suggestions for future research......................... 77

4.3.1 Potential benefits of older females' behavioral strategies..................... 77

4.3.2 Relationship quality with remaining partners ...................................... 78

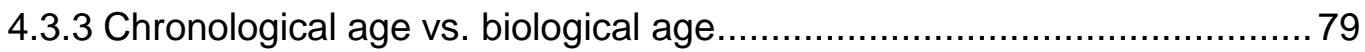

4.3.4 Female aging from a biological perspective ........................................ 79

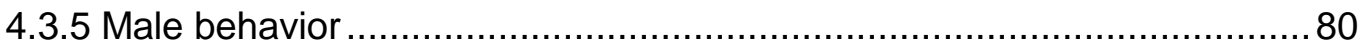

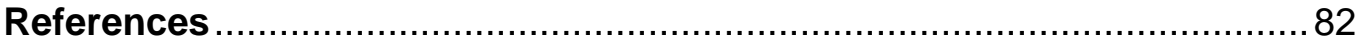

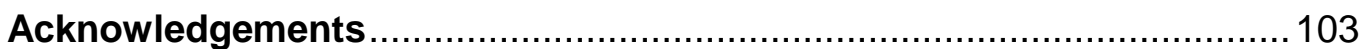




\section{Summary}

With the aging of the human population, studies on the causes and consequences and, particularly, age-associated diseases, are attracting substantial attention. But how does aging affect peoples' motivation to engage with the environment, and their social lives? Throughout adulthood humans' openness to experience, social activity, and the sizes of their social networks decrease. Several models of successful aging have been put forward to explain changes in older peoples' social lives, of which the socio-emotional selectivity theory receives the greatest support. According to this theory, the awareness of a shrinking future time perspective drives shifts in human preferences, resulting in a focus on a circle of emotionally close persons over gaining new experiences. Yet, physiological changes may also contribute to motivational shifts.

To explore the evolutionary origins of human behavior, researchers have frequently turned to our closest relatives - the nonhuman primates. Macaques exhibit an aging phenotype similar to humans, but most likely lack an insight into their limited lifetime. My dissertation study set out to test core components derived from models of successful aging by investigating age-related variation across social and cognitive domains in Barbary macaques (Macaca sylvanus). Specifically, I studied a large ageheterogeneous population living in the outdoor enclosure La Forêt des Singes in Rocamadour, France. These monkeys are food-provisioned and do not experience any predation, resulting in a relatively large number of older individuals in the population. This provided me with the opportunity to study the motivational and social consequences in an aging non-human primate population, in the absence of cognitively sophisticated processes and cultural conventions that accompany human aging. I used an experimental approach to determine Barbary macaques' interest in social and nonsocial stimuli and assessed the behavioral patterns of females.

I found that the motivation to engage in novel object tasks declined in early adulthood. In contrast, I did not observe any age-related changes in interest in social information. Similar to younger monkeys, older monkeys were more interested in portrait photographs of important social partners compared to other group members. Irrespective of age, females responded more strongly to playbacks of their main female affiliation partner compared to females with which they do not have an affiliative relationship. Finally, age had no effect on the frequency female's emitted vocalizations when observing social interactions between third parties. However, older females engaged less in grooming and groomed fewer partners themselves. Average grooming 
bout length increased with age, suggesting that faster tiring might not account for the decrease in grooming patterns and that the older females still seem to be interested in physical affiliative interaction. I observed that older females tended to be more spatially reclusive and the frequency of events in which females were the target of aggression declined with age. However, other group members still groomed the older females at similar rates. Thus, the aging females themselves seem to be responsible for the shrinking network size. Finally, I did not find evidence for a decrease in active aggression rates, but the proportion of low-level aggression increased with age. Thus, older females appear to avoid situations with uncertain outcome, and particularly potentially harmful ones.

In sum, monkeys became overall more selective with age regarding interactions with their environment, in terms of shifting the focus on social rather than non-social stimuli. Moreover, female subjects became more socially selective with age. This observation does not seem to be due to physical deterioration, but older females' social life does seem to be characterized by a greater avoidance of situations with uncertain outcomes and risky situations. In conclusion, the findings reported in this dissertation suggest that at least some of the motivational changes observed across the human lifespan are a shared trait with nonhuman primates. This does not rule out that, in humans, consciousness about a limited life span contributes to shifting preferences with age, but it does suggest that physiological changes may account for some of the observed age-related variation. My dissertation study paves the ground for further research into the predictors of successful aging in primates, as well as the potential benefits of social selectivity. As such, my dissertation study contributes to the growing field of evolutionary developmental psychology. Future studies should focus on the potential age-related avoidance of negative situations, as it appears to be an important explanatory variable contributing to similarities in old humans' and monkeys' behavioral patterns. Moreover, combining psychological and biological methods might facilitate the understanding of the similarities and dissimilarities that occur in the progress of aging across the primate order. 


\section{Chapter 1: General introduction}

The human population is aging (United Nations Report, 2015). By the year 2050, onefifth of the world's human population will be older than 60 (United Nations Report, 2015). Population aging is driven by changes in reproductive and mortality patterns associated with social and economic development (United Nations Report, 2015). It can be considered as a sign of success, for instance, in reducing child mortality (United Nations Report, 2015). At the same time, it poses substantial economic challenges to the societies it affects (Prettner, 2013) - for example, in terms of improving the health and well-being of older citizens (Fontana, Partridge, \& Longo, 2010; Freund, Nikitin, \& Riediger, 2012). Accordingly, research interest in age-related physiological and cognitive decline and, particularly, in age-associated diseases like dementia and Alzheimer's, is intense (Blackburn, Epel, \& Lin, 2015; Keene \& Joiner, 2015; O'Toole \& Jeffery, 2015). As social participation is positively associated with self-perceived health and negatively associated with loneliness (Gilmour, 2012), the impact of aging on sociality is also an important research question. Across adulthood, humans show a decrease in social activity and the sizes of their social networks (Ajrouch, Antonucci, \& Janevic, 2001; Carstensen, 1992; Verbrugge, Gruber-Baldini, \& Fozard, 1996). Models of successful aging aim to explain these changes (Carstensen, 1993; Cumming \& Henry, 1961; Havighurst, 1961; Lemon, Bengtson, \& Peterson, 1972). Socio-emotional selectivity theory has the greatest evidential support. According to socio-emotional selectivity theory, the awareness of one's increasingly limited time left to live induces one to focus on one's circle of emotionally close people (see Carstensen, Fung, \& Charles, 2003; Carstensen, Isaacowitz, \& Charles, 1999 for reviews on studies supporting this hypothesis).

In exploring the evolutionary origins of human behavior, researchers frequently study our closest living relatives: the nonhuman primates (hereafter 'primates') (e.g., Maestripieri \& Roney, 2006). Given the absence of thinking about one's limited lifetime, elaborated future planning abilities, and cultural conventions, studies of primates help to elucidate which age-associated changes in human behavior may be due to shared biological processes (Crockford, 2016). My dissertation study sets out to investigate age-related variations across different social and cognitive domains in Barbary macaques (Macaca sylvanus). 
In this general introduction, I first describe the common conception of aging and address the question of how to define the category 'old age' in humans and primates. Second, I review some of the age-related physiological, physical, cognitive, and reproductive changes in humans and primates. Third, I take a psychological perspective on aging and review the motivational changes in humans and primates that come with old age (section 1.1). Fourth, I consider the importance of sociality for the health, well-being, and fitness of humans and primates (section 1.2). Fifth, I address age-associated changes in sociality in humans and provide an overview of the models of successful aging with a focus on socio-emotional selectivity theory (section 1.3). Sixth, I summarize the evidence from social aging studies of primates (section 1.4). Next, I introduce Barbary macaques and explain why the population at La Forêt des Singes is particularly well suited for this type of research (section 1.5). Finally, I outline the research questions and hypotheses of my study (section 1.6).

\subsection{Aging and its characteristics}

'Aging' is commonly defined in terms of the progressive losses in physiological functioning, decreasing fertility, and increasing mortality that accompany advancing chronological age (Archer \& Hosken, 2016; Kirkwood \& Austad, 2000). Aging is a universal process (Austad, 1997); it occurs in humans, other mammals, birds, insects (Jones et al., 2014), and can even be observed in bacteria (Ackermann, Stearns, \& Jenal, 2003). As natural selection shapes organisms for optimal survival and reproductive success, aging poses an evolutionary paradox (e.g., Fabian \& Flatt, 2011). It did not evolve as an adaptation or for the good of the species, as for some time was thought, but is merely a by-product of natural selection (see Fabian \& Flatt, 2011 for a review). This is because natural selection becomes inefficient at old age, for genes with deleterious mutations that have effects in later life have already been passed on to the next generation. This hypothesis has been formalized by Hamilton (1966).

But how should the category of old age be defined? Since aging exhibits significant intra-individual variability (McDonald, 2014), there is no objective physiological marker for old age, as there is for sexual maturation (Carey \& Gruenfelder, 1997). For example, the human thymus gland starts to atrophy at approximately 14 years of age, a point in life when the rate of bone growth may be at its maximum (McDonald, 2014). This high intra-individual variability also makes functional criteria for the onset of old age difficult to determine (McDonald, 2014). 
There are also large inter-individual differences due to several factors, such as stress (Ahola et al., 2012), smoking (Vogel, Davis, Nomura, Wasnich, \& Ross, 1997), and personality (Aldwin, Spiro, Levenson, \& Cupertino, 2001). For instance, a study by Ahola and colleagues (2012) showed that work-related exhaustion was associated with shorter telomere length, indicating an accelerated aging rate. Still, an operational definition of 'old age' is would be useful. For humans, lifespan developmental psychologists often use the age of 65 , the beginning of retirement, as a somewhat arbitrary threshold (e.g., Freund \& Baltes, 2000). This criterion seems justified because retirement constitutes a major change in lifestyle (Carter \& Cook, 1995). Psychologists have also defined the category of the 'very old', with age for its onset set differently by different authors (for individuals over 70 or 85 years of age, for instance) (Bukov, Maas, \& Lampert, 2002; Wahl \& Rott, 2002). For non-human animals, Carey and Gruenfelder (1997) have suggested the last third of the specific lifespan as an operational definition of 'old age.' Unless chronological exact ages are not available, as it may occur in wild populations (e.g., Ratnayeke, 1994), primatologists studying aging usually use a category that roughly meets this criterion. For macaques in semi-free ranging and captive populations, old age is supposed to start somewhere between 14 and 20 years of age (Corr, 2003; Paul, Kuester, \& Podzuweit, 1993; Veenema, Spruijt, Gispen, \& van Hooff, 1997). Morphological measures, for instance, the degree of wear of the teeth, were used to justify to classify an individual as old (Berghänel, Ostner, \& Schülke, 2011). In sum, aging includes wide inter- and intra-individual variability, which makes previous definitions of 'old age' arbitrary and, so, of limited use. Thus, even though wide variation implies that chronological age does not correlate perfectly with biological condition, I use chronological age in all of my analyses while keeping limitations of this approach in mind.

Research into various aspects of biological aging uses animal models extensively, particularly species with short lifespans, for example, the molecular mechanisms of lifespan determination in yeast (Nakamura et al., 1997) and ageassociated stem cell dysfunction in Drosophila (Park et al., 2012). Because of our shared ancestry (Maestripieri \& Roney, 2006; Rhesus Macaque Genome Sequencing and Analysis Consortium, 2007), primate aging deserves particular attention. Studies of primate aging are more demanding than studies of rodents, for instance. These have largely focused on macaques (Verdier et al., 2015). In particular, rhesus macaques (Macaca mulatta) have been well studied in medical research (Verdier et al., 2015). Such studies have shown that humans and macaques exhibit similar physiological and 
cognitive aging phenotypes (Roth et al., 2004; Verdier et al., 2015). For both, aging is associated with, for example, impaired hearing (Magariños, Milo, \& Varela-Nieto, 2015; Torre \& Fowler, 2000) and sight (Duane, 1922; Ryu, Graham, Sakamaki, \& Furuichi, 2016). Aging humans (Verbrugge et al., 1996) and macaques (Corr, 2003; Kato, 1999; Nakamichi, 1984; Pavelka, 1990; Suomi, Novak, \& Well, 1996; Veenema et al., 1997) were both observed to be less physically active and to spend more time resting. The diminished fighting ability observed in older monkeys may be due to physical decline (Bissonnette, Lange, \& van Schaik, 2009; Fischer, Kitchen, Seyfarth, \& Cheney, 2004; Paul \& Kuester, 1987).

In humans, age-associated changes in endocrine and cardiovascular functioning result in a decreased ability to cope with stressors (see Charles, 2010 for a review on studies supporting this hypothesis). For example, older people show an enhanced cortisol response to challenges as compared to younger people (Otte et al., 2005). Moreover, the hearts of the older require more oxygen than those of the younger (Folkow \& Svanborg, 1993). Similarly, Sapolsky and Altmann (1991) reported evidence for an age-related increase in dexamethasone resistance in wild yellow baboons (Papio cynocephalus). And older captive bonnet macaques (Macaca radiata) show higher mortality subsequent to new group formation compared to younger animals (Jensen, Blanton, \& Gribble, 1980).

The aging brains of humans and monkeys experience similar structural alterations with age (see Roth et al., 2004; Verdier et al., 2015 for reviews). Which of these changes are associated with which aspects of the cognitive decline observed in older subjects is controversial and beyond the scope of this chapter. For further reading on this topic see Peters et al., 1996; Raz, Gunning-Dixon, Head, Dupuis, \& Acker, 1998. Still, I want to give a few examples of studies supporting the view that aging is associated with mild cognitive impairment. Davis and colleagues (2003) used a verbal recall test to demonstrate that older people show a decline in memory functioning. Moreover, when asked to sort cards according to one category (e.g., number) and then to use a different category (e.g., color), older subjects made more errors than younger ones (see Rhodes, 2004 for a meta-analysis). Similarly, in rhesus monkeys, older subjects performed worse than younger ones in a task in which subjects were to identify a new stimulus among an increasing number of familiar stimuli (Herndon, Moss, Rosene, \& Killiany, 1997). Manrique and Call (2015) demonstrated with subjects of several ape species an age-associated decrease in how quickly a subject changed its behavior when a previously rewarded strategy for solving a problem was no longer 
rewarded and a new strategy was required. However, they also observed that subjects in young adulthood had pronounced difficulties in changing strategies (Manrique \& Call, 2015). Changes in social cognition throughout adulthood are comparatively less frequently acknowledged, but a few studies suggest that there is some age-related decline (Rosati, Arre, Platt, \& Santos, 2016; Slessor et al., 2016). As it has been observed in humans (Slessor et al., 2016), an age-related decrease in the propensity to follow gaze was reported for rhesus macaque (Rosati et al., 2016).

A striking, though not unique, characteristic of humans, is that females experience a post-reproductive period of life (Alberts et al., 2013). Some studies have supported the hypothesis that the life history of female primates resembles that of female humans with regard to menopause (e.g., Borries \& Koenig, 2008). However, the current evidence suggests that, except for some decline in fertility, female primates do not experience a period of post-reproductive life comparable to humans (Alberts et al., 2013).

From a psychological perspective, there is more to aging than these biological changes. Aging also includes psychological aging (which involves, e.g., feelings, attitudes, interests) and social aging (involving, e.g., life activities) (Aiken, 1989). Because of their findings about some resource gains in old age, psychologists criticize the tendency of biologists to define 'aging' solely in terms of its detrimental effects (Baltes, 1987). Resources here include all of the means that help one to reach one's goals, for example, physical and cognitive capacities, skills, social status, and social relationships (Freund \& Riediger, 2001). Older adults experience enhanced or at least stable capacities for emotional experience and emotional regulation (see Carstensen et al., 2003; Charles \& Carstensen, 2010, for reviews on this topic). Furthermore, older people function at least as well as younger adults in pragmatic aspects of cognition, such as wisdom (e.g., Staudinger, Smith, \& Baltes, 1992). The animal kingdom also provides some cases of older individuals experiencing resource gains. For example, in killer whales (Orcinus orca), a species that experiences a post-reproductive period of life, post-reproductive females show enhanced ecological knowledge (Brent et al., 2015), as evidenced by the observation that post-reproductive females take the lead in collective movements and leadership was pronounced during years when salmon are scarce (Brent et al., 2015). To my knowledge, there is no evidence of resource gains for older primates.

Lifespan developmental psychologists have suggested expanding the concept of development to include processes other than growth (i.e., gains), namely, losses, 
which both occur throughout the human lifespan (Baltes, 1987). Still, an increase in the loss of resources together with a decrease in resource gains characterizes aging (Baltes, 1987). This changing ratio of losses to gains is associated with motivational changes (Freund \& Baltes, 2000). Humans are highly averse to losing resources (Kahneman \& Tversky, 1979), which can lead to a cascade of further losses (Hobfoll, 1989). Accordingly, as they grow old, people orient themselves towards maintaining their resources and avoiding losses (Freund \& Baltes, 2000). In contrast, younger adults still strive to acquire resources (Freund \& Riediger, 2001). So, openness to new experiences decreases with age (Lucas \& Donnellan, 2011). So does the willingness to take risks, as performance on a computer-based gambling task appeared to demonstrate (Deakin, Aitken, Robbins, \& Sahakian, 2004). A recent meta-analysis found no evidence for consistent changes in risk-taking across the lifespan, although (Mata, Josef, Samanez-Larkin, \& Hertwig, 2011). Studies of lifespan changes in the motivation of adult primates to engage with their environment are rare. In chimpanzees (Pan troglodytes), exploratory behavior, defined in terms of reactions to new situations (e.g., habitat, food, object) (Reale, Reader, Sol, McDougall, \& Dingemanse, 2007), decreases with age (Baker, 2000; Massen, Antonides, Arnold, Bionda, \& Koski, 2013).

\subsection{Sociality: Measures and associated benefits}

Before I come to the social changes that may arise with age, I point out the importance of sociality for humans and primates. Humans are termed ultra-social (Richerson \& Boyd, 1998). But how is their sociality assessed? 'Sociality' is a very broad term. The term itself is not used in psychology. Psychologists distinguish implicit social motives (i.e., dispositions to strive for particular types of satisfaction (Atkinson, 1957)), such as affiliation-intimacy (Winter, 1994), from explicit traits like extroversion (Costa \& McCrae, 1992). On the one hand, social motives can be focused on a rewarding end-state, i.e. "approach" (Gable, 2006). On the other hand, they can be focused on an undesired, punishing, end-state, i.e. "avoidance" (Gable, 2006). Typically, psychologists assess outcome variables with the aid of self-questionnaires (Campo et al., 2009). In this context, their main interests are 1) measuring the duration and frequency of engagement in several types of social activities (e.g., time spent visiting friends and frequency with which support is given or received) and 2) measuring the number of social partners of different categories (e.g., relatives and acquaintances) (Campo et al., 2009). Researchers complement these measures with others, e.g., relationship quality 
and frequency of perceived support or feelings of loneliness (Campo et al., 2009; Dykstra, 2009).

Having friends is associated with subjective well-being throughout life (Hartup \& Stevens, 1997). Very happy people spend more time socializing than averagely happy or unhappy people (Diener \& Seligman, 2002). Frequent engagement in social activities is associated with a lower risk of dementia (Wang, Karp, Winblad, \& Fratiglioni, 2002), and a higher number of supportive ties predicts lower levels of interpersonal stress (Uchino, Holt-Lunstad, Uno, \& Flinders, 2001). Moreover, the lack of social support is associated with an increased risk of coronary heart disease (Lett et al., 2005). The presence of satisfying relationships with trusted individuals is negatively correlated with cholesterol and uric acid levels and positively correlated with total numbers of lymphocytes and mitogene response, indicating an overall positive effect on responsiveness to stress and an enhanced immune response for socially wellembedded people (Thomas, Goodwin, \& Goodwin, 1985). Sociality also has consequences for fitness. For instance, the amount of time spent with friends is associated with increased survival (Maier \& Klumb, 2005); a meta-analysis indicated a $50 \%$ increase in the likelihood of survival for subjects with stronger social relationships (Holt-Lunstad, Smith, \& Layton, 2010).

In primatology, sociality is defined as the extent to which an individual is embedded in its social milieu (Brent, Lehmann, \& Ramos-Fernández, 2011). In contrast with human studies, however, how subjects perceive social relations can be addressed only indirectly through endocrinology (Crockford et al., 2013). In primates; grooming, which is an essential part of their lifestyle, is taken to be the key indicator of sociality (Dunbar, 1991). Several studies support the hypothesis that, as in humans, social affiliation in primates is associated with subjective well-being (see Dunbar, 2010 for a review). For example, grooming (Gust, Gordon, Hambright, \& Wilson, 1993) and grooming another individual (Shutt, MacLarnon, Heistermann, \& Semple, 2007) is associated with lowered glucocorticoid metabolite levels. Being groomed decreases heart rates (Aureli, Preston, \& de Waal, 1999; Boccia, Reite, \& Laudenslager, 1989), lowers the frequency with which individuals engage in displacement behaviors such as scratching and yawning (Schino, Scucchi, Maestripieri, \& Turillazzi, 1988), and stimulates the release of brain opioids such as ß-endorphins (Keverne, Martensz, \& Tuite, 1989). These physiological responses associated with grooming might ground an individual's positive attitude, which, in turn, may be a prerequisite for forming a social bond (Aureli \& Schaffner, 2002; de Waal, 2000; Schino \& Aureli, 2009). 
Monkeys in strong relationships are often genetically related (Silk, Alberts, \& Altmann, 2003; Silk et al., 2010). Whether or not it is appropriate to apply 'friendship' to primates is the subject of debate (Silk, 2002). However, the cumulative evidence suggests that primates form relationships similar to human friendship (see Seyfarth \& Cheney, 2012 for a review on studies supporting this hypothesis). Strong social relationships are also prevalent among non-kin (e.g., Goffe, Zinner, \& Fischer, 2016; Haunhorst, Schülke, \& Ostner, 2016; Ostner, Vigilant, Bhagavatula, Franz, \& Schülke, 2013; Patzelt, Pirow, \& Fischer, 2009; Roubová, Konečná, Šmilauer, \& Wallner, 2015). Interaction with close associates appears to be particularly valuable, as indicated by increased oxytocin levels following grooming with a strongly bond partner but not with other partners (Crockford et al., 2013). Vocalizations of strongly bond partners are of particular salience, as playback studies on black crested macaques (Macaca nigra) (Micheletta et al., 2012) and olive baboons (Papio hamadryas anubis) (Lemasson, Palombit, \& Jubin, 2008) have shown. The occurrence of post-conflict affiliative behavior in several primate species (Kappeler \& van Schaik, 1992) further reveals the importance of social relations (de Waal \& van Roosmalen, 1979). In yellow baboons, social connectedness is negatively correlated with basal glucocorticoid levels (Sapolsky, Alberts, \& Altmann, 1997). Young and colleagues (2014) reported that the strength of a male Barbary macaque's three main male affiliations buffers against social stressors like aggression rates, and environmental stressors such as low temperatures. Sociality also has fitness consequences. For example, strong affiliative relationships enhance reproductive success in Assamese macaques (Macaca assamensis) (Schülke, Bhagavatula, Vigilant, \& Ostner, 2010), infant survival (Silk et al., 2003) and longevity (Silk et al., 2010) in baboons (Papio hamadryas ursinus). Moreover, female baboons with higher frequencies of social affiliation have an increased likelihood of survival (Archie, Tung, Clark, Altmann, \& Alberts, 2014). Taken together, the evidence shows that in both humans and primates sociality enhances health, well-being, and fitness.

\subsection{Social aging in humans}

Despite the positive effects of sociality, humans' amount of social activity and their network size decrease with age (Field \& Minkler, 1988; Fung, Stoeber, Yeung, \& Lang, 2008; Verbrugge et al., 1996). It is a common belief that the older individuals are lonely. Loneliness is defined as the discrepancy between a persons' desired and achieved levels of social embeddedness (Perlman \& Peplau, 1981), so it is not 
necessarily linked to levels of social activity or network size (Lansford, Sherman, \& Antonucci, 1998). Dykstra (2009) reported on the basis of an overview of crosssectional studies that loneliness is common only among the very old ( $>80 \mathrm{yrs}$.) but is not a problem for older people in general. Overall life satisfaction seems to be stable throughout adulthood until after age 70 (Baird, Lucas, \& Donnellan, 2010).

I will discuss changes in social behavior within the framework of successful aging (Freund et al., 2012; Havighurst, 1961), a concept I must first explain. Describing an outcome as a success, assumes that it is desired (Freund et al., 2012). Accordingly, the criteria for success are tied to values. So, there can be no generally accepted definition of successful aging (Freund et al., 2012). Nonetheless, researchers agree that successful development entails the optimization of gains and losses (Baltes \& Baltes, 1990). Optimization of two major domains is considered to be important for successful aging, viz., health and well-being (Freund et al., 2012). Researchers conceptualize well-being in several different ways, but all give happiness a significant role (Graney, 1975). Recently, objective criteria have been considered. For example, household income as a measure of well-being or the number of diagnosed diseases as a measure of health (Freund et al., 2012).

The first important theory of social aging was Cumming's and Henry's (1961) disengagement theory. According to this theory, the mutual withdrawal of older people from society is an inevitable process of preparing for death (Cumming \& Henry, 1961). Cumming and Henry (1961) claimed that old people are a burden on a society, as they contribute to its functioning less efficiently. So, the disengagement process contributes to a society's optimal functioning (Cumming \& Henry, 1961). Thus, it is both normal and a norm that older individuals, even those in optimal personal circumstances, decrease their activity as the disengagement process prepares them for the time of lower overall performance (e.g., Fry, 1992). One's readiness to disengage starts when one realizes how little time remains to one and the available amount of ego energy (i.e., energy for coping with internal and external stimuli (Rosen \& Neugarten, 1960)) decreases (Cumming \& Henry, 1961). Disengagement theory implicitly suggests that there is a positive relationship between disengagement and the well-being of older people (Tobin \& Neugarten, 1961). Accordingly, a successfully aging individual desires to withdraw from active life (Havighurst, 1961). Disengagement theory aroused controversy (e.g., Maddox, 1964), and reports that many older people were leading active social lives (e.g., Lemon et al., 1972) challenged its empirical 
adequacy. Consequently, the psychological literature no longer includes work on disengagement theory (Achenbaum \& Bengtson, 1994).

As part of the backlash against the view that older adults willingly become passive, the so-called activity theory took up the opposite view (Havighurst, 1961; Lemon et al., 1972). Initially, activity theory was a loose bundle of ideas associated with no particular authors until it was explicitly formulated by Robert Havighurst (see Knapp, 2009). Its basic tenet is that older individuals want and need to engage in activities, but they become increasingly likely to undergo resource losses, which hamper activity (Fry, 1992; Havighurst, 1961; Lemon et al., 1972). The theory explains reduced activity largely in terms of losses of internal resources, like health problems, and losses of external resources, like the death of friends and relatives and the loss of one's accustomed roles as a result of retirement and widowhood (Havighurst, 1961; Lemon et al., 1972). Activity theory views the reduction in social contacts as problematic for older people and, thus, it has substantial implications for counseling concepts and practices (see Fry, 1992 for a review). According to activity theory, the key to successful aging is to maintain the activities and attitudes of middle age until that becomes impossible (Havighurst, 1961). Hence, a successfully aging individual responds to losses in activities by replacing them with new ones that are physically less taxing, for instance, but still socially engaging (Fry, 1992; Havighurst, 1961). Empirical evidence showed that an active lifestyle enhances the well-being of older people (Graney, 1975; Lemon et al., 1972). Those who engaged frequently in social activities (e.g., visiting friends and relatives, talking on the telephone) were found to be happier than those who were less active (Graney, 1975). Investigating changes in the social lives of very old people (70 years old or older), Bukov and colleagues (2002) reported that level of health predicts level of social participation in a wide variety of activities. However, it has also been observed that changes in levels of social activity begin in early adulthood, before age-related losses occur (Carstensen, 1992). A 4-year study of older adults revealed that more than half of the discontinued relationships were ended deliberately (Lang, 2000).

Neither disengagement theory nor activity theory provides a complete framework for studying the social relations of older people, for according to neither theory do older individuals actively shape their development and environment, as several lifespan psychologists have suggested (Baltes, 1987; Heckhausen \& Schulz, 1995). For the last two decades, the socio-emotional selectivity theory (Carstensen, 1993) is the successful aging theory that has received the most attention. Socio- 
emotional selectivity theory is a lifespan theory of social motivation, according to which the perception of time is a crucial determinant of changes in the social goal hierarchy and the resulting partner preferences (see Carstensen et al., 2003; Carstensen et al., 1999 for reviews on studies supporting this hypothesis). While a perspective that includes an extended future is associated with the prioritization of knowledge-related goals, a limited-time perspective leads to a prioritization of emotionally meaningful goals in interaction (Carstensen et al., 1999). Later, when Carstensen and colleagues extended their research interest in explaining the enhanced or at least stable emotional well-being with age (e.g., Carstensen et al., 2003) the model also contrasted goals that serve to regulate emotional states with more generally all other goals (Carstensen, 2006). Interactions with close associates are more likely to be meaningful and emotionally satisfying than interactions with less significant people (Carstensen, 1993). Accordingly, a successfully aging individual focuses on close partners in order to maximize positive affect. Fredrickson and Carstensen (1990) presented subjects with cards depicting different types of social partners, which were previously rated in terms of anticipated affect and information seeking prospects. For example, a close friend scored high on positive affect but low in terms of information seeking prospects while an artist scored high in both regards (Fredrickson \& Carstensen, 1990). Participants were asked to choose with whom which they would like to spent time with and whom of the potential partners they would like to get to know better. Results suggest that older people give more importance to the affect anticipated in the interaction than to information seeking. Several studies have showed that an age-associated reduction in social network size is due to an increased focus on close partners (Field \& Minkler, 1988; Fung et al., 2008; Lang \& Carstensen, 1994; Lang, Staudinger, \& Carstensen, 1998). Moreover, older people are hardly interested in getting to know new people (Fredrickson \& Carstensen, 1990). Older adults are also more satisfied with their number of friends than are younger adults and do not desire larger networks (Lansford et al., 1998). This occurs despite younger adults having more frequent contact with their network's members than do older people (Lansford et al., 1998). By manipulating subjects' perspectives on the future, some experimental studies have established the existence of a causal relation. In one experiment, investigators imposed a hypothetical time constraint on subjects by asking them to imagine that they would soon be moving across the country but currently had 30 minutes free (Fredrickson \& Carstensen, 1990). Both older and younger adults preferred spending the half-hour with a familiar social partner (Fredrickson \& Carstensen, 1990). In another study, subjects were asked to 
imagine that a recent medical discovery would extend their lives by 20 healthy years (Fung, Carstensen, \& Lutz, 1999). The preference of older subjects for familiar partners disappeared, and their social choices did not differ from those of younger subjects (Fung et al., 1999).

Studies on whether and how social motives changes with age yielded conflicting results (Nikitin, Burgermeister, \& Freund, 2012; Nikitin \& Freund, 2011; Nikitin, Schoch, \& Freund, 2014). Rather the ratio but the absolute differences in approach and avoidance motivation changes, and older adults experience a shift towards stronger avoidance motivation with age (Nikitin et al., 2014). In line with socio-emotional selectivity theory, the focus that older people put on their emotional well-being may also induce changes in their conflict behavior. Older people reported fewer interpersonal tensions and less frequent arguing than younger people (Birditt, Fingerman, \& Almeida, 2005). Moreover, older adults seem to preferentially engage in passive strategies to avoid conflicts (Charles, Piazza, Luong, \& Almeida, 2009). Older adults also profit from using passive strategies, as older age was related to less affective reactivity among those who avoided arguments but was unrelated to affective reactivity among people who engaged in arguments (Charles et al., 2009). One should note that the strength and vulnerability integration model (SAVI model), a model of successful aging that aims to explain the stable or enhanced emotional well-being in older age, provides an alternative explanation of these patterns (Charles, 2010). The SAVI model considers as important factors not only the amount of time an older adult has left but also the amount of time already lived as well as reduced physiological flexibility (Charles, 2010). Charles (2010) claimed that because of their increased susceptibility to stressors older individuals make enhanced use of strategies that result in the avoidance of, or limited exposure to, negative stimuli.

Socio-emotional selectivity theory is compatible with broader models of lifespan development (Fredrickson \& Carstensen, 1990), such as the selection, optimization, and compensation model (SOC model) (Baltes \& Baltes, 1990; Freund \& Baltes, 2002). According to the SOC model, successful aging includes the selection of functional domains on which to focus one's resources (Freund, Li, \& Baltes, 1999). People adapt to losses in certain areas (e.g., cognitive functioning) by selecting and concentrating on other areas with a high priority (Baltes, 1987). Empirical evidence suggests that older adults not only pursue fewer goals but also they focus more on central goals (Riediger \& Freund, 2006). The amount of previous investment and the threat of loss are the 
main predictors of selectivity (Ebner, Freund, \& Baltes, 2006). However, the SOC model does not specifically address selectivity in the social domain.

\subsection{Social aging in (other) primates}

Studies of social aging in primates are relatively rare (see Table 1.1 for an overview of studies with more than 3 individuals per age category). In the text, I focus on studies of female social aging but include also those studies in which the data on both sexes were pooled for the analysis (namely these two studies: Picq, 1992; Suomi et al., 1996). I do so for two reasons. First, previous studies focused predominantly on females. Second, my behavioral observations were restricted to female subjects. For the details on studies of male primate social aging, see chapter 4.3.5.

Table 1.1: Overview of social aging studies of primates

\begin{tabular}{|c|c|c|c|c|c|}
\hline Study & Species & $\begin{array}{l}\text { Housing } \\
\text { conditions } \\
\end{array}$ & $\begin{array}{l}\text { Sample } \\
\text { size }\end{array}$ & $\begin{array}{l}\text { Age } \\
\text { range }\end{array}$ & $\begin{array}{l}\text { Observation } \\
\text { time } \\
\end{array}$ \\
\hline $\begin{array}{l}\text { Hauser \& Tyrell } \\
1984\end{array}$ & $\begin{array}{l}\text { Japanese macaques } \\
\text { (Macaca fuscata) }\end{array}$ & $\begin{array}{l}\text { free-ranging, } \\
\text { provisioned }\end{array}$ & 18 운 & 8-28 yrs. & unclear \\
\hline $\begin{array}{l}\text { Nakamichi } \\
1984 \\
\end{array}$ & $\begin{array}{l}\text { Japanese macaques } \\
\text { (M. fuscata) }\end{array}$ & $\begin{array}{l}\text { free-ranging, } \\
\text { provisioned }\end{array}$ & $14 ?$ & $11-29$ yrs. & $\begin{array}{l}140 \mathrm{~h}, \\
\sim 4 \text { month }\end{array}$ \\
\hline $\begin{array}{l}\text { Pavelka } \\
1990 / 91 \\
\end{array}$ & $\begin{array}{l}\text { Japanese macaques } \\
\text { (M. fuscata) }\end{array}$ & $\begin{array}{l}\text { semi-free } \\
\text { ranging }\end{array}$ & $40 ㅇ$ & $5-30$ yrs. & $\begin{array}{l}450 \mathrm{~h}, \\
29 \text { month }\end{array}$ \\
\hline $\begin{array}{l}\text { Picq } \\
1992 \\
\end{array}$ & $\begin{array}{l}\text { Grey mouse lemurs } \\
\text { (Microcebus murinus) }\end{array}$ & $\begin{array}{l}\text { captive, } \\
\text { pairs }\end{array}$ & $\begin{array}{l}8 \stackrel{0}{+} \\
4 \stackrel{1}{0}\end{array}$ & 1-12 yrs. & $\begin{array}{l}40 \mathrm{~h}, \\
2 \mathrm{month}\end{array}$ \\
\hline $\begin{array}{l}\text { Kato } \\
1999 \\
\end{array}$ & $\begin{array}{l}\text { Japanese macaques } \\
\text { (M. fuscata) }\end{array}$ & $\begin{array}{l}\text { free-ranging, } \\
\text { provisioned }\end{array}$ & $16 \stackrel{+}{+}$ & 10-25 yrs. & $\begin{array}{l}383 \mathrm{~h}, \\
19 \text { month }\end{array}$ \\
\hline $\begin{array}{l}\text { Suomi } \\
1996\end{array}$ & $\begin{array}{l}\text { Rhesus macaques } \\
\text { (Macaca mulatta) }\end{array}$ & captive & $\begin{array}{l}40 \\
4 \stackrel{1}{1} \\
\end{array}$ & $6-20$ yrs. & $\begin{array}{l}\sim 980 \mathrm{~h}, \text { (est.) } \\
15 \text { yrs. }\end{array}$ \\
\hline $\begin{array}{l}\text { Veenema } \\
1997\end{array}$ & $\begin{array}{l}\text { Long-tailed macaques } \\
\text { (Macaca fascicularis) }\end{array}$ & $\begin{array}{l}\text { captive, } \\
\text { group-housed }\end{array}$ & 35 & 3-25 yrs. & $\sim 485 \mathrm{~h}$ \\
\hline $\begin{array}{l}\text { Baker } \\
2000 \\
\end{array}$ & $\begin{array}{l}\text { Chimpanzees } \\
\text { (Pan troglodytes) }\end{array}$ & $\begin{array}{l}\text { captive, } \\
\text { pairs or trios }\end{array}$ & $\begin{array}{l}14 \stackrel{9}{1} \\
20 \stackrel{\lambda}{0} \\
\end{array}$ & 11-44 yrs. & $240 \mathrm{~h}$ \\
\hline $\begin{array}{l}\text { Corr } \\
2002 \\
\end{array}$ & $\begin{array}{l}\text { Rhesus macaques } \\
\text { (Macaca mulatta) }\end{array}$ & $\begin{array}{l}\text { semi-free } \\
\text { ranging }\end{array}$ & 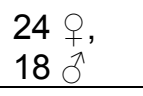 & $7-20+$ yrs. & $627 \mathrm{~h}$ \\
\hline $\begin{array}{l}\text { Nakamichi } \\
2003\end{array}$ & $\begin{array}{l}\text { Japanes macaques } \\
\text { (M. fuscata) }\end{array}$ & $\begin{array}{l}\text { free-ranging, } \\
\text { provisioned }\end{array}$ & $38 ?$ & 5-22 yrs. & $261 \mathrm{~h}$ \\
\hline
\end{tabular}

Aging has been associated with reduced spatial embeddedness in the group. Older female Japanese macaques (Macaca fuscata) spend less time within 2-meter (Kato, 1999) and 3-meter (Nakamichi, 1984) radii to other group members than do younger animals. Moreover, fewer individuals were observed to be within 1.5-, 3-, and 
10-meter radii of them, and they were more frequently isolated from the group (i.e., with no other individual within a 10-meter radius) (Hauser \& Tyrrell, 1984). Since older females were not outranked by younger ones, rank differences cannot account for their spatial reclusiveness; rather, it seems to reflect older females' unwillingness to interact (Hauser \& Tyrrell, 1984). Social contact time was also reported to decrease with age for rhesus macaques (Corr, 2003) and a group of Japanese macaques (Nakamichi, 1984). In contrast, age was not observed to have any effect on social contact time in a different population of Japanese macaques (Pavelka, 1991). While a decrease in the number of social partners was observed in female rhesus macaques (Corr, 2003), the number of social partner did not vary by age in Japanese macaques (Pavelka, 1991). Overall grooming activity was reported to remain stable for female chimpanzees (Baker, 2000) and even to increase with age in rhesus macaques (Suomi et al., 1996). Several studies that distinguished active and passive grooming (e.g., Nakamichi, 2003) provide some insight into the directionality of potential changes. Older female Japanese macaques (Nakamichi, 1984) and rhesus macaques (Corr, 2003) were observed to invest less time in active grooming. The amount of time that females of both species received grooming was not affected by their age (Corr, 2003; Nakamichi, 1984).

Several studies reported a focus on important partners with increased age (Kato, 1999; Nakamichi, 2003; Veenema et al., 1997). While older female Japanese macaques groomed fewer unrelated partners, the number of related partners that were groomed did not vary across age categories (Nakamichi, 2003). For older females that were low-ranking, Nakamichi (2003) also reported a decrease in the number of unrelated females from which a subject received grooming (Nakamichi, 2003). However, older high-ranking females were observed to be attractive social partners (Nakamichi, 2003). Similarly, in another study of Japanese macaques, age had no effect on the number of related partners (Kato, 1999). Finally, in female long-tailed macaques (Macaca fascicularis), the only observed age-related decrease in grooming interactions involved unrelated partners (Veenema et al., 1997).

Overall involvement in conflicts was reported to decrease with age for rhesus macaques (Suomi et al., 1996). Aging has also been associated with lowered levels of active aggression for chimpanzees (Baker, 2000), while long-tailed macaques did not exhibit any changes in this regard (Veenema et al., 1997). Older mouse lemurs aggress their cage mates with higher frequencies than younger animals (Picq, 1992). Furthermore, age has been associated with a reduced frequency of victimization in 
female long-tailed macaques (Veenema et al., 1997) and older female rhesus macaques were more frequently the targets of aggression compared to younger ones (Corr, 2003).

In sum, these studies yield conflicting results but indicate that an age-related decrease in social activity and social network size and an increased focus on important partner may occur in primates. Species differences as well as differences in housing conditions may affect how social behavior changes with age. Further detailed studies are necessary to determine the extent to which changes in social behavior are similar to those in humans.

\subsection{Study species}

Barbary macaques belong to the genus Macaca (Primates, Cercopithecidae), which shared an ancestor with humans approximately 23 million years ago (Kumar \& Hedges, 1998). They live in female-bonded, multi-male groups (Wrangham, 1980) with a more or less balanced sex ratio (von Segesser et al. 1999). At La Forêt des Singes, three stable social groups (166 individuals in April 2014) are housed on approximately 20 hectares (Turckheim, Merz, \& Fa, 1984). In Barbary macaques females remain in their natal groups (Paul \& Kuester, 1987), and some males migrate when they reach sexual maturity, at the earliest, in both wild and semi-free ranging populations (Kuester \& Paul, 1999; Menard \& Vallet, 1993). Males (Preuschoft, Paul, \& Kuester, 1998) and females (Paul \& Kuester, 1987) have separate hierarchies. Females exhibit a relative stable linear dominance hierarchy based on matrilines (Paul and Kuester, 1987). For males the dominance relationships are more variable (Henkel, 2008) and are characterized by a high degree of coalition formation (Berghänel, Schülke, \& Ostner, 2010; Bissonnette, de Vries, \& van Schaik, 2009). Barbary macaques exhibit strong sexual dimorphism (Fooden, 2007), and males are mostly dominant over the females. They have a promiscuous mating system (Small, 1990b) and are seasonal breeders with the mating season in autumn and the birth season in spring (Fooden, 2007). The tolerance of their social style is 3 on a scale of 4 (4=tolerant), i.e., the influence of dominance status and kinship on social interactions is less extreme than in despotic species like rhesus macaques and Japanese macaques (Thierry, 2000a, 2000b). Females form strong relationships with related and unrelated group members, which are characterized by frequent grooming (Patzelt et al., 2009; Roubová et al., 2015). Females are more central and active in the grooming network than are males, and they preferentially groom with females (Sosa, 2016). Moreover, females show extensive alloparental 
behavior (Small, 1990a). Although faced with high paternity uncertainty (Small, 1990b), adult males still exhibit great interest in infants, which is unique among Old World primates (Whitten, 1987). Males start to care for newborns a few days after birth and carry babies towards other males, leading to triadic male-infant interactions (Taub, 1980). Males use infants to establish their position in the male social network (Henkel, Heistermann, \& Fischer, 2010). For example, rates of triadic male-infant interactions during the non-mating season were found to be correlated with rates of coalition support among males during the mating season (Berghänel, Ostner, Schroder, \& Schülke, 2011). Acoustical analysis has revealed that the calls of Barbary macaques are individually distinct (Hammerschmidt \& Todt, 1995). Playback studies have showed that infants are able to recognize the vocalizations of their mothers (Fischer, 2004), and vice versa (Hammerschmidt \& Fischer, 1998). Playback studies have also indicated that voice recognition extends to other group members (Pfefferle, Heistermann, Hodges, \& Fischer, 2008). Barbary macaques can recognize the faces of at least 57 individuals, as is demonstrated by their differential looking time at portrait photographs of group members and strangers (Schell, Rieck, Schell, Hammerschmidt, \& Fischer, 2011).

The population at La Forêt des Singes is particularly well suited for this study. First, unlike wild populations, the monkeys face no risk of predation, and they are provided with food every day. In macaques, such conditions are associated with a reduced risk of mortality and increased longevity (Maestripieri \& Hoffman, 2012). A large proportion of the population consists of older monkeys. In April 2014, about onethird were 20 years old or older with the oldest being 30 years old. Second, the exact ages and matrilineal relationships of the majority of individuals are available (provided by Ellen Merz). Third, the monkeys are well habituated to humans. From April until November, the park is open to visitors, who may walk along a circular path. Monkeys approach visitors to take the popcorn they offer directly out of their hands. However, the monkeys can also avoid human contact, so that human influence does not restrict their social lives (see Turckheim \& Merz, 1984 for a detailed information on the park management). This arrangement permits experimentation in addition to behavioral observations; playback and photograph experiments have been successfully conducted in this population (e.g., Pfefferle et al., 2008; Schell et al., 2011). 


\subsection{Aims and hypotheses}

My aim is to demonstrate that models of successful aging can inform comparative research and that basic research in primates can, in turn, contribute to a better understanding of the evolutionary origins of social aging in humans. Some of the studies I mentioned in section 1.4 have included discussions of disengagement or socio-emotional selectivity theory, while others lack any such theoretical framework (see Tarou, Bloomsmith, Hoff, Erwin, \& Maple, 2002). This can be explained by the fact that it is difficult to apply models of successful aging to primates (Tarou et al., 2002). Except for activity theory, models of successful aging take awareness of the limited amount of lifetime remaining as a precursor for changes in the behavioral patterns and preferences of aging humans, though not always a precursor of the same significance. Further, one of the main precursors for changes in behavioral patterns in the framework of activity theory is role-loss in the context of retirement. Thus, we cannot directly test any of these models in nonhuman primates. Motivational changes are core components in all of the models of successful aging. Such changes, or their absence, are well suited for investigations in a comparative framework (see Table 1.2 for summary). By comparing variations in age across different social and cognitive domains in Barbary macaques, I aim to determine whether these monkeys exhibit any of the models' core motivational changes. If I can find patterns in nonhuman primates that are similar to those in humans, then it may be possible to show that changes in human behavior are driven much more by physiology than present theories acknowledge and that the reasoning attributed to humans may be at least partly a posthoc rationalization for changes in subjective experience and disposition.

Table 1.2: Core components of models of successful aging

\begin{tabular}{l|lll} 
& Age $\uparrow$ & \\
\hline Related human model & $\begin{array}{l}\text { Social activity } \\
\text { and network } \\
\text { size }\end{array}$ & $\begin{array}{l}\text { Interest in } \\
\text { physical } \\
\text { environment }\end{array}$ & $\begin{array}{l}\text { Interest in } \\
\text { social } \\
\text { environment }\end{array}$ \\
\hline $\begin{array}{l}\text { Disengagement theory } \\
\text { (Cumming and Henry 1961) }\end{array}$ & Mutual $\downarrow$ & $\downarrow$ & $\downarrow$ \\
\hline $\begin{array}{l}\text { Activity theory } \\
\text { (Havighurst 1961) }\end{array}$ & Passive $\downarrow$ & $\leftrightarrow$ & $\leftrightarrow$ \\
\hline $\begin{array}{l}\text { Socio-emotional selectivity } \\
\text { theory (Carstensen 1993) }\end{array}$ & Active $\downarrow$ & $\downarrow$ & $\begin{array}{l}\text { important partner } \\
\text { rel.to other } \uparrow\end{array}$ \\
\hline
\end{tabular}

In chapter 2, I address the following questions. (A) Is there a decrease in social activity and network size with increasing age? Using behavioral observations of 
females (including some from a Diploma thesis (Ploss, 2010)), I assess grooming activity in terms of the total grooming time both given and received within a network. I also determine the number of adult grooming partners and the number of partners from whom females receive grooming. To assess the existence of motivational changes, I consider (B) whether or not interest in the environment, including novel objects, problem-solving, and the social environment, decreases with increasing age? (C) Is it possible that a decrease in interest is domain-specific in that it is the result of a focus on social over non-social information? And, (D) could a potential age-associated decrease in interest in the social domain be partner-specific, in that it is restricted to unimportant individuals? I assess interest in the physical environment with the aid of novel-object tests. I present subjects of varying ages with three types of novel objects, one of which provides a food reward after suitable manipulation of the object. To investigate the effects of age in the social environment, I conduct an experiment in which I present subjects of different ages with portrait photographs of conspecifics from three different categories: main female affiliation partner, non-friend group members, and newborn. I measure looking time as a proxy for interest in social information (Schell et al., 2011). I also play to female subjects recorded screams of their main female affiliation partners and non-friend group members elicited in agonistic interactions. Again, I determine looking time as a proxy for interest (Cheney, Moscovice, Heesen, Mundry, \& Seyfarth, 2010). Finally, with the aid of behavioral observations I determine the frequency with which females vocalize as a response to the social interactions of group members under natural conditions (Brumm, 2005).

In chapter 3, I build on the conclusion of chapter 1 . This chapter is a follow-up study in which I have exploited behavioral data sets on Barbary macaque females, including those from two Diploma theses (Patzelt, 2006; Ploss, 2010), as a first step to answering the following questions. (E) To which extent are age-associated changes in grooming patterns due to physical decline? As a proxy for physical deterioration, I determine the frequency with which females engage in physically challenging behaviors and relate it to the lengths of active grooming bouts. If changes in grooming patterns with age are a result of diminished strength, then the average length of grooming bouts should decrease with age. (F) To which extent are the social lives of older female Barbary macaques characterized by the avoidance of potentially stressful social encounters? To address this question, I assess spatial group integration, conflict behavior, and the extent of conflict severity. 
In the general discussion (chapter 4), I come back to my research question, summarize my results and discuss their implications in the context of models of successful aging. I summarize my thoughts and draw an overall conclusion. Finally, I name some limitations of my study and make suggestions for future directions in comparative studies of social aging. 


\section{Chapter 2: Study 1}

Motivational shifts in aging monkeys and the origins of social selectivity

Authors: Laura Almeling ${ }^{1^{\star}}$, Kurt Hammerschmidt ${ }^{1}$, Holger Sennhenn-Reulen ${ }^{2}$, Alexandra M. Freund ${ }^{3}$, Julia Fischer ${ }^{1}$

\section{Affiliations:}

${ }^{1}$ Cognitive Ethology Laboratory

German Primate Center / Leibniz Institute for Primate Research

Kellnerweg 4

37075 Göttingen, Germany

${ }^{2}$ Leibniz ScienceCampus "Primate Cognition"

German Primate Center/ Leibniz Institute for Primate Research

Kellnerweg 4

37077 Göttingen, Germany

${ }^{3}$ Department of Psychology

University of Zurich

Binzmuehlestrasse 14/11

8050 Zurich, Switzerland

Published 2016 in:

Current Biology, 26(13), 1744-1749

DOI: 10.1016/j.cub.2016.04.066 


\section{Graphical abstract}

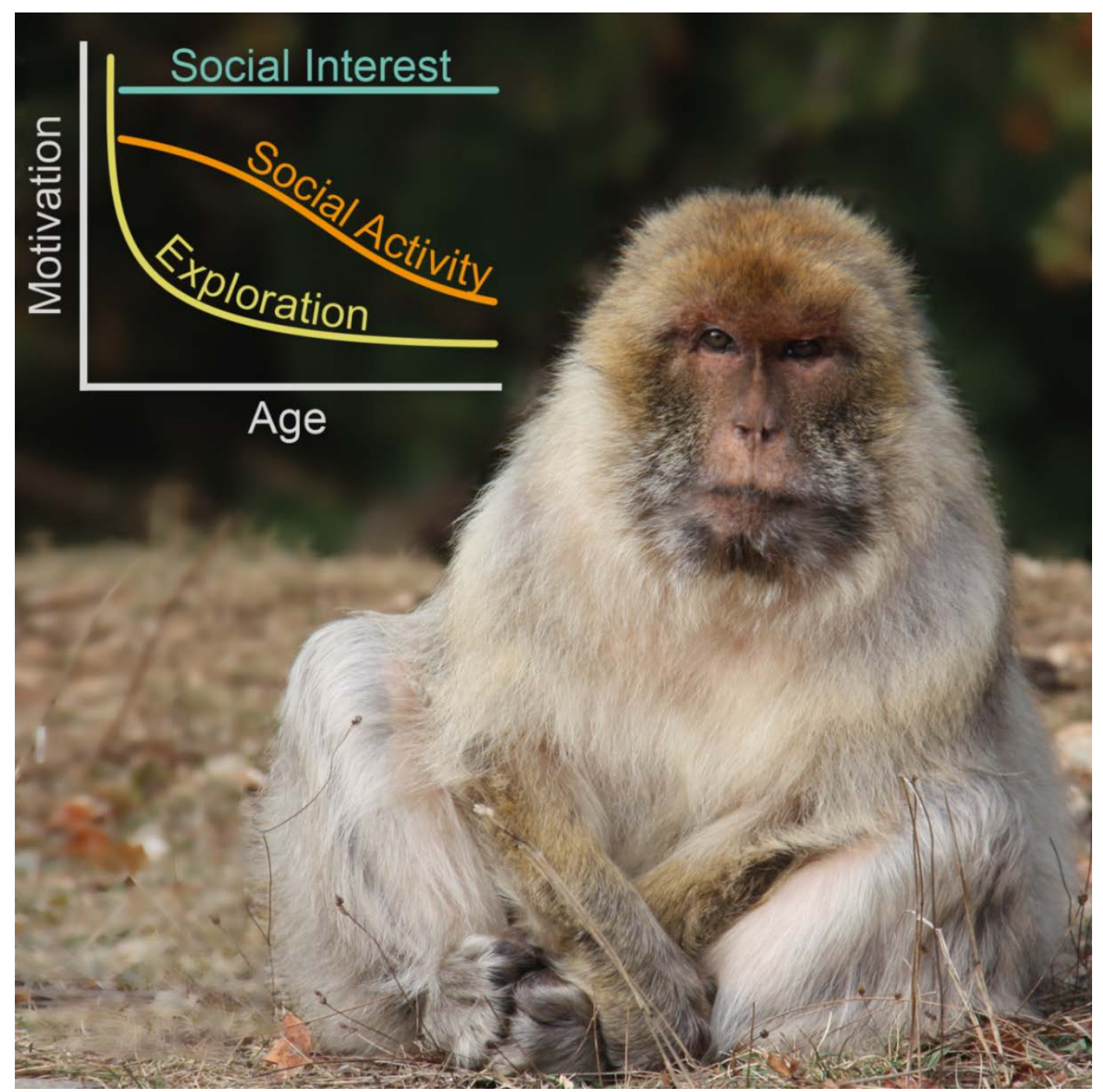

\section{Highlights}

- We studied social and cognitive aging in a large age-heterogeneous group of monkeys

- Experiments and observations revealed differential motivational shifts with age

- Monkeys shifted their focus to the social domain and became socially more selective

- Monkeys maintained their general interest in social information into very old ag 


\section{In brief}

Almeling et al. investigated motivational changes with age in Barbary macaques to explore the foundations of cognitive aging. The monkeys lost interest in the physical environment relatively early in adulthood, while they maintained an interest in social information into very old age, irrespective of a decrease in social activity.

\section{Summary}

As humans age, they become more selective regarding their personal goals (Riediger \& Freund, 2006) and social partners (Carstensen et al., 1999). Whereas the selectivity in goals has been attributed to losses in resources (e.g. physical strength) (Baltes, 1997), the increasing focus on emotionally meaningful partners is, according to socioemotional selectivity theory, driven by the awareness of one's decreasing future life time (Carstensen et al., 1999). Similar to humans, aging monkeys show physical losses (Roth et al., 2004) and reductions in social activity (Carstensen et al., 1999; Corr, 2003; Nakamichi, 2003; Veenema et al., 1997). To disentangle a general resource loss and the awareness of decreasing time, we combined field experiments with behavioral observations in a large age-heterogeneous population of Barbary macaques (Macaca sylvanus) at "La Forêt des Singes". Novel object tests revealed a loss of interest in the nonsocial environment already in early adulthood, which was modulated by the availability of a food reward. Experiments using vocal and visual representations of social partners indicated that monkeys maintained an interest in social stimuli and a preferential interest for friends and socially important individuals into old age. Old females engaged in fewer social interactions, although other group members continued to invest into relationships with them. Consequently, reductions in sociality were not due to a decrease in social interest. In conclusion, some of the motivational shifts observed in aging humans, particularly the increasing focus on social over nonsocial stimuli, may occur in the absence of a limited time perspective, and are most likely deeply rooted in primate evolution. Our findings highlight the value of nonhuman primates as valuable models for understanding human aging (Maestripieri \& Roney, 2006; Verdier et al., 2015). 


\section{Results}

\section{Exploratory and problem-solving behavior}

To assess potential age-related changes in Barbary macaques' interest to engage with the nonsocial environment, we presented male and female subjects with three different types of novel objects: animal toys, a cube filled with colorful plastic pieces and glitter in a viscose liquid and an opaque tube closed with soft tissue at both ends and baited with a food reward (Supplemental Experimental Procedures 1 and 2). Monkeys lost interest in toys in early adulthood, but did not show further age-related variation (Figure 1). The interest in the baited tube was generally higher than in the other toys and the exploration time (Figure 1), as well as the likelihood of physical manipulation in this task was reduced only for individuals > 24 years (Generalized Linear Mixed Model (GLMM): $\mathrm{n}$ subjects $=98$ in 1-3 experimental conditions, $\mathrm{n}$ trials $=202$, Age $\times$ Novel object type: $\left.x^{2}=191.37, d f=2, p<0.05\right)$. The latency to open the tube steadily increased from young adulthood on, however, and subjects $>19$ years were unable to retrieve the reward (Figure 2).

A

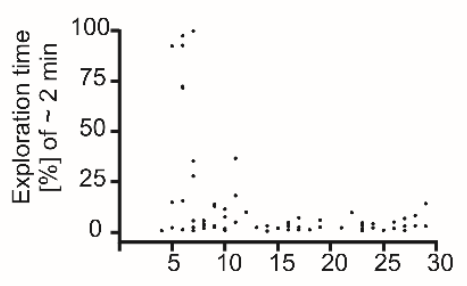

B

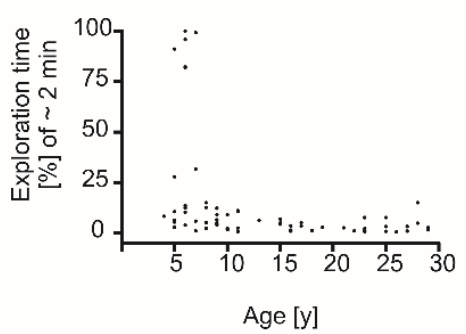

C

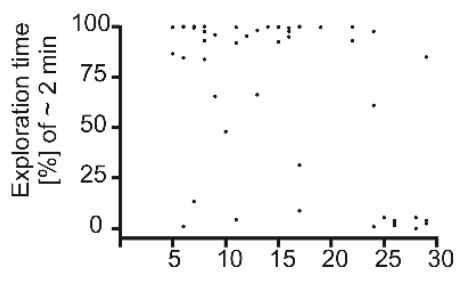

Figure 1. Aging and exploratory behavior

Barbary macaques' exploration times of animal toys (A), cube (B) and opaque tube baited with peanuts $(C)$, indicating that the age-related change in interest during adulthood was modulated by the potential availability of a food reward (Permutation test of Linear Mixed Model: $n$ trials $=192, n$ subjects $=93$, Age $\times$ Novel object type: $\mathrm{p}<0.05$ ) (see SI Movies 1, 2 and 4). 
A

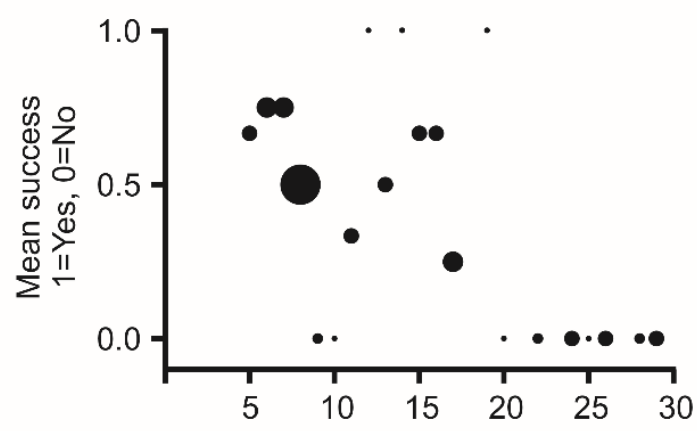

B

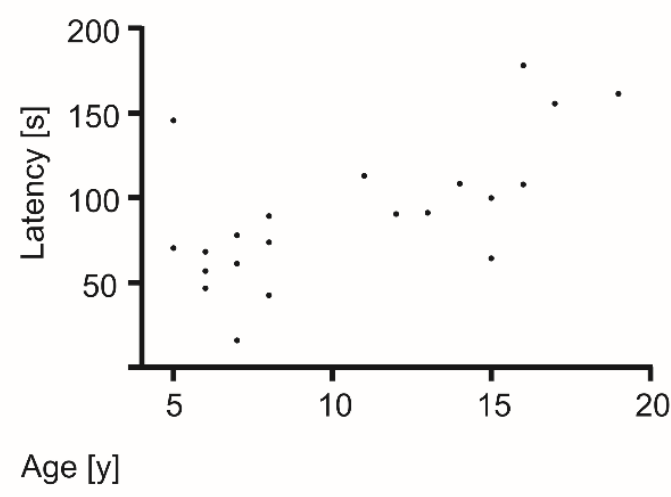

Figure 2. Aging and problem-solving behavior

(A) Old subjects ( $>19$ years) failed to retrieved the peanut out of the tube (Generalized Linear Model: $n$ trials and subjects $=53$, Age: $x^{2}=11.81, d f=1, p<0.001$; sizing of points corresponds to number of subjects (1-6) tested at a certain age), and the latency to open the tube steadily increased from young adulthood on (Spearman-rank correlation: $n$ trials and subjects $=21$, rho $=0.61, p<0.01)(B)($ see SI Movies 3, 4 and 5).

\section{Social interest}

In order to determine potential age-related changes in social interest, we presented male and female subjects with portrait photographs (Schell et al., 2011) of newborn Barbary macaques, a close friend or a non-friend (Supplemental Experimental Procedures 3 and 4). Note that in this species, females maintain close bonds with both related and unrelated females (Patzelt et al., 2009) and males interact with infants remarkably frequently (Henkel et al., 2010). The close friend was defined as the female in the group with which a subject exchanged most affiliative interactions during group scans, while the non-friend was a female with whom no affiliative interactions were recorded. For female subjects, we additionally conducted playback experiments (Fischer, Noser, \& Hammerschmidt, 2013) in which we played recruitment screams elicited in agonistic contexts (Fischer \& Hammerschmidt, 2002) from close partners and non-friends (Supplemental Experimental Procedures 5). In all experiments, stimuli that represented socially important individuals elicited stronger responses than those representing other group members (Figure 3). The preferential interest in photographs of important partners remained constant into old age (Linear Mixed Models (LMMs): Males: $\mathrm{n}$ subjects $=44$ in 1-3 experimental conditions, $\mathrm{n}$ trials $=85$, Age $\times$ Partner type: $x^{2}=1.92, d f=2, p>0.1$, Females: $n$ subjects $=54$ in $1-3$ experimental conditions, $n$ 
trials $=127$, Age $\times$ Partner type: $x^{2}=1.50, d f=2, p>0.1$ ) as did females' preferential interest in recruitment screams for close partners (Permutation test of LMM: $n$ subjects $=47$ in 1-2 experimental conditions, $n$ trials $=69$, Age $\times$ Partner type: $p>0.1$ ). Moreover, there was no general effect of age on looking time to portrait photographs (Males: $x^{2}=0.89, p>0.1$, females: $x^{2}=1.46, p>0.1$ ) or on female responses towards recruitment screams (Permutation test of LMM: $p>0.1$ ). As a further measure of social interest, we quantified the frequency at which Barbary macaques emit vocalizations, while observing interactions of conspecifics (Brumm, 2005; Fischer \& Hammerschmidt, 2002) for a subset of focal females ( $n=26)$ (Supplemental Experimental Procedures 6). We found no effect of age on the frequency females emitted vocalizations in response to infant interactions (Linear Model (LM): $p>0.1$ ) or conflicts (LM: $p>0.1$ ) among third parties (Supplemental Experimental Procedures 7).

A

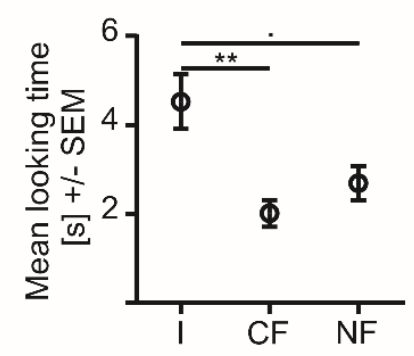

B

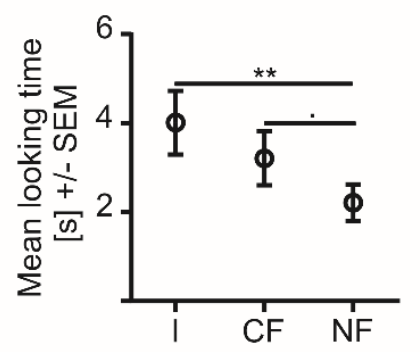

C

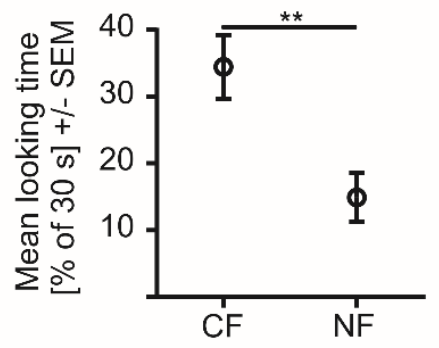

\section{Figure 3. Preferential interest for different types of social partners}

(A) Males spent more time looking at photographs (Linear Mixed Model (LMM) with $\log _{10}$-transformed response: $n$ subjects $=44$ in 1-3 experimental conditions, $n$ trials $=85$ ) depicting an infant of conspecifics (I) than a close friend (CF) (Est.=-0.32, SE=0.09) or a non-friend (NF) (Est.=-0.22, SE=0.09). (B) Females spent more time looking at photographs (LMM with $\log _{10}$-transformed response: $n$ subjects $=54$ in 1-3 experimental conditions, $n$ trials=127) depicting an infant of conspecifics (I) (Est.=-0.27, SE=0.08) or a close friend (CF) (Est.=-0.18, SE=0.09) compared to a non-friend (NF) (see SI Movie 6). (C) Females looked longer towards the loudspeaker after playback of close friend's (CF) compared to non-friend's (NF) recruitment screams (Permutation test of LMM with $\log _{10}$-transformed (after adding $\mathrm{c}=1$ ) response: $\mathrm{n}$ subjects=47 in 1-2 experimental conditions, $\mathrm{n}$ trials=69) (see SI Movie 7). 


\section{Social activity and network size}

In order to determine potential age-associated decreases in sociality (Corr, 2003; Nakamichi, 2003; Pavelka, 1991; Veenema et al., 1997) we conducted focal observation of females $(n=45)$ of two groups (GB and PB) (Patzelt et al., 2009) (Supplemental Experimental Procedures 6). With increasing age, females spent less time actively grooming and groomed fewer adult partners (Figure 4, Supplemental Experimental Procedure 8). For the females of the GB group ( $n=26)$, we additionally determined the frequency of affiliative contact. Older females had lower frequencies of affiliative interactions (LM with $\log _{10}$-transformed response: $F_{1,23}=9.45, p<0.01$ ) and a lower number of adult partners $\left(L M: F_{1,23}=5.54, p<0.05\right)$ than younger ones. The time females received grooming and the number of individuals by whom they were groomed did not vary with age, however (Figure 4). An inspection of the grooming data revealed no clear pattern for the partners of old females ( $>19$ years, $n=16$ ). The females did not show an increasing focus on relatives with age, as there were only 3 daughters or sons among the top two grooming partners of the old females. 
A

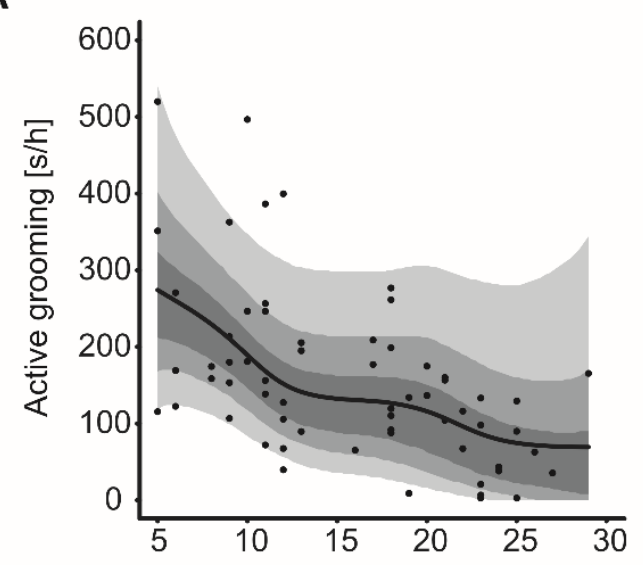

C

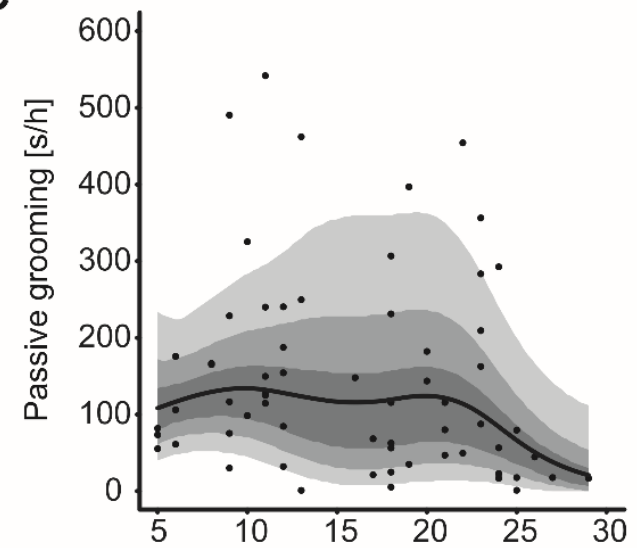

B

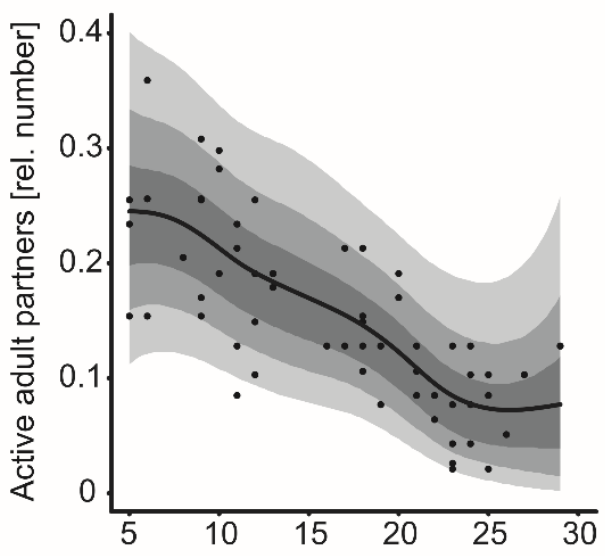

D

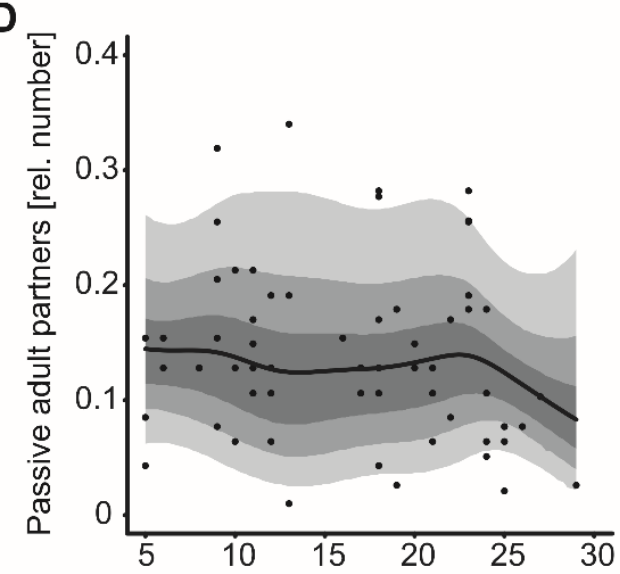

Age $[y]$

\section{Figure 4. Aging and grooming behavior}

Depicted are the estimated (MADR) 2.5\%, 10\%, 25\%, 75\%, 90\%, 97.5\% quantiles (shaded areas) and expected values (line) of the respective response distribution over the domain of age ( $n$ observations $=68$, $n$ subjects $=45$ ). Pairs of values with exclusive expected values and inner $97.5 \%$ quantile intervals reveal strong evidence for agerelated distributional differences. With increasing age, female Barbary macaques engaged less in active grooming ( $A$ ) and had a lower number of adult partners they actively groomed (active partners) (B). There was no substantial change in the time females received grooming $(C)$ or the number of adult partners by which females were groomed (passive partners) (D). 


\section{Discussion}

We found a sharp loss of monkeys' interest in the nonsocial environment in young adulthood. This mirrors findings for humans where adolescents also show a higher degree of novelty and sensation seeking than adults, leading to a greater propensity to take risks (Blakemore \& Robbins, 2012), while the eagerness for new experiences declines across adulthood (Lucas \& Donnellan, 2011). Thus, the nonlinear development of the internal reward system, which has been associated with risk taking in adolescence (Blakemore \& Robbins, 2012), is most likely a shared and ancestral trait (Spear, 2004). Notably, the potential availability of a food reward strongly influenced the monkeys' approach behavior: Except for very old individuals, monkeys continued to explore the tube, albeit with diminishing success. Whether this is due to a loss of cognitive competence or due to motor impairments remains an issue for further investigation.

For the older monkeys, we found a striking dissociation between the diminished social activity and a narrowing social network on the one hand, and the continued interest in social information on the other. The reduction in social activity was apparently driven by the old individuals themselves, while they were not less attractive to other group members. The keen interest of old individuals in social information challenges the notion that their shrinking social activity and social networks are a result of a general loss of social interest (Cumming \& Henry, 1961). In contrast to our expectations, old individuals also maintained a basal interest in social information involving non-friends. In other words, we did not observe a relative increase in interest in socially important partners. In sum, the increased social selectivity at the behavioral level is not based on shifts in social interest.

For humans, the increased selectivity in personal goals (Riediger \& Freund, 2006) has been linked to losses in resources (e.g., declines in some physical and cognitive abilities) (Baltes, 1997). Increasing resource losses are associated with a shift in motivational orientation across adulthood, such that younger adults are more oriented towards achieving gains whereas older adults are more oriented towards maintaining functioning and avoiding losses (Ebner et al., 2006; Freund, 2006). Future studies should aim to clarify to which degree the decrease in active social time is driven by energy constraints; more specifically, to which degree the assumed reduction in motor activity is the result of reduced energy intake and/or metabolic deficiencies (Roth et al., 2004). In addition, the valuation of specific social interactions or activities might change, possibly due to differential internal reward patterns. 
Counter to our expectations, we observed that other group members continued to groom older females (Corr, 2003), raising questions about the value of social relationships per se. For Barbary macaques, there is some evidence that grooming lowers stress levels in the groomer (Shutt et al., 2007), which may account for the continued grooming of non-reciprocating older females at the proximate level. At the ultimate level, it has been shown that female monkeys that maintain strong bonds experience higher infant survival (Silk et al., 2003) and an enhanced longevity (Silk et al., 2010), indicating that the maintenance of strong bonds has been selected for. Thus, social bonds may acquire an intrinsic value, so that the animals continue to invest into relations with older individuals although they may only provide marginal benefits to them.

Taking these data together, we found evidence for higher selectivity in aging Barbary macaques. Their interest in novel objects waned first, followed by withdrawal from social interactions as well as a narrowing in network size, and finally a reduction in problem-solving even with the prospect of a reward, while attentiveness to social information remained stable into old age.

What are the implications of these results for socioemotional selectivity theory (Carstensen et al., 1999)? According to socio-emotional selectivity theory the prioritization of emotional goals and a narrowing in network in particular results from subjective impending endings (Carstensen et al., 1999). In humans, the awareness of limited lifetime clearly has a strong impact on one's preferences and goals (Carstensen et al., 1999), as young adults who are struck by terminal illness or who are confronted with a geographic relocation scenario experience similar shifts in motivation and preferences as aged individuals (Fredrickson \& Carstensen, 1990). This does not rule out the possibility that physiological decline also contributes to shifting preferences in older humans.

Our data provide evidence that in the absence of awareness of limited lifetime nonhuman primates experience an increasing focus on social over nonsocial stimuli and a reduction in social investment with age. Accordingly, in aging humans both ancestral motivational shifts as well as the awareness of one's increasingly limited remaining life time likely contribute to shifting preferences and goals.

\section{Conclusion}

The finding that nonhuman primates experience marked and differential motivational shifts with age, particularly an increasing focus on social over nonsocial stimuli and 
shrinking circle of social partners, suggests that some of the motivational changes observed during the human lifespan may be grounded much more deeply in evolution than previously assumed, and may not necessarily be tied to an awareness of limited lifetime. Combining an evolutionary perspective (Lemaître et al., 2015) with a lifespan psychological approach (Freund \& Baltes, 2000) constitutes a promising avenue for investigations of age-related changes in motivation and cognition (Craik \& Bialystok, 2006; Verdier et al., 2015), contributing to the growing field of evolutionary developmental psychology (Maestripieri \& Roney, 2006).

\section{Experimental procedures}

\section{Study site and subjects}

The study population lives at "La Forêt des Singes", an touristic outdoor enclosure (20 ha) in Rocamadour, France (see Turckheim \& Merz, 1984 for a detailed description of the park management, Supplemental Experimental Procedures 1). In the park, the population $(\mathrm{N}=166)$ is split into three distinct social groups (known as Grand Bassin (GB), Petit Bassin (PB) and Volerie (V)), with the oldest individual being 30 years old. Individuals were included in the study when they reached sexual maturity (males 5 years, females 4 years (Menard \& Vallet, 1993)). In total 118 Barbary macaques (age range: 4-29 years) were tested in at least one experiment and/or served as focal subject. All experiments were in accordance with the European Directive 2010/63/EU and were approved by the scientific director of the enclosure.

\section{Experimental design and data collection}

Experiments were conducted in three periods: October 2012, April-September 2013, April-October 2014. Novel objects (animal toys (see SI Movie 1), cube (see SI Movie 2), baited tube (see SI Movies 3, 4 and 5) were placed in front of male and female subjects that had never seen or not seen the object for at least 3 months (Supplemental Experimental Procedures 2). Responses were videotaped for 2 minutes. In case the subject still manipulated the tube after 2 minutes had passed, the trial was extended for a further minute. To determine the experimental partners (close friend, non-friend) for the social experiments we relied on group scans (minimum $n=255$ per season for the GB and PB group, Supplemental Experimental Procedures 3) during which we recorded the occurrence of grooming and affiliative proximity $(<1 \mathrm{~m})$. For the photograph experiments (Schell et al., 2011) (infants, close friend, non-friend), the experimenter sat down in front of the male or female subject with a covered photo on a 
clipboard and initiated the trial by uncovering the photo, while videotaping the subjects' behavioral response. Trials lasted until the subject left or ceased looking at the picture for 1 minute (Supplemental Experimental Procedures 4, SI Movie 6). For the playback experiments, one experimenter placed the loudspeaker behind the female subject in the direction where the experimental partner was assumed to be (Fischer et al., 2013), while the second experimenter stood in front of the subject videotaping its behavioral response to the playback for 2 minutes (Supplemental Experimental Procedures 5, SI Movie 7). All videos of experiments were analyzed on a frame by frame basis ( $25 \mathrm{fps}$ ) (Supplemental Experimental Procedures 2, 4 and 5). Focal observations of females (Patzelt et al., 2009) ( $n=45$ of two groups), during which we continuously recorded the behavior for half an hour, were conducted in three periods (PB group: April-June 2009, September-October 2009; GB group: May-August 2014) resulting in 883.5 hours of observation (Supplemental Experimental Procedures 6).

\section{Statistical analysis}

All statistical analyses were performed with R v. 3.0.2 (R Core Team, 2015). Regarding the exploration time of novel objects (amount of time that an individual visually and physically inspected the object relative to total trial length) we used a Liner Mixed Model (LMM). We included age, type of novel object, their interaction, and sex as fixed effects and subject as random effect. Because of a ceiling effect in the data, we ran a permutation test (number of permutations: 10,000) to determine p-values. For the proportion of physical manipulation ( $\mathrm{Y} / \mathrm{N}$ ) we used a Generalized LMM (GLMM), with age, type of novel object, as well as their interaction, and sex as fixed effects, and subject as random effect. Regarding the proportion of successful tube opening, we used a Generalized Linear Model (GLM) including age and sex as fixed effects. For successful subjects, we determined whether age and latency to tube opening were correlated (Spearman-rank correlation) (Supplemental Experimental Procedures 2). Concerning the looking time to photographs, we used LMMs, separately for male and female subjects, in which we incorporated age and partner type, and their interaction as fixed effects, and subject as random effect (Supplemental Experimental Procedures 4). For the looking time to playbacks (proportion of time subjects spent looking and approaching the speaker in $30 \mathrm{~s}$ after the onset of the playback), we used a LMM in which we incorporated age, partner type as well as their interaction, overall stimulus length and the overall call duration as fixed effects, and subject as random effect. Due to a floor effect in the distribution of the dependent variable, we conducted a 
Permutation test (number of permutations:1,000) to determine the p-values (Supplemental Experimental Procedures 5). We analyzed the frequency of female vocalizing to conflicts and infant interactions among third-parties using LMs with age and dominance rank as fixed effects (Supplemental Experimental Procedures 7). Concerning the behavioral data, active and passive grooming time were analyzed using mixed additive distributional regression (MADR) Gamma-distribution models with BayesX v. 3.0.3. (Belitz et al., 2015), following (Klein, Kneib, Lang, \& Sohn, 2015), and using penalized B-splines (Eilers \& Marx, 1996) for non-linear effects of continuous covariates. We incorporated age, dominance rank, season (spring, autumn) and group (PB, GB) as fixed effects and focal subject as random effect. Concerning the number of partners, which females actively groomed and the number of partners by whom females were groomed, we used the same procedure, except that we used a Betadistribution. For all females of the group GB $(n=26)$, we ran LMs regarding the frequencies of affiliative contacts with all adult partners and focal females' number of adult partners with age and dominance rank as fixed effects (Supplemental Experimental Procedures 8).

\section{Acknowledgements}

We are grateful to Ellen Merz for permission to conduct this study at 'La Forêt des Singes' in Rocamadour, and thank the staff at the park for support. We thank Andreas Ploss, Elena Jeß, Dominique Treschnak, Laura Tschernek, Heather Sanders, Julia Mörchen, Lisa Wenzel and Annika Huber for help with the data collection and analysis and Ludwig Ehrenreich for technical support. Thanks go to Thomas Kneib and Roger Mundry for statistical support, and Dorothy Cheney and James Higham for comments on the manuscript. We acknowledge support by the Alexander von HumboldtFoundation (Humboldt Research Award to A.M.F.). Three anonymous reviewers provided helpful suggestions. The authors declare no conflict of interest.

\section{Author contributions}

L.A., K.H. and J.F. designed the study, L.A. collected the data, L.A. and H.S.-R. executed the analyses and L.A., A.M.F. and J.F. wrote the manuscript. 


\section{Supplemental Experimental Procedures}

\section{Study site and subjects}

The study population lives at "La Forêt des Singes", an outdoor enclosure in Rocamadour, France (see Turckheim \&Merz, 1984 for a detailed description of the park management). The park is open for tourists from April-November. The tourists are restricted to a circular path. They are allowed to feed the monkeys with popcorn, provided by the park guides at the entrance. Therefore, the monkeys are well habituated to humans. The population ( $N=166$ in April 2014) is split into three distinct social groups known as Grand Bassin (GB), Petit Bassin (PB) and Volerie (V). The monkeys move freely in the park, but the groups mainly avoid each other. The monkeys are fed with fruit and vegetables several times per day, and water is available ad libitum. Moreover, the monkeys face no predation risk. For management purposes, some females receive hormonal implants. The population is highly age-heterogeneous and approximately one third of the population is older than 19 years.

Both, male and female Barbary macaques can be roughly categorized as "old" from the age of 20 years on (see Berghänel, Ostner, \& Schülke, 2011; Menard \& Vallet, 1993; Paul et al., 1993 for age categorization in this species). This is usually the point in life where physical deterioration starts to become obvious (pers. observation). The oldest male in the population was 29 years old and the oldest female in the population was 30 years old (in April 2014). Individuals were included in the study when they reached sexual maturity (males 5 years, females 4 years), termed adult. Adult males in the population had a mean age of 14 years and adult females in the population had a mean age of 16.5 years (in April 2014). The subset of the population that served as subjects covered almost the whole range of adulthood, as both, the oldest male and oldest female in our study were 29 years old.

\section{Novel object tests}

Procedure. For the novel object tests, males (age range: 5-29 years) and females (age range: 4-29 years) were used as subjects. We used 14 different toy animals, a cube $(0.1 \times 0.1 \times 0.1 \mathrm{~m})$ containing colorful plastic pieces and glitter in a viscose liquid, and an opaque tube $(I=30 \mathrm{~cm}, \mathrm{~d}=4.5 \mathrm{~cm})$ baited with nuts and stuffed with soft tissue at both ends. The subjects were presented with objects they had never seen or not seen for at least 3 month. 
The experimenter approached the subject with the object hidden in a shoebox and sat or kneeled down. Experiments were initiated when no other subjects were within $3 \mathrm{~m}$. Whether other individuals were allowed beyond $3 \mathrm{~m}$ depended on the characteristics of the other individual (rank, prior experience with the task, behavior etc.) and the type of novel object. For most tube trials, the subject needed to be out of sight for other monkeys. To prevent subjects from carrying the novel objects away, the tube and some of the animal toys were fixed via a metallic chain $(\sim 1.5 \mathrm{~m})$ to bushes or tree trunks. The experimenter opened the box and placed the object in front (maximum distance $2 \mathrm{~m}$ ) of the subject. Moreover, the cube was agitated before it was placed on the ground. The experimenter started the trial by removing her hand from the object and then walking away. Responses were videotaped for 2 min. by a second experimenter. If a subject still manipulated the tube after two min., the trial was prolonged for a further minute. If the subject left $(>6 \mathrm{~m})$ and it was deemed unlikely that it would return, the video recording was terminated.

Novel object tests were conducted over the course of three years (9.10.-12.10.2012, 17.4.-13.9.2013 and 21.4.-14.10.2014). Trials were mostly widely distributed over the course of data collection (mean=170, $\min =1$ day, $\max =713$ days). In case a trial in a certain experimental condition was discarded, we repeated the experiment if possible. In total we conducted 224 novel object tests, from which 22 were discarded for the analysis ( 7 because of experimenters' mistake, 9 because subjects were accidentally tested repeatedly, 3 because of severe disturbance by other monkeys, or in one case tourists, directly after the onset of the trial, and 3 subjects walked away before the onset of the trial while the experimenter was still in the process of setting up the object, resulting in 202 valid experiments. In detail, we tested 75 subjects (40 males, 35 females) with the animal toys, 74 subjects (37 males, 37 females) with the cube and 53 subjects (32 males, 21 females) with the tube.

Video analysis. The analysis was started when the experimenter removed her hands from the novel object. We measured the relative duration of exploration time (visual and physical inspection, including monopolization of the object and attempts to steal the object) for $2 \mathrm{~min}$. and up to $3 \mathrm{~min}$. for the tube task. For the tube task, the trial ended either when the subject retrieved the peanut, or reached the maximum time. Trials that were disturbed directly after the onset of the experiments were discarded. However, we included 5 trials that ended prior to the predetermined time due to disruption. Specifically, disturbances by other monkeys occurred in 4 cases at $47.4 \mathrm{~s}$, 
$59.4 \mathrm{~s}, 71.4 \mathrm{~s}, 96.6 \mathrm{~s}$, and by a tourist after $100.9 \mathrm{~s}$. In these cases, the trials ended the moment the disturbance occurred. Similar to the other trials, we calculated the relative time spent exploring the novel object. Approaches by infants or juveniles, or clearly lower ranking animals were not considered as disturbances.

In addition, we determined whether the subjects physically manipulated the tube on a yes/no basis. The videos for which the determination of visual inspection time was impossible due to poor video quality $(\mathrm{N}=10)$ were included in the analysis of handling at the yes/no basis, resulting in a differing sample size for these analyses. For the tube task, we determined the occurrence of success in tube opening (i.e. point in time the subject managed to retrieve the first bit of peanut, yes/no basis) and latency to tube opening.

Inter-observer reliability, tested by reassessing $1 / 3$ of the experiments by $a$ second observer, was: exploration time of novel objects (Pearson $r=0.89, n=88$ ), occurrence of physical manipulation of the novel object (Cronbachs alpha=1, $n=96$ ), latency to tube-opening (Pearson=0.99, $\mathrm{n}=8$ )

Statistical analysis. To investigate whether age had an effect on exploration time we ran a Linear Mixed Model (LMM) using the package "Ime4" (Bates, Maechler, Bolker, \& Walker, 2014). Into this we included age, type of novel object (animal toy, cube, baited tube) and sex as fixed effects. We accounted for repeated testing by including subject as random intercepts. To account for the possibility that subjects' interest was modulated by a food reward in the tube task, we also included the interaction of age and novel object type in the model. To achieve a more symmetrical distribution, we squareroot-transformed age. Afterwards, we z-transformed age to get comparable estimates and a reliable model regarding the interaction. Subjects responded particularly strongly towards the tube, resulting in a ceiling effect in the distribution of exploration time. Therefore, we ran a permutation test (number of permutations: 10,000 ) to determine $p$-values. Sex had no effect on exploration time ( $n$ trials $=192, n$ subjects $=93, p>0.1)$.

To investigate whether age had an effect on the likelihood of physical manipulation (yes/no basis) we ran a Generalized Linear Mixed Model (GLMM), with age (sqrt-transformed, z-transformed), type of novel object and sex as fixed effects and specified random intercepts for subjects using the packages "Ime4" (Bates et al., 2014) and "Imertest" (Kuznetsova, Brockhoff, \& Christensen, 2015). To account for the possibility that subjects' interest was modulated by a food reward in the tube task, we 
also included the interaction of age and novel object type in the model. Sex had no effect on the likelihood subjects engaged in physical manipulation with the novel objects $\left(n\right.$ trials $=202, n$ subjects $=98, x^{2}=191.37, d f=1, p>0.1$ ).

In the case of the tube task, we additionally analyzed the effect of age on the likelihood of the occurrence of tube-opening (success) with a Generalized Linear Model (GLM) including age (sqrt- and z-transformed), and sex as fixed effects using the packages "Ime4" (Bates et al., 2014) and "Imertest" (Kuznetsova et al., 2015). Sex had no effect on the likelihood subjects retrieved the reward out of the tube ( $n$ trials and subjects $\left.=53, x^{2}=0.05, d f=1, p>0.1\right)$. Moreover, for successful subjects, we determined whether age and latency to tube opening were correlated with Spearman-Rank correlation.

\section{Group scans}

In order to identify "close friends" and "non-friends" for the photograph (Schell et al., 2011) and playback experiments (Fischer et al., 2013), we used group scans including all of the adult monkeys (males $>4$, females $>3$ years of age) in the groups GB and PB. During one scan (duration of $30 \mathrm{~min}$.) we recorded for at least $75 \%$ of the adult group members whether and with whom they engaged in grooming or affiliative proximity. Grooming is defined as A separating the fur of B using one or both hands and then picking with thumb and forefinger in the fur. Affiliative proximity is defined if two individuals stand, sit, or lie together with a distance not exceeding 1 meter for at least 3 s. They may eat, walk together for a few meters, or hug each other. The data were recorded using a mini tablet computer (HP iPAQ, Hewlett-Packard Development Company, L.P. or Samsung Galaxy S4), while running a program created with Pendragon Forms (Pendragon Software Cooperation, Libertyville, IL, U.S.A.). The "close friend" for potential male and female subjects was defined as the female with whom an individual exchanged most affiliative interactions during the scans. The nonfriend was another female, with whom an individual never engaged in affiliative interactions during scans. In 2013, we conducted 274 scans (15.4.-20.7.13) for the PB group and 259 scans (8.5.-18.8.13) for the GB group. In 2014, we conducted 255 scans (1.5.-4.7.14) for the PB group and 263 scans (1.5.-27.6.14) for the GB group. Moreover, we recorded affiliative behavior ad libitum (Altmann, 1974) in order to enable a more precise determination of the non-friend. 


\section{Photograph experiments}

Procedure. For the photograph experiments, males (age range: 5-28 years) and females (age range: 4-29 y) were used as subjects. Photos (taken with Canon DS 126071 or Canon Powershot SX1) depicted 11 infant Barbary macaques from another social group and 49 adult females, all with a neutral facial expression, and were trimmed to fit a $17 \mathrm{~cm}$ diameter circle (Adobe Photoshop CS4). The experimenter, wearing a baseball cap and dark sunglasses, in order to avoid possible eye contact with the subject sitting on the ground or on walls and benches, approached a subject and sat or kneeled down. Alternatively, the experimenter already sat on a bench, and the assisting experimenter placed a piece of popcorn on the bench to attract a subject to approach (Schell et al., 2011). The experimenter placed a clipboard with a covered photograph in front of the subject (distance up to $2 \mathrm{~m}$ ). Whether other individuals were allowed in the vicinity depended on the characteristics of the other individual (rank, behavior etc.). The closest distance a subject had to other individuals in the moment a trial was initiated was $0.5 \mathrm{~m}$ (a yearling close by the mother). The experimenter started the trial by un-covering the photo when the subject was visually oriented towards the clipboard (encouraged by the experimenter knocking on the clipboard). Throughout the trial the subject was monitored through the camera display. Responses were videotaped (HDC-SD909, Panasonic, Ōsaka, Japan) until the subject left. Alternatively, the recording was discontinued after the subject had stopped looking at the picture for one minute.

We presented photographs of the close friend and non-friend from 13.6.-15.9.2013 and infant photographs from 12.7.-15.9.2013 as well as 21.4.-12.10.2014. An assisting experimenter prepared a clipboard with a covered portrait photo of the experimental partner. Thus the experimenter was blind concerning the close friend vs. non-friend study part, except for a few cases where she remembered in which experimental condition she had tested the subject before. The experimenter was sometimes aware of whether she presented an infant photograph, as these experiments included subjects from the group $\mathrm{V}$, which were only presented with photographs of babies. As a rule, at least 4 days passed between repeated trials with the same subject (mean=28, $\max =317$ days), except for those cases where subjects had studiously ignored the prior presentation, resulting in a discarded trial (see below). In these cases, the next trial could be initiated on the same day.

In total, we conducted 257 photograph presentations, from which 45 were discarded (29 because of experimenters' mistake, 5 because monkeys were tested 
accidentally repeatedly, 2 because of severe monkey disturbance during the trial, and 9 because the monkey did not look at all at the picture within 1 minute after the trial start), resulting in 212 valid experiments. In detail, we obtained picture experiments with 78 adults (38 males, 40 females) using infant photographs, 67 adults (23 males, 44 females) with photographs of the close friend and 67 adults (24 males, 43 females) and non-friend.

Video analysis. For the picture experiments, the analysis was started when the cover was removed and half of the picture was apparent to the subject. The time that the subject spent looking at the photograph was recorded until the subject (i) left, or (ii) had ceased looking at the picture for one minute. In one case, the recording was stopped after the subject had ceased looking for 27 seconds and began to masturbate. In two cases, tourists interfered after the subjects had ceased looking at the picture for 24 and 43 seconds, respectively. Here, the analysis was stopped in the moment the recording ended, or the disturbance occurred. The analyzer was blind concerning the experimental condition regarding close friend and non-friend photographs and did not knew they were later analyzed together with trials were baby photographs were presented. Those were analyzed a few weeks before by the same observer. Interobserver reliability, tested by reassessing $1 / 3$ of the experiments by a second observer, was 0.81 (Pearson, $\mathrm{n}=84$ ).

Statistical analysis. We split the dataset by sex because we had differential predictions for males and females. As relationships are more pronounced among females than between males and females in Barbary macaques (Sosa, 2016) we expected a differential response concerning the experimental conditions close friend and non-friend only for females, but not for males. To determine whether age had an effect on looking time, we ran LMMs using the packages "Ime4" (Bates et al., 2014) and "Imertest" (Kuznetsova et al., 2015). We incorporated age and partner type (infant, close friend, non-friend) as fixed effects and specified random intercepts for subjects and partners. Since we assumed that the difference in preference could increase with age, we also included the interaction of age and partner type as fixed effect. To achieve a more symmetrical distribution, we squareroot-transformed the predictor age for the data of male subjects. Afterwards, we z-transformed age to receive comparable estimates and a reliable model regarding the interaction. Looking time was $\log _{10^{-}}$ transformed to meet normal distribution assumption on residuals: Inspection of QQ- 
and residuals vs. fitted values plots indicated no relevant deviation from normally and homogeneously distributed residuals. As the interactions did not provide substantial improvements for the models concerning either male or female subjects, they were removed from the models. Partner type had an effect (Males: $n$ trials $=88, n$ subjects $=44, x^{2}=12.06, p<0.01$, females: $n$ trials $=127, n$ subjects $=54, x^{2}=10.92, p<0.01$ ) on looking time to photographs. P-values of post-hoc pairwise comparison of different categories of partner type were adjusted using "multcomp" (Hothorn, Bretz, Westfall, \& Heiberger, 2008). Males looking times to photographs of close friends and non-friends did not differ from each other (Estimate $=0.09, \mathrm{SE}=0.10, \mathrm{p}>0.1$ ). Females looking times to photographs of infants and close friends did not differ from each other (Estimate $=0.10, \mathrm{SE}=0.08, \mathrm{p}>0.1$ ).

\section{Playback experiments}

Procedure. In the playback experiments, females (age range: 5-29 years) were used as subjects. One experimenter placed a loudspeaker (DAVID Active, Visonik, Berlin, Germany) in the direction of where the experimental partner was assumed to be, at a distance of $18 \pm 1 \mathrm{~m}$ behind the back of the subject. Stimuli were presented only if the subject was sitting away (min. distance $5 \mathrm{~m}$ ) from the other group members and the female whose calls were presented needed to be out of sight of the subject (min. distance $30 \mathrm{~m}$ ). We used 42 stimuli created from call sequences of recruitment screams recorded from 31 females in agonistic contexts using a solid-state recorder (Marantz Professional PMD 661, Kanagawa, Japan, sampling frequency=44.1 kHz) and a directional microphone (ME66, Sennheiser electronic $\mathrm{GmbH}$, Hanover, Germany). Stimuli (edited with Avisoft SASLab Pro) were overall similar in total scream length (mean=1.55 s, SD=0.13 s), overall length (mean=3.05 s, SD=0.30 s) and peak amplitude (mean=82.50 dB, SD=0.72; obtained by Sound pressure measuring device (SL-400, Rion) at a distance of $1 \mathrm{~m}$ to the loudspeaker). A second experimenter videotaped the subject's behavioral response for 2 min. (HDC-SD909, Panasonic, Ōsaka, Japan). We conducted the playback experiments from 4.7.-9.8.2013 and 10.6.-14.10.2014. We conducted only one experiment per day and group and at least 23 days elapsed until subjects were tested again (mean=148, $\max =439$ days). In case a trial in a certain experimental condition needed to be discarded, it could be potentially repeated, which occurred twice. These trials were repeated after 59 and 91 days respectively, using different stimuli. In total, we conducted 74 playbacks, from which 5 were discarded ( 2 because of experimenters' mistake and 3 because of severe 
disturbance of other monkeys), resulting in 69 trials (33 with close friend and 36 with non-friend experimental partner) included in the analysis.

Video analysis. We determined the subjects' looking time towards the loudspeaker, i.e., if the subject turned her head into the direction of the loudspeaker more than $45^{\circ}$ from her initial position. The onset was the point at which the subject started to turn her head and the offset the point at which the subject had turned the head back to the initial position or another direction. We also included subject's locomotion time if looking was followed or accompanied by the subject's approach in the direction of the speaker. Here, the analyzer was blind regarding the experimental condition. Interobserver reliability, tested by reassessing $1 / 3$ of the experiments by a second observer was 0.93 (Pearson, $\mathrm{n}=25$ ).

Statistical analysis. We ran a LMM to determine the effect of age, partner type and their interaction on looking time (proportion of time subjects spent looking and approaching the speaker in $30 \mathrm{~s}$ after the onset of the playback) using the package "Ime4" [S5]. A constant with the value one was added to looking times due to zerovalues in the data followed by a $\log _{10}$-transformation. We included overall stimulus length as well as the sum of call length as further fixed effects; this also allowed us to control for a trial in which one stimulus was accidentally played for a third of its length. Repeated observations on subjects were taken into account using random intercepts. To achieve a more symmetrical distribution, we squareroot-transformed the predictor age. Afterwards, we z-transformed age to receive comparable estimates and a reliable model regarding the interaction. For convenience, all other predictors were $z-$ transformed, too. In 14 out of 69 experiments, subjects did not show any interest leading to a floor effect in the distribution of the dependent variable. Therefore, we conducted a Permutation test $(\mathrm{N}$ perm $=1,000)$ of the $L M M$ to determine the $p$-values. As the interaction was not significant, it was removed. The Permutation test of the reduced LMM revealed a significant influence of stimulus length ( $n$ trials $=69, n$ subjects $=47, p<0.01$ ), while sum of call length $(p>0.1)$ had no effect on looking time. 


\section{Focal observations}

We recorded continuously for half an hour the behavior of all adult females (Altmann, 1974; Patzelt et al., 2009) of the GB group ( $n=26,19.5 .-5.8 .2014$ for 285 hours). In addition, we analyzed data recorded from $n=19$ females from a second group (PB) that had been collected previously for two periods (28.4.-26.6. and 3.9.-31.10.2009 for 598.5 hours) by Andreas Ploss. The total time of hours of observation was 883.5. Specifically we recorded the duration of active and passive grooming (see 2. Group scans for a definition) and the respective partner identity. However, not all juveniles could be individually identified. Moreover, we recorded for subjects of the group GB the frequency of affiliative proximity with adult group members (see 2. Group scans for a definition) and of vocalizing to third-party interactions (Brumm, 2005) for conflicts (rasping calls or pants uttered while observing aggression (Fischer \& Hammerschmidt, 2002)) and infant handling (pants uttered while observed infant handling (Fischer \& Hammerschmidt, 2002)). Data were recorded using a mini tablet computer running Pendragon Forms (see 2. Group scans). The focal females were observed at equal shares across four different time frames (morning, lunch, afternoon and evening) in a balanced order.

\section{Vocalizations to third-party interactions}

We determined the effect of age on the frequency at which focal females of the group GB $(n=26)$ uttered vocalizations in the context of conflicts and infant interactions among third-parties (Brumm, 2005; Fischer \& Hammerschmidt, 2002), using LMs with age and dominance rank as fixed effects using the packages "Ime4" (Bates et al., 2014) and "Imertest" (Kuznetsova et al., 2015). Residual assumptions were checked and found to be slightly violated. For both LMs the comparison of full vs. null model revealed that the full model provided no significantly better fit than the null model (LM for vocalizing to conflicts: $F_{2,23}=0.18, p>0.1$; LM for vocalizing to infant handling: $F_{2,23}=1.85, p>0.1$ ). As none of these two predictors had any relevant influence on the dependent variables, the deviations from residual assumptions were considered to be negligible.

\section{Social activity and network size}

Social network analysis. We established directed weighted matrices for durations of grooming bouts, separately for each group and season. From these sociomatrices we determined how many adult partners focal females actively groomed, ("out-degree" 
(Croft, James, \& Krause, 2008)) termed "active partners", and from how many adult partners focal females were groomed ("in-degree" (Croft et al., 2008)), termed "passive partners". We could not include juveniles as partners, as not all juveniles could be identified individually. Moreover, we determined the time a focal female spent actively grooming and the time a focal female received grooming ("node strength" (Croft et al., 2008)). Here, juveniles were included as partners. All durations were corrected for dyadic observation time.

For focal females from the GB group we established a weighted undirected matrix for frequencies of affiliative contacts $(<1 \mathrm{~m})$ with all adult partners. From this matrix we derived focal females' number of adult partners ("degree" (Croft et al., 2008)). Moreover we determined the frequency focal females were in affiliative contact with other adult individuals ("node strength" (Croft et al., 2008)). Frequencies were corrected for dyadic observation times.

Dominance hierarchies. To establish dominance hierarchies, we entered the outcome from dyadic conflicts among adult females as well as approach retreat interactions in sociomatrices, separately for each group and season. We took into account the data we collected during the focal observations, as well as ad libitum observations (Altmann, 1974). We determined dominance hierarchies using MatMan (Version 1.1, 2007 Noldus Information Technology b.v., Wageningen, The Netherlands). The strength of linearity is represented by $h^{\prime}$ (corrected for unknown relationships), which can range between 0 and 1 . To assess the p-value a two-step randomization test was performed, with the number of randomization set on 10,000 . We obtained linear hierarchies for focal females of GB (Spring: 2014: $n=26, x 2=123.41, d f=32.23, h^{\prime}=0.49, p<0.001$ ), and females (including the subset of focal females) of PB (Spring 2009: $n=24, x 2=88.56$, $d f=30.36, h^{\prime}=0.42, p<0.001$, Autumn 2009: $\left.n=24, x^{2}=87.1, d f=30.36, h^{\prime}=0.41, p<0.001\right)$.

Statistical analysis. In order to determine whether age had an effect on active grooming time we ran a mixed additive distributional regression model (MADR) with Gamma-distributed response following (Klein et al., 2015). The estimation was based on Markov chain Monte Carlo (MCMC) sampling from the posterior distribution, as implemented in the software "BayesX" (Belitz et al., 2015) v. 3.0.3. We estimated nonlinear effects of continuous covariates using penalized B-splines (Eilers \& Marx, 1996). Age, dominance rank (female's dominance rank relative to number of females in the group to account for varying numbers of females in the two groups), season (spring, 
autumn) and group (PB, GB) were incorporated as fixed effects. Random intercepts were included for focal subjects. We used the same method to determine the effect of age on passive grooming time. Likewise, we determined the effect of age on females' number of active grooming partners and females' number of passive grooming partners, except that we assumed the response to be Beta-distributed. We used relative numbers (number of partners relative to the number of adults in the group) for the analysis due to differing group sizes. All prior distribution assumptions were kept on the BayesX default: Diffuse priors are considered for fixed effects hyperparameters as noted on p. 11, BayesX methodology manual (www.statistik.Imu.de/ bayesx/manual/methodology_manual.pdf). For nonlinear effects modeling using penalized B-splines, a second order random walk prior is used, the degree of the spline is 3 and the number of inner knots is 20 . The hyperparameters $a$ and $b$ of the inverse Gamma prior IG $(a, b)$ for the variance of smooth nonlinear effects are set to $a=b=0.001$. To cope with unobserved heterogeneity with respect to the grouping variable focal subject, unstructured Gaussian i.i.d. random effects with hyperparameters $a$ and $b$ (as well set to 0.001) of the inverse Gamma-distributed prior for the variance of random intercepts are included. According to the Bayes $X$ reference manual (www.statistik.Imu.de/ bayesx/manual/reference_manual.pdf, p. 162) for distributional regression models with more than one equation, the starting value for the smoothing parameter lambda is specified equal to 100. MCMC sampling is performed for 120000 iterations, with 20000 burn-in iterations and a thinning by each $100^{\text {th }}$ iteration. One focal female never received grooming within the network. Therefore, the smallest value (0) for passive grooming time was modified from 0 to 1 ( $2^{\text {nd }}$ smallest value in the data set is 1.12) in order to meet the response's distributional assumption. For the same focal female and the same reason, the value of 0 for number of passive grooming partners (relative to group size) was modified from 0 to 0.01 ( $2^{\text {nd }}$ smallest value in the data set is 0.021). Sensitivity checks for these modifications were performed, and showed only negligible consequences. Note, this type of analysis provides no $p$-values, but the influence of a certain predictor variable on a certain response is visually obtained from plots depicting the mean posterior expectation and the corresponding prediction intervals, showing the probability of any new observation to fall in the respective colored areas.

For all females of the group GB ( $n=26)$, we analyzed the effect of age on further behaviors, which were not recorded for the group PB using the packages "Ime4" (Bates et al., 2014) and "Imertest" (Kuznetsova et al., 2015). To determine whether age had 
an effect on the frequency females were in affiliative contact with other adults, we ran a LM with age and dominance rank as fixed effects. The dependent variable was $\log _{10^{-}}$ transformed to achieve normally distributed residuals. To test whether age had an effect on the number of females' adult contact partner (number rel. to adult individuals in the group), we ran a LM with age and dominance rank as fixed effects. Inspection of QQ- and residuals vs. fitted values plots for both LMs indicated no relevant deviation from normally and homogeneously distributed residuals. The LMs revealed that dominance rank had no influence on the frequency focal females were in contact with other adults $\left(F_{1,23}=0.66, p<0.1\right)$, but higher ranking females had trend wise more adult contact partners than lower ranking females $\left(F_{1,23}=3.51, p<0.1\right)$. 


\section{Chapter 3: Study 2}

Social interactions and activity patterns of old Barbary macaques: further insights into the foundations of social selectivity

Authors: Laura Almeling ${ }^{1,2,3}$, Holger Sennhenn-Reulen ${ }^{3}$, Kurt Hammerschmidt ${ }^{2,3}$, Alexandra M. Freund ${ }^{4}$, Julia Fischer ${ }^{1,2,3}$

Short title: Activity patterns of old macaques

\section{Affiliations:}

${ }^{1}$ University of Göttingen, Germany

${ }^{2}$ Cognitive Ethology Laboratory, German Primate Center - Leibniz Institute for Primate Research, Germany

${ }^{3}$ Leibniz ScienceCampus 'Primate Cognition', Göttingen, Germany

${ }^{4}$ Department of Psychology, University of Zurich, Switzerland

Published in 2017 in:

American Journal of Primatology, 79(11), e22711

Doi: 10.1002/ajp.22711 


\title{
Research highlights
}

- With increasing age, female Barbary macaques become socially more selective

- $\quad$ They are less physically active, spatially more reclusive, less likely to engage in chases and physical attacks, and appear to avoid potentially negative interactions

\begin{abstract}
Human aging is accompanied by a decrease in social activity and a narrowing in social networks. Studies in nonhuman primates may provide valuable comparative insights in which way aging impacts social life, in the absence of cultural conventions and an awareness of a limited lifetime. For female Barbary macaques at 'La Forêt des Singes' in Rocamadour, France, we previously reported an age-associated decrease in active grooming time and network size. Here, we aimed to extend these findings by investigating in which way physical decline, spatial proximity, and aggression vary with age in female Barbary macaques. We analyzed $>1200$ hours of focal observations for 46 females aged 5 - 29 years. As expected, older females engaged less frequently in challenging locomotor activity, such as climbing or running, than younger ones. The previously reported decrease in grooming time was not due to shorter grooming bout duration. Instead, active grooming bouts lasted even longer, which discounts the idea that manual fatigue explains the shift in grooming pattern. We found that older females tended to be spatially reclusive and that they were less frequently the targets of aggression. Although older females showed aggressive behaviors at similar rates as younger females, the proportion of low-level aggression (i.e. threats) increased with age. We suggest that these threats are not simply a signal of dominance, but also function to deter approaches by others. Overall, these findings are in line with the idea that older females aim to avoid potentially negative interactions, specifically if these are costly. In sum, these findings support the idea that shifts in female Barbary macaques' grooming activity, do not simply result from physical deterioration, but are instead due to a higher selectivity in the choice of social partners.
\end{abstract}

Keywords: aging, social behavior, avoidance, Barbary macaques, selectivity 


\section{Introduction}

Human aging is associated with a decrease in social activity and network size (Ajrouch et al., 2001; Fung, Stoeber, Yeung, \& Lang, 2008). With increasing age, people tend to narrow their social networks and focus on emotionally meaningful relationships such as close friends or relatives (Charles \& Carstensen, 2010; Lang, 2000). According to socio-emotional selectivity theory (SST; Carstensen, Isaacowitz, \& Charles, 1999; Charles \& Carstensen, 2010), the increasing awareness of a limited remaining future time that older people experience, leads to an enhanced selectivity in their choice of social partners.

SST is in line with a more general theory of lifespan development stressing the importance of selectivity: the model of selection, optimization, and compensation (SOC-model; Baltes \& Baltes, 1990; Freund \& Baltes, 2002). According to the SOCmodel, successful aging encompasses the management of limited resources across the life span by focusing one's resources on a subset of possible alternatives (i.e., selection), optimizing functioning in the selected domains by investing available resources, and by compensating for potential losses.

According to the strength and vulnerability integration model (SAVI; Charles, 2010), one of the losses that older adults experience is a decrease in the capacity to cope with stressors, presumably due to physiological changes. SAVI provides an integrative framework to explain the observation that emotional wellbeing is stable into old age. In stressing the importance to adapt to and manage losses for successful aging, SAVI is consistent with the SOC model. The strength in the SAVI model refers to better emotion regulation skills with age due to life experience; the vulnerability refers to a reduced physiological flexibility that impedes emotion regulation. Therefore, SAVI predicts that older adults are more likely and better than younger adults in avoiding negative situations that lead to high arousal. Similar to SST, SAVI considers future time perspective as an important aspect shaping older adults' social lives. However, extending SST, Charles (2010) pointed out that time lived (i.e., life experience) is also essential for understanding how older adults regulate their social relations.

In older humans, both the awareness of their limited future time and cultural conventions could potentially contribute to changes in self-reported and behavioral selectivity. Due to the absence of elaborate future planning abilities and normativity in nonhuman primates (hereafter 'primates'), studies on primates can provide important insights into the evolutionary foundations of human social aging (Almeling, Hammerschmidt, Sennhenn-Reulen, Freund, \& Fischer, 2016; Crockford, 2016). 
Humans and primates have a similar life history (Bronikowski et al., 2011) and both experience physiological senescence (Müller, Heistermann, Strube, Schülke, \& Ostner, 2017; Roth et al., 2004), although, in contrast to humans, primates do not experience menopause (Alberts et al., 2013). As humans do, primates also seem to experience conflicts as stressful, as indicated by increased levels of self-scratching and glucocorticoid-metabolite levels in both the actor and recipient of aggression (Aureli, 1997; Wittig, Crockford, Weltring, Deschner, \& Zuberbühler, 2015; but see Koski, Koops, \& Sterck, 2007). In addition to the diminished fighting abilities observed in older primates (Berghänel, Ostner, \& Schülke, 2011; Bissonnette, Lange, \& van Schaik, 2009; Fischer, Kitchen, Seyfarth, \& Cheney, 2004), age-associated physiological changes may result in a decreased ability to cope with stressors (Jensen, Blanton, \& Gribble, 1980; Sapolsky \& Altmann, 1991).

Given these biological changes, a number of studies have addressed the question in which way aging affects social behavior (Corr, Martin, \& Boysen, 2002), also referred to as 'social aging' (Hosaka \& Huffman, 2015). Empirical studies focused mostly on females. This may be due to the fact, that males experience a higher mortality across the primate order (Colchero et al., 2016), and thus old primate males may be less frequently available as study subjects compared to old females. Studies on female social aging yielded partly conflicting results (Borries \& Koenig, 2008): For wild chimpanzees (Pan troglodytes) (Huffman 1990), wild toque macaques (Macaca sinica) (Ratnayeke 1994), semi-free ranging Japanese macaques (Macaca fuscata) (Hauser \& Tyrrell, 1984; Nakamichi 1984) and captive stump-tailed macaques (Macaca arctoides) (Hauser \& Tyrell, 1984) a reduced spatial integration of older females was observed. Moreover, older females of various species and different rearing conditions showed reductions in active grooming: Wild chimpanzees (Huffman 1990), semi-free ranging rhesus macaques (Macaca mulatta) (Brent, Ruiz-Lambides, \& Platt, 2017; Corr, 2003), semi-free ranging Japanese macaques (Nakamichi, 1984) and captive long-tailed macaques (Macaca fascicularis) (Veenema et al., 1997). In contrast, Pavelka (1990) reported no evidence for an age-related decrease studying the same population of Japanese macaques as Nakamichi. Remarkably, older females received the same amount of grooming as younger females (Brent et al., 2017; Corr, 2003; Huffman 1990; Nakamichi, 1984, 2003). While older female rhesus macaques (Corr, 2003) and long-tailed macaques (Veenema et al., 1997) affiliated with fewer social partners, such a pattern was not found in older female Japanese macaques (Pavelka, 1991). 
In terms of agonistic behavior, aging was associated with lower levels of aggression given in wild female toque macaques (Ratnayeke, 1994) and captive female chimpanzees (Baker, 2000). In contrast, Piqc (1992) observed an age-related increase in the frequency of aggression given in captive mouse lemurs (Microcebus murinus). Captive long-tailed macaques (Veenema et al., 1997) and semi-free ranging rhesus macaques at Cayo Santiago (Brent et al., 2017) experienced age-related reductions in aggression received. Studying the same population, however, Corr (2003) observed the opposite pattern, namely an age-associated increase in the frequency of aggression received. Yet, several other studies did not provide evidence for ageassociated changes in aggression or dominance-related behavior in rhesus macaques (Brent et al., 2017), Japanese macaques (Pavelka, 1990), long-tailed macaques (Veenema et al., 1997), stump-tailed macaques (Hauser \& Tyrrell, 1984) and vervet monkeys (Chlorocebus pygerythrus) (Fairbanks \& McGuire, 1986). Taken together, then, the empirical evidence regarding social aging in primates is not completely consistent.

For female Barbary macaques (Macaca sylvanus) at 'La Forêt des Singes', we showed an age-associated decrease in overall active grooming time and number of adult partners that females groomed (Almeling et al, 2016). This age-related change seemed to be driven by the aging individual itself when considering that the time females received grooming and the number of adult partners who groomed them did not vary significantly with age. Moreover, the effect of a decreased active grooming time could not be explained by a general loss in social interest, as Barbary macaques continued to be interested in social information. More specifically, this became apparent in older females' vocal 'commenting' (Brumm, 2005) on social interactions in their immediate surrounding at similar rates compared to younger ones.

Here, we combined focal observations obtained from Barbary macaque females over several years, to determine how physical activity, spatial proximity, and agonistic behavior vary with age. We used the frequency of females' engagement in demanding locomotor activities such as running, climbing, jumping and branch-shaking as a proxy for physical strength. To test whether the observed decrease in active grooming duration was due to manual fatigue (Roth et al., 2004), we assessed active grooming bout duration for cases that were initiated and terminated by the female, as a proxy for their endurance. We recorded spatial integration in the group and conflict behavior to assess in more detail how interactions changed with age. Since dominance rank was found to be an important factor determining sociality in Barbary macaques (Sosa, 
2016) and other species (Kato, 1999; Veenema et al., 1997), we considered dominance rank as a potential confounding factor. With these analyses, we aim to contribute to a more nuanced understanding of aging processes in nonhuman primates and macaques.

\section{Methods}

\section{Ethics statement}

This study was non-invasive and based on observational data collection in a private facility. This type of data collection is in accordance with the European Directive 2010/63/EU and was approved by the scientific director of the enclosure. Moreover, it adheres to the American Society of Primatologists' principles for the ethical treatment of primates.

\section{Study species, study site and subjects}

Barbary macaques live in female bonded multi-male groups (Wrangham, 1980) with female philopatry and male migration (Menard \& Vallet, 1993; Paul \& Kuester, 1985), and have a rather tolerant social style (Thierry, 2000). Females establish strong relationships to related and non-related individuals of both sexes characterized by frequent grooming (Patzelt, Pirow, \& Fischer, 2009; Roubová, Konečná, Šmilauer, \& Wallner, 2015). They also exhibit a relative stable linear dominance hierarchy based on matrilines. Senescent females are outranked by their daughters (Paul \& Kuester, 1987).

We conducted the study in the visitor park 'La Forêt des Singes' in Rocamadour, France, where monkeys are outdoors throughout the year (Turckheim \& Merz, 1984). During the time of April until November the summer enclosure is open to visitors who are restricted to a circular path system, while monkeys can range freely within the entire area. Thus, monkeys are habituated to human observers but also have the possibility to avoid them. Monkeys forage on vegetation of the park as oak leaves, bark, grass and insects. Additionally, food such as pellets, wheat, fruits and vegetables is offered several times a day. Water is available ad libitum from large ponds or one of the three water basins in the park. The majority of adult females received hormonal transplants in order to control reproduction. All monkeys are tattooed at the inner thigh.

Within the park there are three stable social groups. Females of two of the groups served as focal subjects (see Table 1 for details). Individuals were classified as adult at the age they commonly reach sexual maturity (males 5 years, females 4 years 
(Menard \& Vallet, 1993); see Table 1 for group composition). Under these housing conditions, female Barbary macaques may reach an age of 30 years. Altogether 46 individual focal females (age range: 5-29 yrs.) were included in the study.

Data were collected in four periods over the course of several years (see Table 1 for details). The subset of focal females observed in period 2 and 3 comprised all females observed in period 1, except for one that had died.

Table 1: Observation period, subjects, group composition (numbers in parentheses refer to adjusted values in case of the death of animals in the progress of the observation period) and types of behavior recorded ( $\mathrm{Y}=\mathrm{Yes}, \mathrm{N}=\mathrm{No}$ ).

\begin{tabular}{|c|c|c|c|c|}
\hline Observation period & 1 & 2 & 3 & 4 \\
\hline Year & 2005 & 2009 & 2009 & 2014 \\
\hline Dates & Sep 18 - Dec 4 & Apr 28 - Jun 26 & Sep 3 - Oct 31 & May 19 - Aug 5 \\
\hline Group & $A$ & $A$ & $A$ & $\mathrm{~B}$ \\
\hline Focal females [N] & 8 & 19 & 19 & 26 \\
\hline Observation time [h] & $\sim 320$ & $\sim 304$ & - 294.5 & $\sim 285$ \\
\hline Females [N] & 25 & 24 & 24 & 26 \\
\hline Males [N] & $16(15)$ & 22 & 22 & 13 \\
\hline Juveniles [N] & 8 & 9 & 9 & 12 \\
\hline Infants [N] & 2 & 2 & 2 & $4(3)$ \\
\hline Locomotor activity & $\mathrm{N}$ & $\mathrm{N}$ & $\mathrm{N}$ & $\mathrm{Y}$ \\
\hline Grooming duration & $\mathrm{N}$ & $\mathrm{Y}$ & $\mathrm{Y}$ & $\mathrm{Y}$ \\
\hline Spatial proximity & $N$ & $N$ & $\mathrm{~N}$ & $\mathrm{Y}$ \\
\hline Agonistic behavior & $\mathrm{Y}$ & $\mathrm{Y}$ & $Y$ & $\mathrm{Y}$ \\
\hline
\end{tabular}

\section{Behavioral observations}

We recorded half-hour protocols of predefined behaviors using the focal sampling method for a total of $\approx 1204$ hours during 4 periods of observation (see Table 1 for details). During all periods of observation, we recorded the occurrence of agonistic behaviors threats (open-mouth face with raised eyebrows), chase away (threats accompanied by following the victim for at least a few meters) and fights with physical contact (beating and biting). For periods 2 - 4, we also recorded the duration of grooming given and received. For a detailed description of the ethogram of Barbary 
macaques see Hesler and Fischer (2007). In period 4, we additionally recorded the occurrence of locomotor activities (running $>5 \mathrm{~m}$ with high velocity, jumping, climbing > $1.5 \mathrm{~m}$, and branch-shaking). Moreover, in period 4, we noted the number of individuals in a 5-m radius before the onset of the focal observation ( $N=561$ scans). Throughout all observation periods, we noted ad libitum dyadic conflicts and displacements for the purpose of establishing a dominance hierarchy. A handheld computer (Palm, Model Zire) or tablet (Samsung Galaxy S4) running a custom program created with Pendragon Forms (Pendragon Software Corporation, Libertyville, IL, U.S.A.) was used to record the data.

When a focal female was out of sight during observation, proceedings were as follows: if the female could be located again within 5 - 10 minutes, the time lacking was added to the half hour session; if the female could not be located again, the time lacking was noted and added to the next session of the focal female in the same period of day. The focal females were observed semi-randomly by following an order which was arranged daily for the observation day so that observation times for single individuals were similarly distributed for each female in period 1 ( $3 / 5$ of protocols during 9:00 - 14:00 and 2/5 during 14:00 - 18:00 and approximately evenly distributed throughout the day (morning: 9:00 - 11:30, midday: 11:30 - 14:00, afternoon 14:00 - 16:30 and evening (16:30 - 19:00) for period 2 - 4.

\section{Analyses}

To determine the effect of age on the frequency that females engaged in 'locomotor activities' we ran a Generalized Linear Model in R version 3.3.1 (R Core Team, 2015), using data obtained in observation period 4, for 26 females of one group (see Table 1). The estimation was performed using BayesX (Belitz et al., 2015). We assumed a negative binomial distributed response (Zeileis, Kleiber, \& Jackman, 2008). We chose this distribution as, in contrast to the Poisson distribution, we directly control for potential overdispersion. We entered 'age' as linear regression coefficient and used the offset log(observation time) in order to take slightly varying observation length into consideration.

In the further analyses addressing the effect of age on various types of social behavior, we included the potential confounder 'dominance rank'. To determine the dominance relations among adult females for each group and observation period we used MatMan 1.1 (Noldus, Wageningen, Netherlands) (de Vries, Netto, \& Hanegraaf, 
1993), in which we entered a winner-looser matrix using ad libitum and focal data of dyadic encounters and approach retreat interactions. We observed linear dominance hierarchies in females for both groups and all data collection periods (Group A: period 1: $x^{2}=115.29, d f=31.29, h^{\prime}=0.48, P<0.001, N=25 ;$ period $2: X^{2}=88.56, d f=30.36$, $h^{\prime}=0.42, P<0.001, N=24$; period 3: $X^{2}=87.1, d f=30.36, h^{\prime}=0.41, P<0.001$, $N=24$; group B: period $\left.4: X^{2}=132.60, d f=32.23, h^{\prime}=0.52, P<0.001, N=26\right)$. In the analyses, we used a females' relative dominance rank position (hereafter: 'dominance rank') within the female hierarchy instead of absolute values, in order to correct for differences in numbers of females in the groups and across periods of observation. In our subset of focal females ( $N=46)$, 'dominance rank' was weakly positively correlated with 'age' (Spearman-Rho $=0.36, P=0.002, N$ observations $=72$ ), i.e. older females tended to be lower in rank.

We checked for potential collinearity between 'age' and 'dominance rank' in the different models using the function 'vif' from R add-on package 'car' (Fox et al., 2016). Variance inflation factors were never larger than 1.43, indicating that there is no collinearity. This also accounts for 'observation period', which was incorporated as a potential confounder in the analyses, if appropriate.

The following analyses were conducted using a Bayesian inference algorithm (Markov chain Monte Carlo, MCMC) as implemented in BayesX Version 3.0.2 (Belitz et al., 2015). Markov chain Monte Carlo (MCMC) estimation is a general tool for the estimation of Bayesian regression models that allows quantifying the joint posterior distribution of the model's coefficients with high accuracy (Gelman, 2006). In the absence of substantial prior knowledge, we used non-informative priors for the regression coefficients included in the different models. Typically, the data provides enough information to estimate $\beta_{0}, \beta_{1}, \ldots$ by the use of any reasonable non-informative prior distribution (Gelman, 2006). This is, however, generally not the case for scale parameters such as $\sigma_{\gamma}^{2}$, and the use of (weakly) informative priors is needed. For the variance $\sigma_{\gamma}^{2}$ of the prior for varying intercept model coefficient $\gamma_{i} \sim N\left(0, \sigma_{\gamma}^{2}\right)$, for individuals $i=1, \ldots, n$, we therefore used a weakly informative inverse Gamma prior with hyper-parameters $a=b=0.001$, i.e. $\sigma_{\gamma}^{2} \sim I G(a=0.001, b=0.001)$ (Belitz et al., 2015). For the MCMC set-up, we used a burn-in of 12,000 iterations, a thinning rate of 40 , and 52,000 iterations in total.

Concerning the dependent variable 'active grooming bout duration', we used the data recorded in observation periods 2 - 4 (see Table 1) and restricted the analysis to those events that were initiated and terminated by the focal female, and which were not 
truncated by the beginning or the end of the focal observation $(N=394)$. This selection reduced the number of focal females in our sample to 39 females, as 6 individuals were not observed to engage in active grooming given the selection criteria. The dependent variable was $\log _{\mathrm{e}}$-transformed in order to meet the normality assumption on residuals. We conducted a Linear Multilevel Model with 'age', 'dominance rank' and 'observation period' as factor covariate. We controlled for variation across 'focal females' by the use of varying intercepts. Inspection of QQ- and residuals vs. fitted values plots indicated no relevant deviation from normally and homogeneously distributed residuals.

To assess the influence of age on the 'number of individuals in 5-m radius' we used data recorded of 26 females of one group in observation period 4 (see Table 1). We conducted a Generalized Linear Multilevel Model with a negative binomial response, in this way controlling for potential overdispersion (Zeileis et al., 2008). We incorporated 'age' and 'dominance rank' in the model and used the offset log(observation time) to account for slightly varying observation times. Moreover, we controlled for variation across 'focal females' by the use of varying intercepts. To estimate a potential non-linear relationship between 'age' and the dependent variable, we used a non-parametric Bayesian P-spline approach (Brezger \& Lang, 2005), a standard non-parametric method to assess non-linear effects (Eilers, Marx, \& Durbán, 2015).

For the dependent variable 'aggression given', we used data from 46 females across observation periods $1-4$ (see Table 1 ). To estimate a regression coefficient for age on the frequency females show aggressive behavior, we conducted a Generalized Linear Multilevel Model with a negative binomial response, controlling for potential overdispersion (Zeileis et al., 2008), and included 'age', 'dominance rank' and 'observation period' as factor covariate. We added 'focal females' as varying intercepts and used the offset $\log$ (observation time) to correct for varying observation times.

For the dependent variable 'aggression received', we used data from 46 females across observation periods $1-4$ (see Table 1). To estimate the role of age on how frequently females were the target of aggression, we conducted a Generalized Linear Multilevel Model with a negative binomial response (Zeileis et al., 2008), and included 'age', 'dominance rank', and 'observation period' as factor covariate. We added 'focal females' as varying intercepts and used the offset log(observation time) to correct for varying observation times. To estimate a potential non-linear relationship between 'age' and the dependent variable, we used a non-parametric Bayesian Pspline approach (Brezger \& Lang, 2005). 
For the proportion of 'threats relative to all aggression (threats, chase away and physical fights)' the focal females engaged in, we used data obtained in observation periods $1-4$ (see Table 1 ). One female (age $=29 \mathrm{yrs}$ ) was removed from this analysis, as she was never observed to engage in aggression throughout the observation period, yielding observations for 45 females instead of the 46 observed in total. To estimate a regression coefficient for age on the proportion females engage in 'threats relative to all aggression', we conducted a Generalized Linear Multilevel Model with a binomial response and included 'age', 'dominance rank', and 'observation period' as factor covariate. We added 'focal females' as varying intercepts.

The results of the described models are presented in a graphical way (Figures 2 - 6). Pairs of expected values with exclusive credible intervals reveal strong evidence for age-related differences in the distribution of the response. Note, that expected values vary non-linearly in all figures, although 'age' was incorporated as a non-linear term only in the models for 'number of individuals in 5-meter radius' and 'aggression received'. The non-linear shapes of expected values in the other models result from non-linear response functions and, in the case of 'active grooming bout duration', from the log-transformation. For an improved readability of these graphs, the values of the estimated expected values are given in numerical form for age at values of 5,15 , and 25 years in the respective figure legends. Moreover, we provide coefficient estimates for the models, except for those that were P-spline based ('number of individuals in 5meter radius' and 'aggression received'). For this type of analysis, coefficient estimates cannot be obtained. Finally, we also provide such graphical displays for the potential confounder 'dominance rank' as well as coefficient estimates, whenever applicable.

\section{Results}

Age had a negative effect on the frequency females $(N=26)$ engaged in demanding locomotor activities (Generalized Linear Model: Est. $=-0.073, S E=0.015, P<0.001, N$ events $=449$, Figure 1$)$. Note that any further statistical inference result are given as the estimated expected values and credible intervals, generally set at $99 \%$, with the aid of plots (Figures 2 - 6). The estimated expected value of active grooming bout duration increased with age (Figure 2a). For the influence of age on grooming bout duration, we obtained a coefficient estimate of 0.034 , with a $99 \%$ credible interval from 0.009 to 0.065 . The estimated expected value of active grooming bout duration did not vary with dominance rank (Figure $2 b$ ). For the influence of dominance rank on 
grooming bout duration, we obtained a coefficient estimate of 0.024 with a $99 \%$ credible interval from -0.500 to 0.510 .

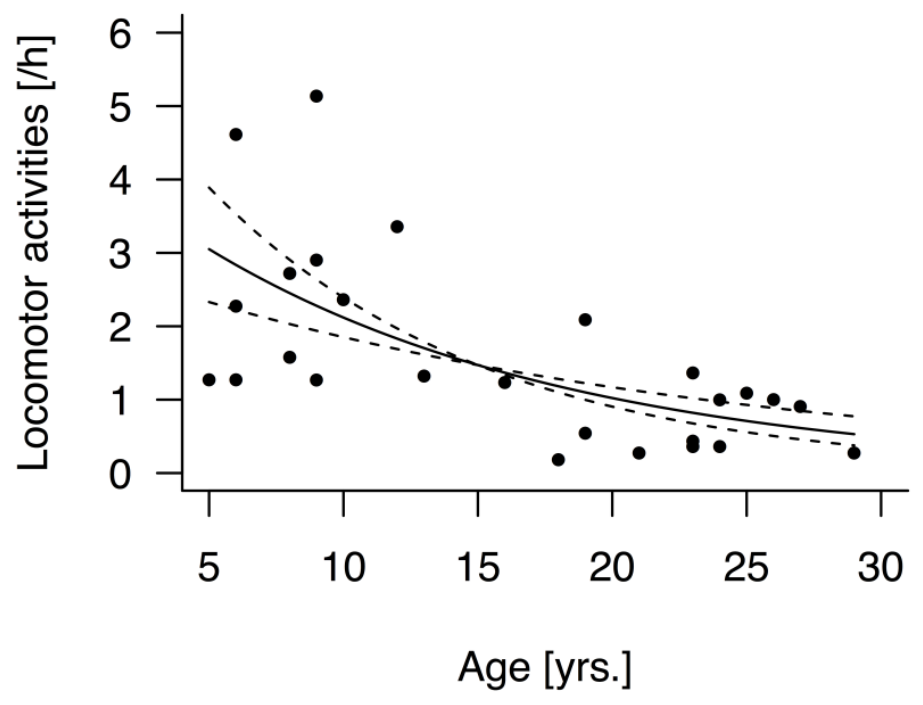

Figure 1 Aging and locomotor activities. Depicted are the expected values (Generalized Linear Model, solid line) for the frequency of locomotor activities behaviors and the credible interval ( $99 \%$, dashed lines) for focal females across ages $(N$ females $=26)$. 
(a)

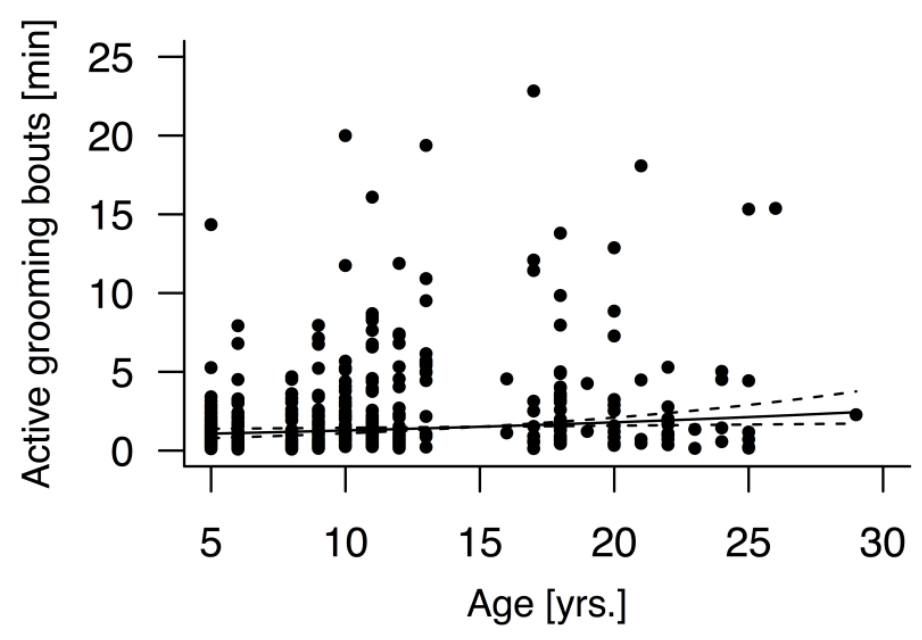

(b)

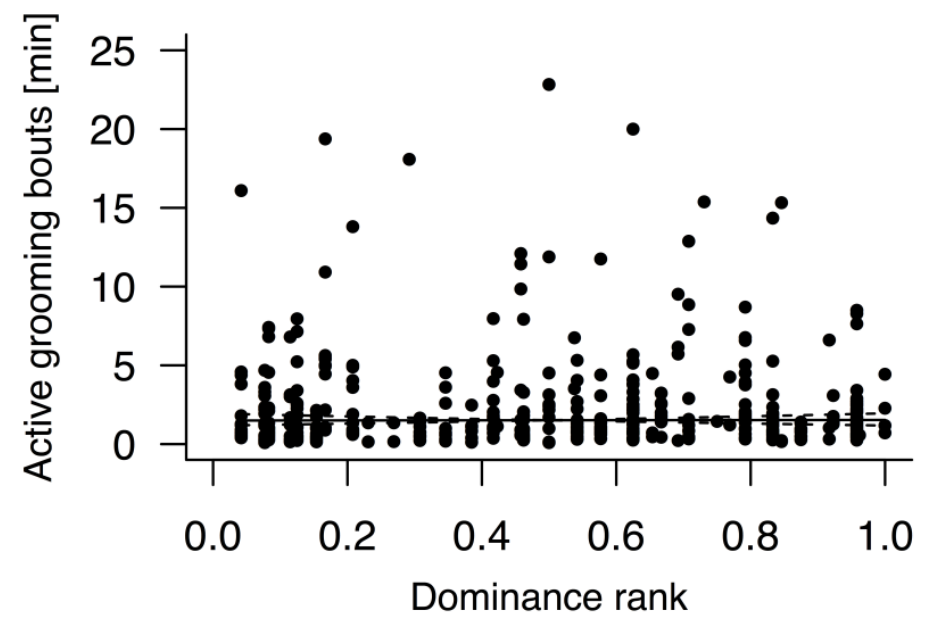

Figure 2 Aging and grooming bout duration. (a) Depicted are the expected values (Linear Multilevel Model, solid line) and the credible interval (99\%, dashed line) for active grooming bouts $(N=394)$ that were initiated and terminated by the focal female $(N=39)$ across age. The predicted value for active grooming bout durations of female Barbary macaques was $1.08 \mathrm{~min}$ at the age of $5,1.51 \mathrm{~min}$ at the age of 15 and 2.13 min at the age of 25. (b) Depicted are the expected values (Linear Multilevel Model, solid line) and the credible interval (99\%, dashed line) for active grooming bout durations $(N=394)$ that were initiated and terminated by the focal female $(N=39)$ across dominance rank (corrected for number of females in the group; 1 denotes the lowest dominance rank). 
The expected value of number of individuals that were recorded within a 5-m radius around the focal females tended to decrease with age (Figure 3a) and did not vary with dominance rank (Figure 3b). We did not find evidence for a change in the frequency of aggression given with age (Figure $4 \mathrm{a}$ ): the coefficient estimate was -0.025 , with a $99 \%$ credible interval from -0.061 to 0.011 . Because dominance rank was inferred from dyadic agonistic encounters among females, it is not surprising that rank varied with aggression given (Figure $4 \mathrm{~b}$ ): the coefficient estimate was -1.471 , with a $99 \%$ credible interval from -2.239 to -0.784 . The expected value of the frequency that females were the targets of aggression decreases at younger ages, and, starting at around 15 years, flats out (Figure 5a). Aggression received varied with dominance rank: The higher the rank, the less frequently a female received aggression (Figure 5b). Note, that dominance rank was inferred from dyadic agonistic encounters among females. The proportion of threats relative to all aggression females engaged in (threats, chase away and physical fights) increased with age (Figure 6a). In other words, older females were more likely to engage in low-level aggression. For the influence of age on proportion of threats relative to all aggression females engaged in, the coefficient estimate was 0.043 , with a $99 \%$ credible interval from 0.011 to 0.073 . The proportion of threats relative to all aggression females engaged in, did not vary with dominance rank (Figure $6 b)$ : the coefficient estimate was 0.039 , with a $99 \%$ credible interval from -0.581 to 0.647 . 
(a)

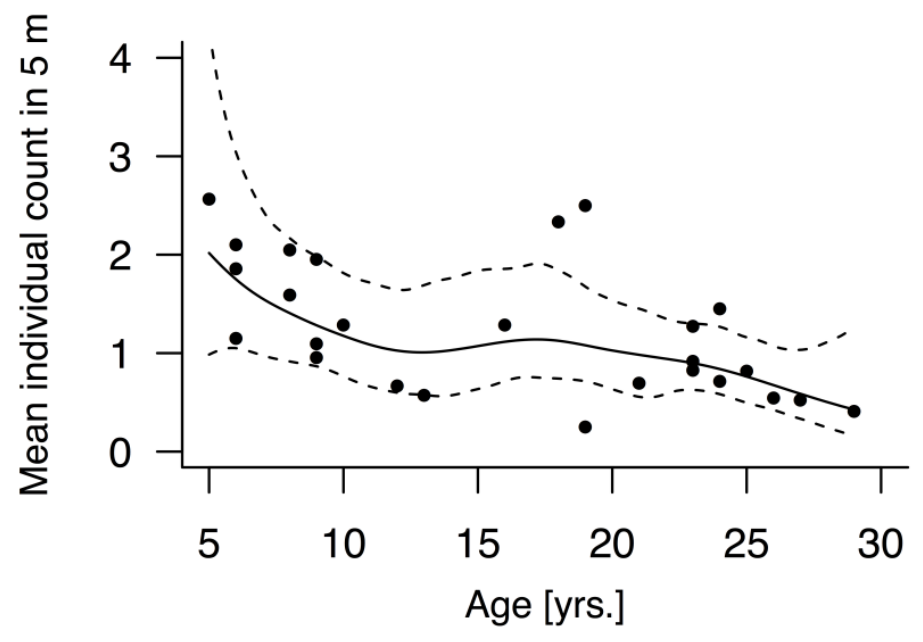

(b)

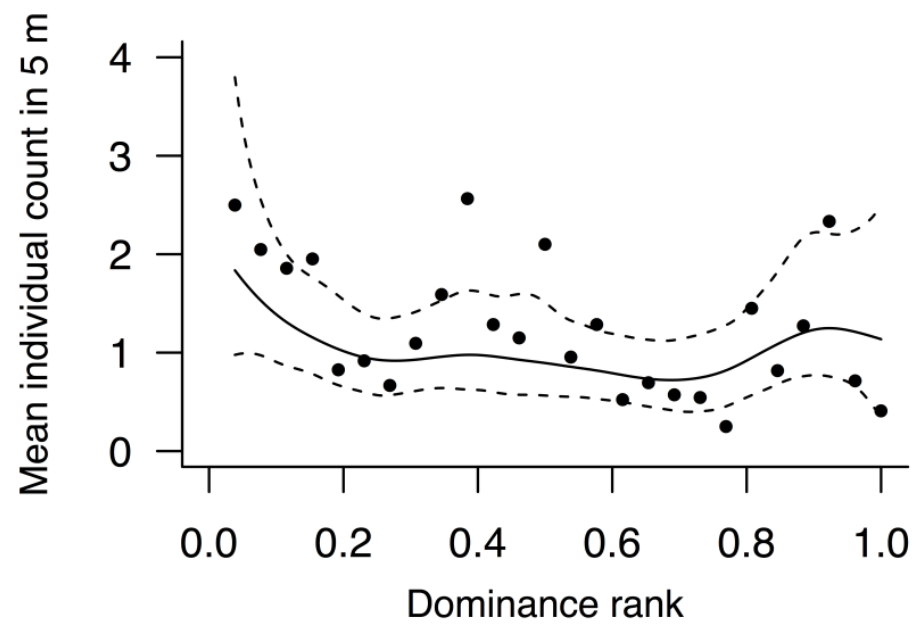

Figure 3 Aging and spatial proximity. (a) Depicted are the expected values for the mean number of individuals in 5-m radius (Generalized Linear Multilevel Model, solid line) and the credible interval (99\%, dashed line) across focal females' age ( $N$ females $=26$ ). The predicted value for number of individuals recorded in 5-m radius around a female was 2.02 at the age of $5,1.07$ at the age of 15 and 0.76 at the age of 25. (b) Depicted are the expected values for the mean number of individuals in 5-m radius (Generalized Linear Multilevel Model, solid line) and the credible interval (99\%, dashed line) across focal females' ( $N$ females $=26$ ) dominance rank (corrected for number of females in the group; 1 denotes the lowest dominance rank) 
(a)

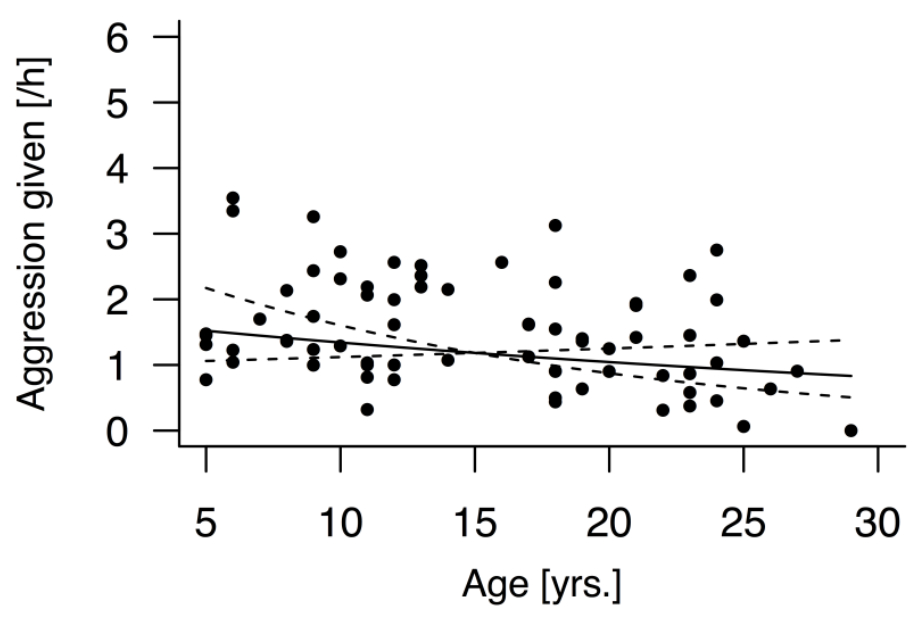

(b)

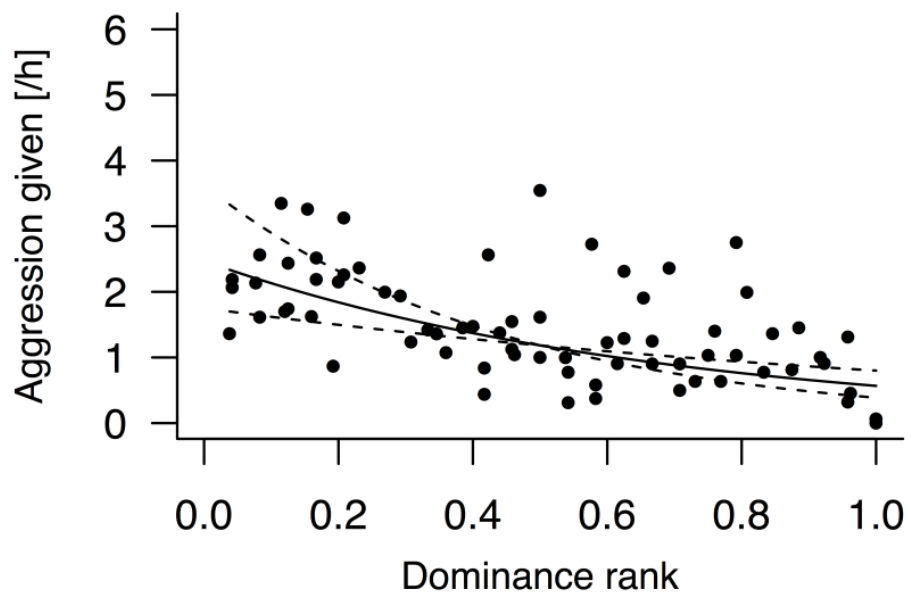

Figure 4 Aging and aggression given. (a) Depicted are the expected values (Generalized Linear Multilevel Model, solid line) for the frequency Barbary macaque females ( $\mathrm{N}$ females $=46$ ) of different ages gave aggression in one up to three periods of observation ( $\mathrm{N}$ observations $=72$ ) and the credible interval (99\%, dashed line). The predicted value for the frequency per hour a female directed aggression was 1.52 at the age of 5, 1.18 at the age of 15 and 0.92 at the age of 25. (b) Depicted are the expected values (Generalized Linear Multilevel Model, solid line) for the frequency Barbary macaque females ( $\mathrm{N}$ females $=46$ ) of different dominance rank positions (corrected for number of females in the group; 1 denotes the lowest dominance rank) gave aggression in one up to three periods of observation ( $\mathrm{N}$ observations $=72$ ) and the credible interval (99\%, dashed line) 
(a)

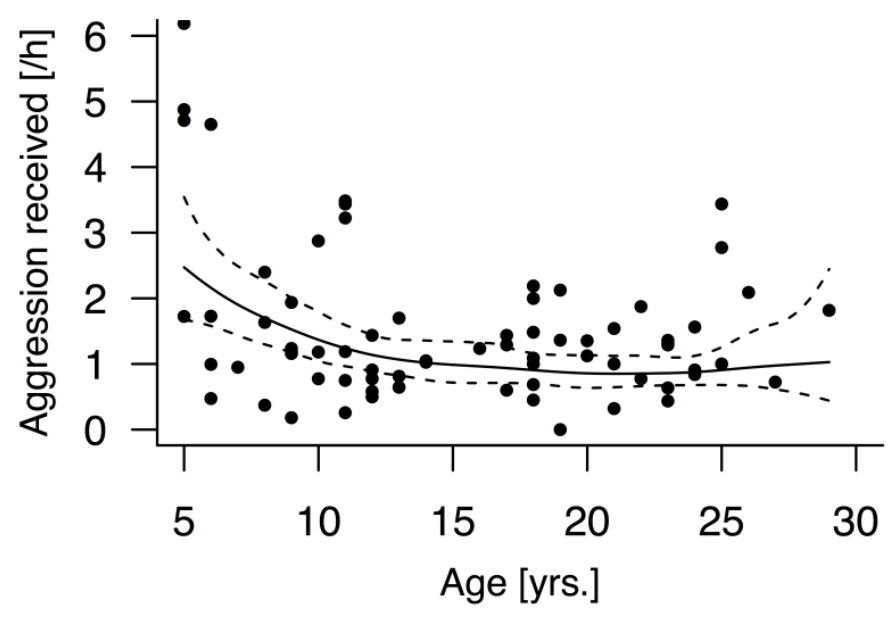

(b)

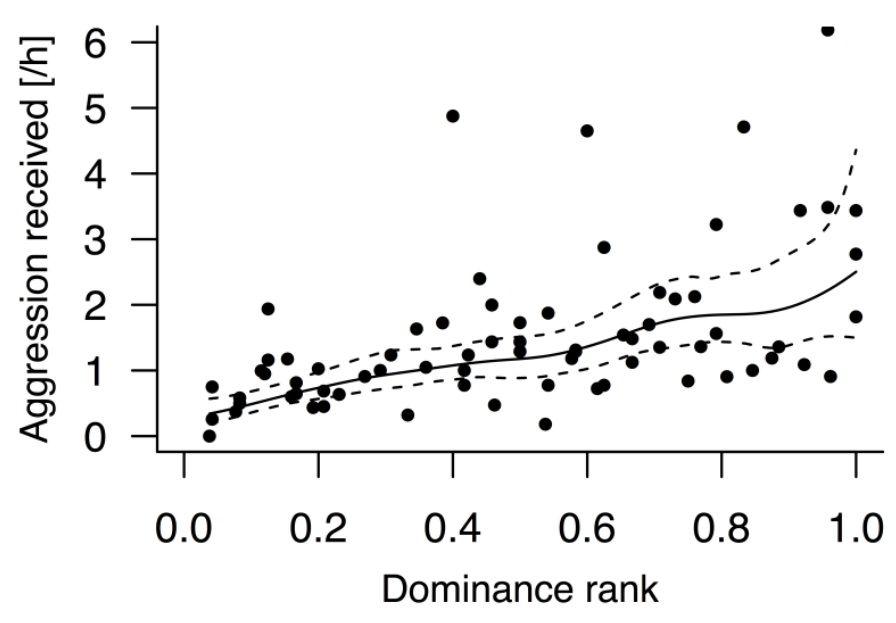

Figure 5 Aging and agonistic behavior received. (a) Depicted are the expected values (Generalized Linear Multilevel Model, solid line) for the frequency Barbary macaque females $(N$ females $=46)$ received aggression at different ages in one up to three periods of observation ( $N$ observations $=72)$ and the credible interval $(99 \%$, dashed line). The predicted value for the frequency per hour a female received aggression was 2.47 at the age of 5, 0.99 at the age of 15 and 0.91 at the age of 25. (b) Depicted are the expected values (Generalized Linear Multilevel Model, solid line) for the frequency Barbary macaque females ( $N$ females $=46$ ) of different dominance rank positions (corrected for number of females in the group; 1 denotes the lowest dominance rank) received aggression in one up to three periods of observation ( $N$ observations $=72$ ) and the credible interval (99\%, dashed line). 
(a)

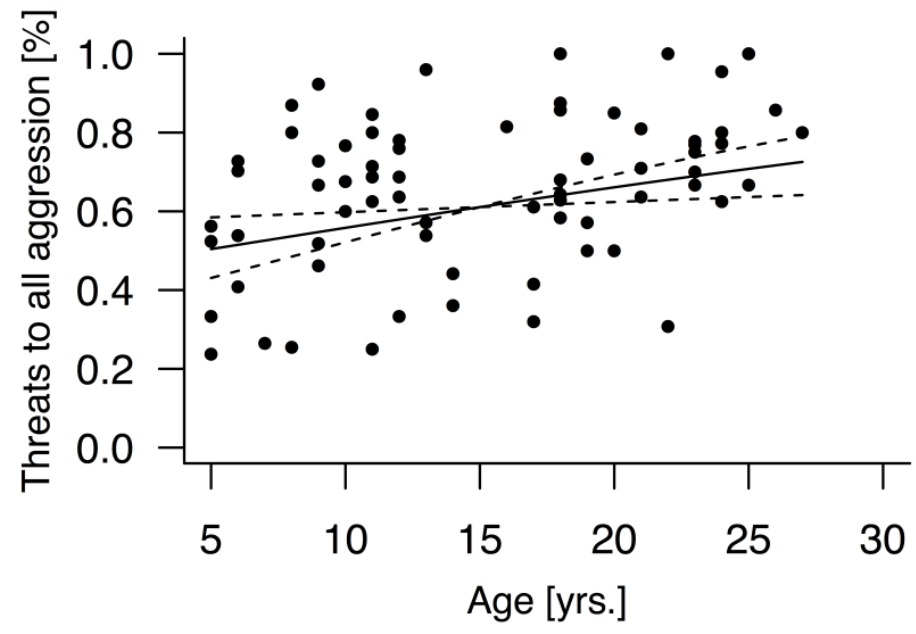

(b)

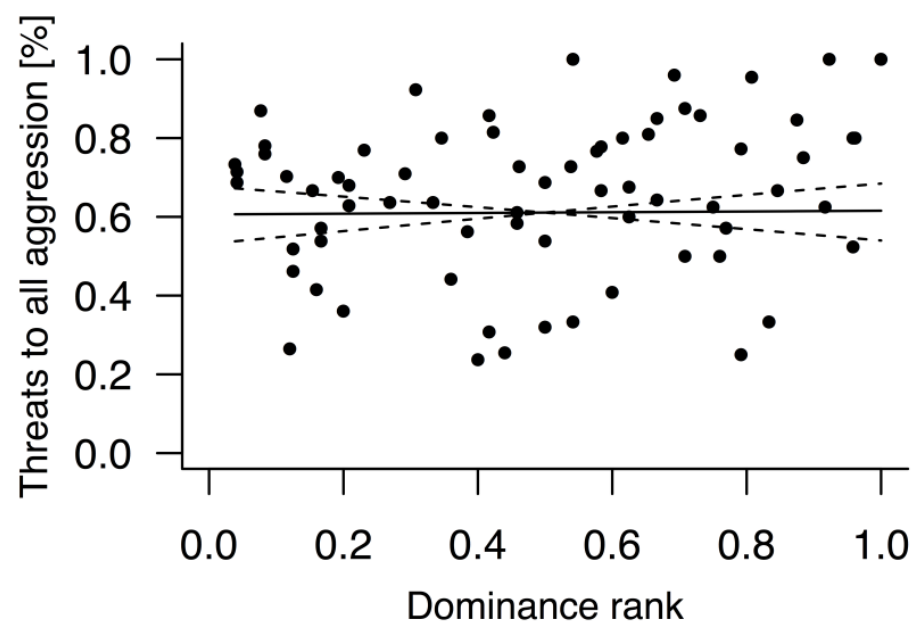

Figure 6 Aging and the proportion of threats relative to all aggression females engaged in. (a) Depicted are the expected values (Generalized Linear Multilevel Model, solid line) for the proportion of threats relative to all aggression Barbary macaque females ( $N$ females $=45)$, observed in one up to three periods of observation ( $N$ observations $=$ 71), engaged in across ages and the respective credible interval (99\%, dashed line). The predicted value for the percentage of threats relative to all aggression given was $51.0 \%$ at the age of $5,61.2 \%$ at the age of 15 and $70.4 \%$ at the age of 25 . (b) Depicted are the expected values (Generalized Linear Multilevel Model, solid line) for the proportion of threats relative to all aggression Barbary macaque females ( $N$ females $=45$ ), observed in one up to three periods of observation ( $N$ observations $=$ 71 ), engaged in across dominance rank (corrected for number of females in the group; 
1 denotes the lowest dominance rank) and the respective credible interval (99\%, dashed line).

\section{Discussion}

This study investigated the changing patterns of physical and social activity of aging female Barbary macaques. We observed a pronounced decrease in demanding locomotor activities with age, likely reflecting waning strength and physical fitness. Active grooming bouts were longer in older compared to younger females. Older females had fewer animals within a five meter proximity radius and were less likely to be the target of aggression than younger ones. Aggression directed against others did not decline, but there was a marked decrease in challenging and physical aggression, accompanied by a relative increase in the use of threats.

The decrease in physical activities could be due to the deterioration in physical status, but might also be caused by changes in motivation to engage in these behaviors. Independent assessments of physical condition would be needed to disentangle these two factors. Yet, the presumed decrease in physical strength specifically manual fatigue as a result of arthrosis (Roth et al., 2014) - does not explain the decrease in overall active grooming time we previously observed (Almeling et al., 2016), because single grooming bouts were on average longer in older females than in younger ones. Thus, older females in this population engaged in active grooming less frequently. One might speculate, that fewer but longer grooming bouts require less movement and, hence, are energetically less costly than frequent changes between social partners. Moreover, staying longer with one social partner instead of moving around might help to avoid potentially negative social encounters and the resulting stress. Indeed, there exists evidence that focused grooming networks were observed to be associated with lowered glucocorticoid metabolite levels (Crockford, Wittig, Whitten, Seyfarth, \& Cheney, 2008).

The finding that the average grooming bout was longer for older females indicates that older primates do not only continue to be interested in their social environment (Almeling et al., 2016; Schino \& Sciarretta, 2016; but see Corr, 2003), but also in affiliation. Pavelka (1990) observed in female Japanese macaques a positive correlation between age and contact calling, a behavior that indicates the desire for social contact. Similar to our observation, older female toque macaques showed a decrease in frequency of grooming, but had a significantly higher proportion of longduration contact events (> $5 \mathrm{~min}$ ) compared to younger ones (Ratnayeke, 1994). 
Pavelka (1990) further suggested that once in a social interaction older females are less likely to switch partners or activities (see also Fitts, 1982; Veenema, van Hooff, Gispen, \& Spruijt, 2001).

In an egalitarian society, such as the one of Barbary macaques, the outcome of interactions may be particularly difficult to predict (Fischer, Farnworth, SennhennReulen, \& Hammerschmidt, 2017); it may thus be safer to keep a spatial distance or avoid interactions with potentially negative outcomes through the use of mild signals of aggression. Indeed, older females in our study tended to be more spatially reclusive from the group, which may reflect the motivation to avoid potentially negative situations (see also Ratnayeke, 1994). Yet, changes in spatial group integration may also be explained by group members being less attracted to older females. However, as other group members continued to groom older females (Almeling et al., 2016), this explanation does not seem likely. Regardless of the specific causes, spatial reclusiveness appears to correlate with a lower likelihood of being aggressed. Brent and colleagues (2017) reported an age-associated decrease in the frequency with which rhesus macaque females were the target of aggression. The authors interpreted their finding as indicating that enhanced experience to navigate through their social lives may help older females to avoid aggression. The tendency for an age-associated avoidance of potentially stressful situations in our study could also be interpreted as a mechanism to counteract age-related losses in the physiological flexibility as assumed by SAVI (Charles, 2010). Further studies are necessary to investigate to which extent the amount of aggression received is related to the behavior of the (potential) victim as well as the spatial positions of the (potential) victim and the aggressor, to establish whether spatial reclusion is a strategy by the older animals to avoid unpredictable or potentially negative interactions.

We found no significant variation in overall aggression directed against others across age. Yet, the proportion of low-level aggression increased with age. More specifically, older females mostly used an open mouth threat face, while they less frequently chased after or physically attacked other group members. Picq (1992) reported an age-associated increase in aggression given in captive grey mouse lemurs, but the aggression was predominantly observed as a response to being approached by their cage-mate. The open-mouth threat face that we observed in our sample might function to deter others to approach and therewith might allow females to avoid situations with potentially negative outcomes. Alternatively, older females may prefer threats over more severe aggressions such as fights as they are the least 
physically demanding form of aggression. Future studies are needed to investigate the precise contingencies between signal usage and partner responses as a function of age to illuminate how old subjects maneuver in their societies.

How do our results relate to the human psychological literature? Similar to observations in humans (Carstensen et al., 1999), the slight increase in active grooming bout duration with age suggests that older females are still motivated to engage in social interactions. Yet, as the number of partners decreases (Almeling et al. 2016), this indicates that older females become more selective in their partner choice. In line with the strength and vulnerability integration model (SAVI, Charles, 2010) older females in our study appeared to avoid negative situations to a greater extent than younger ones. In a similar vein, older people reported fewer interpersonal tensions and less frequent arguing than younger people (Birditt et al., 2005). Older people also reported using passive strategies to avoid conflicts more often than did younger ones (Charles et al., 2009).

At first glance, the observation that overall aggression did not decline with age speaks against the idea that older individuals avoid negative interactions (SAVI, Charles, 2010). Yet, we found that the relative proportion of mild aggression increased. This preferential use of mild aggression could serve to avoid ambivalent situations. Studies on humans suggest that unpredictability associated with ambivalent ties is related to stress (Uchino, Holt-Lunstad, Uno, \& Flinders, 2001). It has been proposed that feeling ambivalent about social ties but not aversion per se relates to accelerated physiological decline (Uchino et al., 2012). Therefore, our study supports the view that age-related avoidance of negative situations (SAVI, Charles, 2010) may be a shared trait within the primate lineage. How aging subjects manage their social interactions deserves further research attention; the strategic avoidance of negative interactions appears to be an important explanatory variable contributing to similarities in old humans' and monkeys' behavioral patterns.

\section{Acknowledgements}

We are grateful to Ellen Merz, Gilbert de Turckheim and Guillaume de Turckheim for permission to conduct this study at 'La Forêt des Singes' in Rocamadour and the team in the park for support. Moreover, we thank Andreas Ploss, Annika Patzelt and Elena Jeß who helped with the data collection. We thank Rebecca Jürgens for comments and corrections on the manuscript. We thank the Leibniz ScienceCampus for Primate 
Cognition for funding. A.M.F. and J.F. would like to thank the Helmut C. Nanz foundation for their hospitality. The authors declare no conflict of interest.

\section{Author contributions}

L.A., K.H., A.M.F. and J.F. designed the study, L.A. collected the data, H.S.-R. and L.A. executed the analyses and L.A., A.M.F., K.H. and J.F. wrote the manuscript. 


\section{Chapter 4: General discussion}

In this dissertation I addressed several questions (A-F), developed in the framework of models of successful aging, by comparing age-related variations across different social and cognitive domains in Barbary macaques. With this general discussion I summarize my findings and discuss their implications for different models of successful aging. At the same time I discuss the applicability of the models of successful aging for crossspecies comparative research (section 4.1). Next, in section 4.2 I provide the conclusions that can be drawn from this thesis. Finally, in section $4.3 \mathrm{I}$ address limitations of the current studies and give an outlook on potential lines of future research in the field of comparative social aging.

\subsection{Main findings in a comparative framework}

\subsubsection{Social activity and network size}

First, I addressed the question of whether female Barbary macaques show similarities to human behavior (Carstensen, 1992; Field \& Minkler, 1988; Fung, Carstensen, \& Lang, 2001; Verbrugge et al., 1996) in terms of age-associated decrease in social activity and social network size (research question A). I reported evidence for an ageassociated decrease in overall active grooming duration and number of adult partners that female Barbary macaques groomed (chapter 2 ). These results resemble previous findings in other macaque species, which reported a decrease in active grooming time (Nakamichi, 1984; Veenema et al., 1997; but see Pavelka 1990) and number of social partners (Corr, 2003; but see Pavelka 1991).

An inspection of the distribution of the grooming data (chapter 2, Figure $4 A+B$ ) revealed that grooming activity and number of partners decreased moderately with age, starting in early adulthood. This indicates that other processes besides internal resource losses, viz. age-associated health problems, which are considered as one possible explanatory factor in activity theory (Havighurst, 1961; Lemon et al., 1972) might be responsible for age-related variation in grooming patterns. In chapter 3 । explored in more detail to which extent age-associated physical decline may explain the decrease in grooming activity (research question E). Female Barbary macaques appear to experience age-related physical deterioration, as the frequency of engagement in physically demanding locomotor activities decreases with age. The 
frequency of engagement in physical activities is an imperfect measure of physical state, as we cannot rule out that older females might also be less motivated to engage in these behaviors even when still in relatively good physical state. A study on humans for instance indicates a profound decline in vigorous activities in between the age of 14 and 21 yrs. (Caspersen, Pereira, \& Curran, 2000). Not surprisingly, this decline in physical activity has not been attributed to a loss in physical resources. Instead, changes in the dopamine system that regulates motivation for locomotion has been suggested as a potential explanation (Sallis, 1999). Crucially, however, the decrease in overall active grooming duration cannot be explained by faster physical exhaustion as the average length of individual grooming bouts even increased with age. This is in accordance with findings in humans, where health is not the main precursor for agerelated changes in social activity and network size (Carstensen, 1992; Lang \& Carstensen, 1994).

The social withdrawal I observed was apparently driven by the aging individuals themselves, as the amount of grooming and the number of adult partners from whom females received grooming did not vary with age (chapter 2). This is an interesting observation from a biological perspective per se, but see chapter 2 for a discussion. This observation further resembles previous findings in macaques, which found no variation in grooming time received with age (Nakamichi, 1984; Corr, 2003). It also speaks to some extent against activity theory. Loss of external resources is one of the key factors to explain the decrease in social activity observed in humans (Lemon et al., 1972). While activity theory appears to be the ideal model for comparative research at first glance, because it does not claim any cognitively demanding factors, its applicability is restricted. The loss of external resources that activity theory suggests to be the possible explanatory factors, is not due to unwillingness of others to interact with older people per se, but the loss of accustomed roles in the context of retirement and death of beloved ones (Havighurst, 1961; Lemon et al., 1972). Older female macaques do not experience such cultural conventions as retirement and do not have specific roles (Pavelka, 1990). Whether the observed changes in grooming patterns might be caused by death of main affiliative long-term partners remains an open question for future observation. Unfortunately, I lack the long-term data to address this question. My findings do suggest, however, that older females' grooming activity is not reduced due to an unwillingness of other group members to interact with them.

In contrast to the other models of successful aging, disengagement theory makes explicit predictions in terms of the society's behavior towards older people, as it 
assumes mutual withdrawal (Cumming \& Henry, 1961). Thus, on the one hand, the observation that social changes are driven only by the aging individuals themselves is a first indicator that disengagement theory does not explain older female Barbary macaques' behavioral patterns. On the other hand, while acknowledging the influence of the behavior of the social environment, disengagement theory focuses on the motivational changes occurring in the aging individual itself. Thus, the observation that the social withdrawal is apparently driven by the aging individual itself is in line with disengagement theory. What speaks against motivational shifts predicted by disengagement theory, however, is that older female Barbary macaques seem to be at least as interested in affiliation as younger ones, evidenced by the increase in average grooming bout length (chapter 2).

So far, this data leads to the conclusion that it is the aging female Barbary macaques themselves who are responsible for changes in their grooming network, rather than other individuals becoming less interested in interacting with them. Moreover, older females seem still interested in affiliation and they seem not to be hampered in their grooming activity by physical deterioration. This challenges to some extent socio-emotional selectivity theory (Carstensen et al., 1999), which assumes that such pattern is tied to the awareness of ones' limited lifetime.

\subsubsection{Interest in social and non-social information}

To gain some deeper insight into potential age-related motivational shifts, I addressed the questions of whether there is a general trend of decreasing interest in the environment with age (research question B) and whether a potential decrease in interest is domain-specific, i.e. an age-related focus on social over non-social stimuli (research question C). I observed domain-specific motivational shifts across adulthood (chapter 2). The interest in different toys waned in early adulthood and is thus rather an effect of adolescence than senescence (see chapter 2 for a discussion). If a food reward was hidden inside the object, however, only the very old individuals refused to handle the baited objects. In contrast, the interest in social information was not affected by age, as evident in subjects' interest in portrait photographs and females' interest in recruitment screams and their vocalizations on third party interactions. How do these observations fit with the motivational core components of the different explanatory models of successful aging? 
These observations indicate that older female Barbary macaques' behavior cannot be explained by a general loss of interest, as suggested by disengagement theory (Cumming \& Henry, 1961). While disengagement theory has been challenged empirically (Lemon et al., 1972) and is largely discarded from the psychological literature (Achenbaum \& Bengtson, 1994), I initially considered this idea for two reasons: First, an inability to reciprocate social exchanges due to age-related physical restrictions might result in "social exclusion" by group members. Primate social relationships are characterized by exchange (Barrett, Henzi, Weingrill, Lycett, \& Hill, 1999). When considering rather long-term observation periods of more than 7 months, giving and receiving grooming is balanced among individuals over repeated interactions (Gomes, Mundry, \& Boesch, 2009). The social status of an individual strongly depends on its ability to reciprocate relative to the extent that other group members reciprocate (Tiddi, Aureli, di Sorrentino, Janson, \& Schino, 2011). To my knowledge, collective responsibility for weak or disabled individuals is absent in monkey societies. It should be noted that very old (25 years old or older) individuals are rare $(\mathrm{N}=5)$ in my behavioral sample. It hence remains an open question, whether individuals that successively show lessened engagement might at least at some point experience social exclusion (see further section 4.3.3). However, this alone would not be sufficient to be in line with disengagement theory, as disengagement theory puts the focus on motivational changes within the aging individual.

Second, and the more crucial point of why I considered disengagement theory, was that it appeared likely to me that an age-associated decline in (socio-) cognitive abilities (Rosati et al., 2016) might be associated with a decreased interest in the environment. Vigilance was observed to decrease with age in rhesus monkeys (Watson et al., 2015). Corr (2003) reported a decreased frequency of glancing at other group members for older rhesus macaque females. In my studies, I found no support for a decrease in social interest at all. My experimental studies involved a substantial number of older individuals ( $<20$ years, tested in at least one experimental condition: $\mathrm{N}=29$ in novel object tests, $\mathrm{N}=32$ in photograph experiments, $\mathrm{N}=16$ in playback experiments) and I feel confident to say that disengagement theory does not help to explain older female Barbary macaques behavior. Several other studies also indicate that the interest in the social environment seems to be at least stable for older female monkeys (Pavelka, 1990,1991; Schino \& Sciarretta, 2016). Older mandrills (Mandrillus sphinx) monitor others behavior even slightly more than younger ones (Schino \& Sciarretta, 2016). 
The general selectivity, viz. the observed focus on social over non-social stimuli, is in line with motivational shifts expected following socio-emotional selectivity theory (Carstensen et al., 1999). Thus, this observation weakly challenges socio-emotional selectivity theory (Carstensen et al., 1999), which assumes that such pattern results the awareness of ones' limited lifetime. Moreover, this observation is in line with motivational shifts expected following the model of selection, optimization and compensation (SOC model) (Baltes \& Baltes, 1990). See chapter 1 section 1.3 and chapter 3 for a description. It seems convincing that social informations are more important for monkeys than toys. Based on this assumption, my observations resemble to some extent findings from studies on humans indicating that older humans focus more on their central goals (Riediger \& Freund, 2006). To test the SOC-model model experimentally one needs to create a situation where subjects are confronted with a potential loss and need to make a choice. For instance, the consequences of falling are assumed to be far greater for older than younger subjects (Lindenberger, Freund, \& Baltes, 2001). A study investigating dual-task performance, of walking on a narrow track while memorizing, showed that older people focus on their physical performance rather than on cognitive aspect, in case of high task difficulty (Li et al., 2001). This effect is exacerbated by the fact that older people were as willing as younger people to score well in the cognitive tasks. At the moment I do not have an idea of how one could apply a similar paradigm to studies on primates.

\subsubsection{Partner preferences}

Socio-emotional selectivity theory assumes an increasing focus on emotionally meaningful partners in older individuals (Carstensen et al., 1999). To determine whether such pattern may occur in the absence of an awareness of ones' limited lifetime, I assessed whether Barbary macaques show relative greater interest in pictures of important (i.e., presumably emotionally salient) social partners than in less significant ones (research question D). My experiments revealed that Barbary macaques expressed a preferential interest for important partners, irrespective of age, as visible in longer looking times at the respectively preferred pictures. Specifically, males showed greater interest in portrait pictures of infants compared to females. Females showed greater interest in pictures of infants compared to non-friends. Moreover, females tended to look longer at portrait pictures of their main female affiliation partner than at pictures of non-friends. This finding is in line with activity 
theory, which assumes that older adults have the same desires as middle aged ones (Havighurst, 1961; Lemon et al., 1972). Albeit activity theory is difficult to apply to primate societies, as noted above, one could argue that this finding speaks to some extent for activity theory, as this theory does not include any cognitively demanding processes as assumed precursors. Moreover, this observation is in accordance with predictions of the socio-emotional selectivity model (Carstensen et al., 1999). This is the case, as this model assumes that an increasing preference for important partners with age is tied to the awareness of one's limited lifetime. Thus, looking at these experimental part of my dissertation study alone one can argue that these are in support of socio-emotional selectivity theory. Note, however, that from a biological perspective one would not expect males to show an increasing preference for infants with age. Barbary macaque males need to build up their male network (Ostner \& Schülke, 2014) and use infants for this purpose (Berghänel, Ostner, Schroder, \& Schülke, 2011; Henkel et al., 2010). Therefore, infants should be particularly important and interesting for young males, too. The current findings are in accordance with this. This example shows the importance of considering the species-specific characteristics when testing psychological theories in other species than humans.

Of further importance in the context of selective partner-choice is that in contrast to previous studies on macaques described in chapter 1 (Kato, 1999; Nakamichi, 2003; Veenema et al., 1997), I did not observe an age-associated increasing preference for grooming maternal related partners (chapter 2). An important difference between those studies and my observations is that the former were conducted on despotic species viz., Japanese macaques and long-tailed macaques. The absence of an age-associated increasing preference for grooming related partners may be explained by Barbary macaques' rather tolerant social style (Thierry, 2000a; Thierry, Iwaniuk, \& Pellis, 2000). A study on females of the same study population revealed that relationship strength but not kinship is positively associated with the occurrence of post-conflict affiliation (Patzelt et al., 2009). Analyses on a subset of the data presented in this thesis showed that maternal relatedness did not explain the distribution of grooming in the female network (Ploss, 2010, unpublished Diploma thesis). Thus, if there is any focus on important partners with age in female Barbary macaques then it should rather occur in terms of their main affiliative long-term partners. What time-frame may constitute as an appropriate criterion would certainly be a matter of discussion. My study was cross-sectional and observation periods of behavioral data presented in this thesis lasted approximately 2.5 months each; 
unfortunately, this is too short to make any claims regarding the durability of relationships. Thus, this presents an interesting open question for future research.

\subsubsection{Avoidance of potentially stressful situations}

According to the strength and vulnerability integration model (SAVI model; Charles, 2010) older adults should avoid negative situations to a greater extent than younger adults, due to their enhanced vulnerability to stressors (see chapter 1 section 1.3 for a description of the model). As described in chapter 1 (section 1.1.) older primates also seem to be more vulnerable to stressors (Jensen et al., 1980; Sapolsky \& Altmann, 1991). In chapter 3 I aimed to make an initial step to shed light on the question of whether older Barbary macaques' focus on fewer partners may be explained by avoidance of situations with potentially negative outcomes (research question F). In line with the SAVI model (Charles, 2010), I found that with increasing age females tended to be spatially reclusive, were less frequently the target of aggression and that the proportion of low-level aggression (i.e. threats) to all aggression given increased with age (chapter 3). I did not find evidence for an age-associated decrease in overall engagement in agonistic behavior. The latter result seems to differ from patterns observed in humans (Birditt et al., 2005; Charles et al., 2009) as described in chapter 1. Note, however that studies on humans do not differentiate between the actor and receiver within a social interaction, making a comparative view difficult. Moreover, lowcost aggression such as threats in Barbary macaques may have a different meaning than arguing in humans (see chapter 3 for a discussion). From a biological perspective, a possible explanation would be that active aggression serves to maintain the dominance position in the group, which in turn may be associated with benefits (Sosa, 2016). The costs of enhanced arousal which has been reported to be associated with aggression (Aureli, 1997; Wittig et al., 2015; but see Koski et al., 2007) may be outweight by the benefits of social dominace. In sum, my findings reported in chapter 3 suggest that older female Barbary macaques' social life could be characterized by greater avoidance behavior of negative situations in line with the SAVI model. Although this certainly needs more detailed evaluation this seems to be a fruitful framework for comparative research. 


\subsection{Conclusion}

While keeping in mind that applicability of psychological theories to primates is restricted the following conclusions can be drawn from my dissertation studies. Disengagement theory (Cumming \& Henry, 1961) does not help to explain social aging in Barbary macaques. Activity theory (Havighurst, 1961; Lemon et al., 1972) is to some extent weakly supported given that my experimental studies suggest that social interest does not vary with age. The focus on social over non-social stimuli I observed is in line with the SOC model (Baltes \& Baltes, 1990), but the value of this observation is restricted. The same accounts for the observation regarding conflict domain and their similarity with patterns observed in humans. A similarity in patterns observed among humans and primates alone is not sufficient to support a given theory, as long as the underlying processes are not the same in humans and nonhuman primates. Observing a pattern in primates which is supposed to be based on cognitive processes they (presumably) do not possess, is important for theory building. Specifically, the observation that female Barbary macaques show social selectivity on the behavioral level accompanied by a focus on the social over the non-social domain highlights the importance to focus on the most parsimonious explanation to explain certain patterns. According to socio-emotional selectivity theory the awareness of limited lifetime constitutes the key explanatory factor of human social selectivity (Carstensen et al., 1999). My dissertation study indicates that social selectivity can occur without cognitively demanding processes, suggesting that more ancestral processes seem to be at work. This challenges to some extent socio-emotional selectivity theory (Carstensen et al., 1999), but does not exclude the possibility that the awareness of a limited future time perspective in humans may enhance the effects of more ancestral processes.

But what kind of processes may drive motivational and behavioral shifts occurring with age? One could speculate that a possible basis for age-related changes in motivation and social behavior concern internal reward structures. The dopamine system plays a crucial role in motivation and response to stimuli (Bunzeck \& Düzel, 2006; Düzel, Bunzeck, Guitart-Masip, \& Düzel, 2010; Ljungberg, Apicella, \& Schultz, 1992). This system is subject to age-associated decline in terms of receptor loss (Kaasinen et al., 2000). Moreover, age-specific relations between dopamine synthesis and reward-related prefrontal activity have been reported (Dreher, Meyer-Lindenberg, Kohn, \& Berman, 2008). Whether such age-associated changes in the internal reward structures are associated with motivational shifts across the lifespan constitutes an 
interesting avenue for future research. In terms of human socio-emotional aging it has been suggested this may be driven by changes in the oxytocin system (Ebner, Maura, MacDonald, Westberg, \& Fischer, 2013). On the behavioral level, one mechanism that could result in a more selective choice of social partner could be age-related avoidance of negative situations as suggested by the SAVI-model (Charles, 2010). This deserves further research attention, as it appears to be an important explanatory variable contributing to similarities in old humans' and monkeys' behavioral patterns.

\subsection{Limitations and further suggestions for future research}

Throughout this discussion I already pointed out open questions and some suggestions for future research, respectively. In the next paragraphs I will give some additional more specific examples and suggestions of potentially interesting lines for future research incorporating a biological perspective on aging.

\subsubsection{Potential benefits of older females' behavioral strategies}

Models of successful aging focus on the question how humans subjectively experience changes in their social activity and sizes of their social networks. To get a better understanding of older nonhuman primates' selectivity, we need measures to assess how they might experience certain situations. A potentially promising way to achieve this to some extent is via endocrinological measures (e.g., Crockford et al., 2013). There is some evidence in support of the idea that focused networks are associated with enhanced well-being in the sense of lowered stress-levels. High ranking rhesus macaque females had significantly lower glucocorticoid metabolite levels in months in which their proximity networks were smaller (Brent, Semple, Dubuc, Heistermann, \& MacLarnon, 2011). During periods in which wild female baboons focus their grooming on fewer partners they were shown to have lower glucocorticoid metabolite levels than in periods during which they distributed their grooming among more partners (Crockford, Wittig, Whitten, Seyfarth, \& Cheney, 2008). Also, focused grooming networks seem to buffer stress. Wild female baboons that were observed to focus their grooming on a few partner, showed smaller magnitudes of rises in glucocorticoid metabolite levels in a period of instability of the alpha males' position, compared to those that had more diverse networks (Wittig, Crockford, Lehmann, Whitten, Seyfarth, \& Cheney, 2008). Studies, which combine behavioral observations with hormonal 
measures and cortisol in particular (Ebner, Kamin, Diaz, Cohen, \& MacDonald, 2015), could reveal that the behavioral strategies that I have observed in older females may have the potential value of reduced physiological stress levels. However, this is probably very difficult as glucocorticoid levels are highly sensible to a variety of factors (e.g., Adam \& Kumari, 2009). Also, one may ask whether glucocorticoid levels are a reliable indicator for well-being. Several studies indicate that stressors and social ones in particular, are associated with elevated cortisol levels (Rohleder, Beulen, Chen, Wolf, \& Kirschbaum, 2007; Stawski, Cichy, Piazza, \& Almeida, 2013).). Subjective feelings of stress in humans, however, are not necessarily accompanied by elevated glucocorticoid levels. For instance, military training was observed to be associated with an increase in subjective feelings of stress, while simultaneously assessed hair cortisol remained unaffected (Boesch et al., 2015). Finally, some studies suggest that aging tends to be associated with hypercorticolism (e.g., Altmann, Gesquiere, Galbany, Onyango, \& Alberts, 2010; Sapolsky \& Altmann, 1991), complicating the interpretation of potential results. Despite all these challenges, I consider glucocorticoid measures as physiological indicator of well-being as the most promising avenue for future research.

\subsubsection{Relationship quality with remaining partners}

Another important aspect would be to investigate the relationship quality with the remaining grooming partners. Uchino and colleagues (2001) reported that the unpredictability associated with ambivalent ties is related to stress and has detrimental health effects. Individuals who had a higher number of ambivalent ties in their network exhibited shorter telomere length - a putative aging marker - independent of age (Uchino et al., 2012). Supporting further the idea that rather the ambivalence and not negative interaction per se has detrimental effects, aversive ties had no influence on telomere length (Uchino et al., 2012). Taken the lowered resilience to stressors which were observed in older primates (Jensen et al., 1980; Sapolsky \& Altmann, 1991), it appears likely that older individuals avoid having ambivalent relationships. Cluster analysis on a subset of the behavioral data presented in this thesis suggests that female Barbary macaques exhibit four distinct relationship types: rarely interacting agonistic dyads, rarely interacting affiliative dyads, moderately frequently interacting ambivalent dyads and frequently interacting affiliative dyads (Fischer et al., 2017). Particularly, the latter two might be of interest in the context of studying partner preferences in older female Barbary macaques. 


\subsubsection{Chronological age vs. biological age}

In my dissertation studies, I investigated changes across the whole range of adulthood using chronological age as a continuous factor. Independent of the framework of the models of successful aging and whether or not either disengagement theory or activity theory may provide an (partial) explanation for the patterns that may occur in highly senescent individuals, it would be interesting to investigate changes within the rather old Barbary macaques (20 years old or older). Even though physical abilities seem not to be the main precursor to explain shifts in grooming patterns occurring in the progress of adulthood (see chapter 3), it appears likely that they have some explanatory value, when looking at the lives of very old macaques. Taken the large inter-individual differences in aging rates (Aldwin et al., 2001; Ahola et al., 2012) it may be interesting to assess physical status as far as possible and test how such measures would predict behavior. Ideally, such studies would implement a broad array of physical and physiological marker of aging, as for instance body mass index (Altmann et al., 2010) or telomere length (Ahola et al. 2015).

\subsubsection{Female aging from a biological perspective}

The biological perspective provides more than the expectation of decline of social activity based on age-associated deterioration. From a biological perspective a successful individual is one that maximizes its inclusive fitness relative to conspecifics. Life history theory addresses how organisms should allocate time and energy to maximize their fitness in the face of various trade-offs (e.g. Vitzthum, 2008). The tradeoff between current reproduction and future reproduction is of particular importance in this context. Predictions for the behavior of older females have been developed within the framework of terminal investment theory (Williams 1966). When a female is in her reproductive prime, she should minimize investment in existing offspring so that she has adequate resources for future reproduction. When a female has surpassed her reproductive prime and her future reproductive potential is low, she should expend more (reproductive) effort in existing offspring. For semi-free ranging Barbary macaques at Salem, behavioral observations revealed that old mothers weaned their offspring significantly later than young mothers, suggesting that increasing inter-birth intervals cannot be solely explained by reproductive decline (Paul et al., 1993). A study 
on semi-free ranging rhesus macaques reported weak evidence for terminal investment, which was partly not mutually exclusive with senescence effects (Hoffman, Higham, Mas-Rivera, Ayala, \& Maestripieri, 2010). In support of terminal investment theory Hoffman and colleagues (2010) reported that older mothers had longer birth intervals and spent more time in contact with infants compared to younger ones. However, infants of older mothers had lower body mass and lower survival rates compared to those of younger mothers. Unfortunately, data on suckling effort was not available. Accordingly, increases in inter-birth intervals and weakened condition of infants of older mothers could simply reflect age-associated deterioration.

\subsubsection{Male behavior}

Males are particularly interesting to study because across the primate order and human populations their lives seem to be more variable than those of females (Colchero et al., 2016). Most of the social aging studies in primates, including mine, focused on females. To my knowledge only four studies included males as subjects. Three were conducted in captivity; one on mouse lemurs (Picq, 1992), one on rhesus macaques (Suomi et al., 1996) and one on chimpanzees (Baker, 2000). The implications of these studies are all limited due to small sample sizes and arbitrary rearing conditions. One study specifically investigated sex-differences in a sample of 42 rhesus macaques of a semi-free ranging population (Corr, 2003). Note, however, that the sample of older (20 years old or older) males was restricted to five individuals. In contrast to females, the time males spent in proximity with other individuals was not affected by age. Moreover, older males were groomed by others more frequently and had a higher number of social partners than younger ones. Older males showed reductions in the frequency of aggressive behaviors compared to younger ones. Finally, older males spent their social contact time with infants rather than adult females. Corr (2003) suggested that the opposing findings for males and females could be a result of the matrifocal social structure in rhesus macaques, i.e. female philopatry and male migration. Therefore, females are securely embedded in their matrilines, while males may be forced to reduce agonistic behaviors with potential detrimental effects and increase social activity to maintain their position within a group. Female philopatry and male migration is not restricted to rhesus macaques, but a general feature of macaque species (Thierry et al., 2000). For Barbary macaques, males' position in the group relies on their ability to build up a supportive network (Ostner \& Schülke, 2014). Post-prime males (14 years 
old or older) are more frequently engaged in coalitions compared to prime-males (Rathke, Berghänel, Bissonnette, Ostner, \& Schülke, 2017). This may help older Barbary macaque males to maintain access to females (Bissonnette et al., 2009). As interactions with infants can be considered as an investment in the male network (Berghänel, Ostner, Schroder, \& Schülke, 2011; Henkel et al., 2010) it would be interesting to investigate whether any age-related changes occur in this regard. In her diploma thesis, Henkel (2008), reported no evidence for an effect of age on the time Barbary macaques spent carrying infants, but the results are restricted to a subset of 12 males with the oldest being 20 years old. Even though male rank did not predict infant carrying in this study, the access to infants may be influenced by dominance rank, particularly if infants are rare. Further studies should take these factors into account. They should also assess whether an infant is 'blocked' by another male during the focal observation. Ideally, these observations should take place over the course of several years, which may enable the establishment of a data set with varying infant availability. Moreover, not only the initiator and terminator of a triadic interaction are important to determine (Henkel et al., 2010), but also whether males try to engage in such an interaction and fail, in order get an understanding of the effort males exhibit. To get a more nuanced picture of aging in primates, and to be able to draw conclusions regarding similarities and differences with humans, future studies should also focus on age-related effects on social behavior in primate males. 


\section{References}

Achenbaum, W. A., \& Bengtson, V. L. (1994). Re-engaging the disengagement theory of aging - On the history and assessment of theory development in gerontology. Gerontologist, 34(6), 756-763.

Ackermann, M., Stearns, S. C., \& Jenal, U. (2003). Senescence in a bacterium with asymmetric division. Science, 300(5627), 1920-1920. doi: 10.1126/science.1083532

Adam, E. K., \& Kumari, M. (2009). Assessing salivary cortisol in large-scale, epidemiological research. Psychoneuroendocrinology, 34(10), 1423-1436. doi: 10.1016/j.psyneuen.2009.06.011

Ahola, K., Sirén, I., Kivimäki, M., Ripatti, S., Aromaa, A., Lönnqvist, J., \& Hovatta, I. (2012). Work-related exhaustion and telomere length: A population-based study. PLos ONE, 7(7), e40186. doi: 10.1371/journal.pone.0040186

Aiken, L. R. (1989). Later life (3 $3^{\text {rd }}$ ed.). Hillsdale, NJ: Lawrence Erlbaum.

Ajrouch, K. J., Antonucci, T. C., \& Janevic, M. R. (2001). Social networks among blacks and whites the interaction between race and age. The Journals of Gerontology Series B: Psychological Sciences and Social Sciences, 56(2), 112-118. DOI: 10.1093/geronb/56.2.S112

Alberts, S. C., Altmann, J., Brockman, D. K., Cords, M., Fedigan, L. M., Pusey, A., ... Bronikowski, A. M. (2013). Reproductive aging patterns in primates reveal that humans are distinct. Proceedings of the National Academy of Sciences, 110(33), 13440-13445. doi: 10.1073/pnas.1311857110

Aldwin, C. M., Spiro, A., Levenson, M. R., \& Cupertino, A. P. (2001). Longitudinal findings from the normative aging study: III. Personality, individual health trajectories, and mortality. Psychology and Aging, 16(3), 450-465. doi: 10.1037/0882-7974.16.3.450

Almeling, L., Hammerschmidt, K., Sennhenn-Reulen, H., Freund, Alexandra M., \& Fischer, J. (2016). Motivational shifts in aging monkeys and the origins of social selectivity. Current Biology, 26(13), 1744-1749. DOI: 10.1016/j.cub.2016.04.066

Altmann, J. (1974). Observational Study of Behavior - Sampling Methods. Behaviour, 49(3-4), 227-267.

Altmann, J., Gesquiere, L., Galbany, J., Onyango, P. O., \& Alberts, S. C. (2010). Life history context of reproductive aging in a wild primate model. In M. Weinstein \& K. Oconnor (Eds.), Reproductive Aging (Vol. 1204, pp. 127-138). Malden: Wiley-Blackwell.

Archer, C. R., \& Hosken, D. J. (2016). Evolution: Escaping the inevitability of ageing. Current Biology, 26(5), 202-204. doi: 10.1016/j.cub.2016.01.015 
Archie, E. A., Tung, J., Clark, M., Altmann, J., \& Alberts, S. C. (2014). Social affiliation matters: both same-sex and opposite-sex relationships predict survival in wild female baboons. Proceedings of the Royal Society of London B: Biological Sciences, 281(1793), 20141261. doi: 10.1098/rspb.2014.1261

Atkinson, J. W. (1957). Motivational determinants of risk-taking behavior. Psychological Review, 64(6,Pt.1), 359-372. doi: doi.apa.org/journals/rev/64/6p1/359

Aureli, F. (1997). Post-conflict anxiety in nonhuman primates: The mediating role of emotion in conflict resolution. Aggressive Behavior, 23(5), 315-328. doi: 10.1002/(sici)1098-2337(1997)23:5<315::aid-ab2>3.0.co;2-h

Aureli, F., Preston, S. D., \& de Waal, F. B. M. (1999). Heart rate responses to social interactions in free-moving rhesus macaques (Macaca mulatta): A pilot study. Journal of Comparative Psychology, 113(1), 59-65. doi: 10.1037//07357036.113.1.59

Aureli, F., \& Schaffner, C. M. (2002). Relationship assessment through emotional mediation. Behaviour, 139, 393-420. doi: 10.1163/156853902760102726

Austad, S. N. (1997). Comparative aging and life histories in mammals. Experimental Gerontology, 32(1), 23-38. doi: 10.1016/S0531-5565(96)00059-9.

Baird, B. M., Lucas, R. E., \& Donnellan, M. B. (2010). Life satisfaction across the lifespan: Findings from two nationally representative panel studies. Social indicators research, 99(2), 183-203. doi: 10.1007/s11205-010-9584-9

Baker, K. C. (2000). Advanced age influences chimpanzee behavior in small social groups. Zoo Biology, 19(2), 111-119. doi: 10.1002/10982361(2000)19:2<111::aid-zoo2>3.0.co;2-5

Baltes, P. B. (1987). Theoretical propositions of life-span developmental psychology On the dynamics between growth and decline. Developmental Psychology, 23(5), 611-626. doi: 0.1037/0012-1649.23.5.611

Baltes, P. B. (1997). On the incomplete architecture of human ontogeny: Selection, optimization, and compensation as foundation of developmental theory. American Psychologist, 52(4), 366-380. doi: 10.1037/0003-066X.52.4.366

Baltes, P. B. \& Baltes, M. M. (1990). Psychological perspectives on successful aging: The model of selective optimization with compensation. In P. B. Baltes \& M. M. Baltes (Eds.), Successful Aging. Perspectives from the Behavioral Sciences (pp. 1-34). Cambridge: University Press.

Barrett, L., Henzi, S. P., Weingrill, T., Lycett, J. E., \& Hill, R. A. (1999). Market forces predict grooming reciprocity in female baboons. Proceedings of the Royal Society of London Series B: Biological Sciences, 266(1420), 665-670. doi: 10.1098/rspb.1999.0687

Bates, D., Maechler, M., Bolker, B., \& Walker, S. (2014). Ime4: Linear mixed-effects models using Eigen and S4. R package version 1.1-7. URL http://CRAN.Rproject.org/package $=$ Ime 4 . 
Belitz, C., Brezger, A., Klein, N., Kneib, T., Lang, S., \& Umlauf, N. (2015). BayesXSoftware for Bayesian inference in structured additive regression models. Version 3.0. URL http://www.bayesx.org.

Berghänel, A., Schülke, O., \& Ostner, J. (2010). Coalition formation among Barbary macaque males: The influence of scramble competition. Animal Behaviour, 80(4), 675-682. doi:10.1016/j.anbehav.2010.07.002

Berghänel, A., Ostner, J., Schroder, U., \& Schülke, O. (2011). Social bonds predict future cooperation in male Barbary macaques (Macaca sylvanus). Animal Behaviour, 81(6), 1109-1116. doi: 10.1016/j.anbehav.2011.02.009

Berghänel, A., Ostner, J., \& Schülke, O. (2011). Coalitions destabilize dyadic dominance relationships in male Barbary macaques (Macaca sylvanus). Behaviour, 148(11-13), 1257-1275. doi: 10.1163/000579511X600628

Birditt, K. S., Fingerman, K. L., \& Almeida, D. M. (2005). Age differences in exposure and reactions to interpersonal tensions: A daily diary study. Psychology and Aging, 20(2), 330-340. doi: 10.1037/0882-7974.20.2.330

Bissonnette, A., de Vries, H., \& van Schaik, C. P. (2009). Coalitions in male Barbary macaques (Macaca sylvanus): Strength, success and rules of thumb. Animal Behaviour, 78(2), 329-335. doi: 10.1016/j.anbehav.2009.05.010

Bissonnette, A., Lange, E., \& van Schaik, C. P. (2009). A cardinal measure of competitive ability in Barbary macaque males (Macaca sylvanus). Ethology, 115(7), 671-681. doi: 10.1111/j.1439-0310.2009.01652.x

Blackburn, E. H., Epel, E. S., \& Lin, J. (2015). Human telomere biology: A contributory and interactive factor in aging, disease risks, and protection. Science, 350(6265), 1193-1198. doi: 10.1126/science.aab3389

Blakemore, S.-J., \& Robbins, T. W. (2012). Decision-making in the adolescent brain. Nature Neuroscience, 15(9), 1184-1191. doi: 10.1038/nn.3177

Boccia, M. L., Reite, M., \& Laudenslager, M. (1989). On the physiology of grooming in a pigtail macaque. Physiology \& Behavior, 45(3), 667-670. doi: 10.1016/00319384(89)90089-9

Boesch, M., Sefidan, S., Annen, H., Ehlert, U., Roos, L., Van Uum, S., . . La Marca, R. (2015). Hair cortisol concentration is unaffected by basic military training, but related to sociodemographic and environmental factors. Stress, 18(1), 35-41. doi: 10.3109/10253890.2014.974028

Borries, C., \& Koenig, A. (2008). Reproductive and behavioral characteristics of aging in female Asian colobines. In. S. Atsalis, S.W. Margulis \& P.R. Hof (Eds.), Primate reproductive aging: Interdisciplinary topics in gerontology (Vol. 36, pp. 80-102). Basel: Karger Publishers.

Brent, L., Ruiz-Lambides, A., \& Platt, M. (2017). Family network size and survival across the lifespan of female macaques. Proceedings of the Royal Society of London B: Biological Sciences, 284(20170515). DOI: 10.1098/rspb.2017.0515 
Brent, L. J., Franks, D. W., Foster, E. A., Balcomb, K. C., Cant, M. A., \& Croft, D. P. (2015). Ecological knowledge, leadership, and the evolution of menopause in killer whales. Current Biology, 25(6), 746-750. doi: 10.1016/j.cub.2015.01.037

Brent, L. J., Lehmann, J., \& Ramos-Fernández, G. (2011). Social network analysis in the study of nonhuman primates: A historical perspective. American Journal of Primatology, 73(8), 720-730. doi: 10.1002/ajp.20949

Brent, L. J. N., Semple, S., Dubuc, C., Heistermann, M., \& MacLarnon, A. (2011). Social capital and physiological stress levels in free-ranging adult female rhesus macaques. Physiology \& Behavior, 102(1), 76-83. doi: 10.1016/j.physbeh.2010.09.022

Brezger, A., \& Lang, S. (2006). Generalized structured additive regression based on Bayesian P-splines. Computational Statistics \& Data Analysis, 50(4), 967-991. DOI: 10.1016/j.csda.2004.10.011.

Bronikowski, A. M., Altmann, J., Brockman, D. K., Cords, M., Fedigan, L. M., Pusey, A., ... Alberts, S. C. (2011). Aging in the natural world: comparative data reveal similar mortality patterns across primates. Science, 331(6022), 1325-1328. doi: 10.1126/science.1201571

Brumm, H. K., S. Riechelmann, C. Todt, D. (2005). Do Barbary macaques 'comment' on what they see? A first report on vocalizations accompanying interactions of third parties. Primates, 46, 141-144. doi: 0.1007/s10329-004-0107-7

Bunzeck, N., \& Düzel, E. (2006). Absolute coding of stimulus novelty in the human substantia nigra/VTA. Neuron, 51(3), 369-379

Bukov, A., Maas, I., \& Lampert, T. (2002). Social participation in very old age crosssectional and longitudinal findings from BASE. The Journals of Gerontology Series B: Psychological Sciences and Social Sciences, 57(6), 510-517. doi: 10.1093/geronb/57.6.P510

Campo, R. A., Uchino, B. N., Holt-Lunstad, J., Vaughn, A., Reblin, M., \& Smith, T. W. (2009). The assessment of positivity and negativity in social networks: The reliability and validity of the Social Relationships Index. Journal of Community Psychology, 37(4), 471-486. doi: 10.1002/jcop.20308

Carey, J. R., \& Gruenfelder, C. (1997). Population biology of the elderly. In K.W. Wachter \& C.E. Finch (Eds.), Between Zeus and the salmon: The biodemographie of longevity (pp. 127-160). Washington DC, US: National Academies Press.

Carstensen, L. L. (1992). Social and emotional patterns in adulthood: Support for socioemotional selectivity theory. Psychology and Aging, 7(3), 331-338. doi:10.1037/0882-7974.7.3.331

Carstensen, L. L. (1993). Motivation for social contact across the life span: A theory of socioemotional selectivity. In J. E. Jacobs (Ed.), Nebraska Symposium on Motivation, 1992: Developmental perspectives on motivation. (pp. 209-254). Lincoln, NE, US: University of Nebraska Press. 
Carstensen, L. L. (2006). The influence of a sense of time on human development. Science, 312(5782), 1913-1915. doi: 10.1126/science.1127488

Carstensen, L. L., Fung, H. H., \& Charles, S. T. (2003). Socioemotional selectivity theory and the regulation of emotion in the second half of life. Motivation and Emotion, 27(2), 103-123. doi: 10.1023/a:1024569803230

Carstensen, L. L., Isaacowitz, D. M., \& Charles, S. T. (1999). Taking time seriously - A theory of socioemotional selectivity. American Psychologist, 54(3), 165-181. doi: 10.1037//0003-066x.54.3.165

Carter, M. A. T., \& Cook, K. (1995). Adaptation to retirement: Role changes and psychological resources. The Career Development Quarterly, 44(1), 67-82. doi: doi.org/10.1037/0882-7974.23.2.422

Caspersen, C. J., Pereira, M. A., \& Curran, K. M. (2000). Changes in physical activity patterns in the United States, by sex and cross-sectional age. Medicine \& Science in Sports \& Exercise, 32(9), 1601-1609.

Charles, S., \& Carstensen, L. L. (2010). Social and emotional aging. Annual Review of Psychology, 61, 383-409. doi: 10.1146/annurev.psych.093008.100448

Charles, S. T. (2010). Strength and vulnerability integration: A model of emotional wellbeing across adulthood. Psychological Bulletin, 136(6), 1068-1091. doi: 10.1037/a0021232

Charles, S. T., Piazza, J. R., Luong, G., \& Almeida, D. M. (2009). Now you see it, now you don't: age differences in affective reactivity to social tensions. Psychology and Aging, 24(3), 645-653. doi: 10.1037/a0016673

Cheney, D. L., Moscovice, L. R., Heesen, M., Mundry, R., \& Seyfarth, R. M. (2010). Contingent cooperation between wild female baboons. Proceedings of the National Academy of Sciences of the United States of America, 107(21), 95629566. doi: 10.1073/pnas.1001862107

Colchero, F., Rau, R., Jones, O. R., Barthold, J. A., Conde, D. A., Lenart, A., ... Torres, C. (2016). The emergence of longevous populations. Proceedings of the National Academy of Sciences, 113(48), 7681-7690.

Corr, J. (2003). Social behavior in aged rhesus macaques. Collegium Antropologicum, 27(1), 87-94.

Corr, J., Martin, L., \& Boysen, S. (2002). Comparative models of cognitive decline in aging great apes. In J. M. Erwin \& P. R. Hof (Eds.), Aging in nonhuman primates (Vol. 31, pp. 196-208). Basel: Karger Publisher.

Costa, P. T., \& McCrae, R. R. (1992). Four ways five factors are basic. Personality and Individual Differences, 13(6), 653-665. 
Craik, F. I., \& Bialystok, E. (2006). Cognition through the lifespan: mechanisms of change. Trends in Cognitive Science, 10(3), 131-138. doi: 10.1016/j.tics.2006.01.007

Crockford, C. (2016). Aging: lessons for elderly people from monkeys. Current Biology, 26(13), 532-534. doi: 10.1016/j.cub.2016.05.002

Crockford, C., Wittig, R. M., Langergraber, K., Ziegler, T. E., Zuberbuhler, K., \& Deschner, T. (2013). Urinary oxytocin and social bonding in related and unrelated wild chimpanzees. Proceedings of the Royal Society of London B: Biological Sciences, 280(1755). doi:10.1098/rspb.2012.2765

Crockford, C., Wittig, R. M., Whitten, P. L., Seyfarth, R. M., \& Cheney, D. L. (2008). Social stressors and coping mechanisms in wild female baboons (Papio hamadryas ursinus). Hormones and Behavior, 53(1), 254-265.

Croft, D. P., James, R., \& Krause, J. (2008). Exploring animal social networks. Princeton, NJ: Princeton University Press.

Cumming, E., \& Henry, W. E. (1961). Growing old: The process of disengagement. New York: Basic Books.

Davis, H. P., Small, S. A., Stern, Y., Mayeux, R., Feldstein, S. N., \& Keller, F. R. (2003). Acquisition, recall, and forgetting of verbal information in long-term memory by young, middle-aged, and elderly individuals. Cortex, 39(4), 10631091.

de Vries, H., Netto, W.J., Hanegraaf, P.L.H. (1993). Matman: A program for the analysis of sociometric matrices and behavioural transition matrices. Behaviour 125, 157-175. DOI: 10.1163/156853993X00218

de Waal, F. B. M. (2000). Attitudinal reciprocity in food sharing among brown capuchin monkeys. Animal Behaviour, 60, 253-261. doi: 10.1006/anbe.2000.1471

de Waal, F. B. M., \& van Roosmalen, A. (1979). Reconciliation and consolation among chimpanzees. Behavioral Ecology and Sociobiology, 5(1), 55-66. doi: 10.1007/BF00302695

Deakin, J., Aitken, M., Robbins, T., \& Sahakian, B. J. (2004). Risk taking during decision-making in normal volunteers changes with age. Journal of the International Neuropsychological Society, 10(04), 590-598. doi: $10.1017 /$ S1355617704104104

Diener, E., \& Seligman, M. E. P. (2002). Very happy people. Psychological Science, 13(1), 81-84. doi: 10.1111/1467-9280.00415

Dreher, J.-C., Meyer-Lindenberg, A., Kohn, P., \& Berman, K. F. (2008). Age-related changes in midbrain dopaminergic regulation of the human reward system. Proceedings of the National Academy of Sciences, 105(39), 15106-15111.

Duane, A. (1922). Studies in monocular and binocular accommodation, with their clinical application. Transactions of the American Ophthalmological Society, 20, 132-157. 
Düzel, E., Bunzeck, N., Guitart-Masip, M., \& Düzel, S. (2010). NOvelty-related Motivation of Anticipation and exploration by Dopamine (NOMAD): Implications for healthy aging. Neuroscience \& Biobehavioral Reviews, 34(5), 660-669. doi: 10.1016/j.neubiorev.2009.08.006

Dunbar, R. I. M. (1991). Functional significance of social grooming in primates. Folia Primatologica, 57(3), 121-131. doi: 10.1159/000156574

Dunbar, R. I. M. (2010). The social role of touch in humans and primates: behavioural function and neurobiological mechanisms. Neuroscience and Biobehavioral Reviews, 34(2), 260-268. doi: 10.1016/j.neubiorev.2008.07.001

Dykstra, P. A. (2009). Older adult loneliness: Myths and realities. European Journal of Ageing, 6(2), 91-100. doi: 10.1007/s10433-009-0110-3

Ebner, N. C., Freund, A. M., \& Baltes, P. B. (2006). Developmental changes in personal goal orientation from young to late adulthood: From striving for gains to maintenance and prevention of losses. Psychology and Aging, 21, 664-678. doi: 10.1037/0882-7974.21.4.664

Ebner, N. C., Maura, G. M., MacDonald, K., Westberg, L., \& Fischer, H. (2013). Oxytocin and socioemotional aging: current knowledge and future trends. Frontiers in Human Neuroscience, 7, 487. doi: 10.3389/fnhum.2013.00487

Eilers, P. H., \& Marx, B. D. (1996). Flexible smoothing with B-splines and penalties. Statistical Science, 11, 89-102.

Fabian, D., \& Flatt, T. (2011). The evolution of aging. Nature Education Knowledge, 2(11), 1-10.

Fairbanks, L. A., \& McGuire, M. (1986). Age, reproductive value, and dominancerelated behaviour in vervet monkey females: cross-generational influences on social relationships and reproduction. Animal Behaviour, 34(6), 1710-1721.

Field, D., \& Minkler, M. (1988). Continuity and change in social support between young-old and old-old or very-old age. Journals of Gerontology, 43(4), 100-106.

Fischer, J., Farnworth, M. S., Sennhenn-Reulen, H., \& Hammerschmidt, K. (2017). Quantifying social complexity. Animal Behaviour, 130, 57-66. DOI: 10.1016/j.anbehav.2017.06.003

Fischer, J. (2004). Emergence of individual recognition by voice in Barbary macaques. Folia Primatologica, 75, 654-661. doi: 10.1016/j.anbehav.2003.08.006

Fischer, J., \& Hammerschmidt, K. (2002). An overview of the Barbary macaque (Macaca sylvanus) vocal repertoire. Folia Primatologica, 73(1), 32-45. doi: $10.1159 / 000060417$

Fischer, J., Kitchen, D. M., Seyfarth, R. M., \& Cheney, D. L. (2004). Baboon loud calls advertise male quality: Acoustic features and their relation to rank, age, and exhaustion. Behavioral Ecology and Sociobiology, 56, 140-148. doi: 10.1007/s00265-003-0739-4 
Fischer, J., Noser, R., \& Hammerschmidt, K. (2013). Bioacoustic field research: A primer to acoustic analyses and playback experiments with primates. American Journal of Primatology, 75(7), 643-663. doi: 10.1002/ajp.22153

Fitts, S. S. (1982). Behavioral stereotypy in old and young rhesus monkeys. Primates, 23(3), 406-415. DOI: 10.1007/BF02381323

Folkow, B., \& Svanborg, A. (1993). Physiology of cardiovascular aging. Physiological Reviews, 73(4), 725-765.

Fontana, L., Partridge, L., \& Longo, V. D. (2010). Extending healthy life span-from yeast to humans. Science, 328(5976), 321-326. doi: 10.1126/science.1172539

Fooden, J. (2007). Systematic review of the Barbary macaque, Macaca sylvanus (Linnaeus, 1758). Fieldiana Zoology 113, 1-58.

Fox, J., Weisberg, S., Adler, D., Bates, D., Baud-Bovy, G., Ellison, S., ... Graves, S. (2016). Package 'car'. Companion to Applied Regression. R Package version, 2.1-2.Retrieved from: https://cran.r-project.org/web/packages/car

Fredrickson, B. L., \& Carstensen, L. L. (1990). Choosing social partners - How old age and anticipated endings make people more selective. Psychology and Aging, 5(3), 335-347. doi: 10.1037//0882-7974.5.3.335

Freund, A. M. (2006). Age-differential motivational consequences of optimization versus compensation focus in younger and older adults. Psychology and Aging, 21, 240-252. doi: 10.1037/0882-7974.21.2.240

Freund, A. M., \& Baltes, P. B. (2000). The orchestration of selection, optimization and compensation: An action-theoretical conceptualization of a theory of developmental regulation. In W. J. Perrig \& A. Grob (Eds.), Control of Human Behavior, Mental Processes, and Consciousness: Essays in honor of the 60th birthday of August Flammer (pp. 35-58). Mahwah, New Jersey London: Lawrence Erlbaum Associates.

Freund, A. M., \& Baltes, P. B. (2002). Life-management strategies of selection, optimization, and compensation: Measurement by self-report and construct validity. Journal of Personality and Social Psychology, 82, 642-662. doi: 10.1037/0022-3514.82.4.642

Freund, A. M., Li, K. Z. H., \& Baltes, P. B. (1999). Successful development and aging: The role of selection, optimization, and compensation. In J. Brandststädter \& R. M. Lerner (Eds.), Action and Self-Development: Theory and Research Through the Life Span (pp. 401-434). CA: Sage: Thousand Oaks.

Freund, A. M., Nikitin, J., \& Riediger, M. (2012). Successful Aging. In R. M. Lerner (Ed.), Handbook of psychology (2 ed., Vol. 6). New York: Wiley.

Freund, A. M., \& Riediger, M. (2001). What I have and what I don't -the role of resource loss and gain throughout life. Applied Psychology, 50(3), 370-380. 
Fry, P. S. (1992). Major social theories of aging and their implications for counseling concepts and practice - A critical review. Counseling Psychologist, 20(2), 246329. doi: $10.1177 / 0011000092202002$

Fung, H. H., Carstensen, L. L., \& Lang, F. R. (2001). Age-related patterns in social networks among European Americans and African Americans: Implications for socioemotional selectivity across the life span. The International Journal of Aging and Human Development, 52(3), 185-206. doi: 10.2190/1ABL-9BE5MOX2-LR9V

Fung, H. H., Carstensen, L. L., \& Lutz, A. M. (1999). Influence of time on social preferences: implications for life-span development. Psychology and Aging, 14(4), 595-604. doi: 10.1037/0882-7974.14.4.595

Fung, H. H., Stoeber, F. S., Yeung, D. Y.-I., \& Lang, F. R. (2008). Cultural specificity of socioemotional selectivity: Age differences in social network composition among Germans and Hong Kong Chinese. The Journals of Gerontology Series B: Psychological Sciences and Social Sciences, 63(3), 156-164.

Gable, S. L. (2006). Approach and avoidance social motives and goals. Journal of Personality, 74(1), 175-222. doi: 10.1111/j.1467-6494.2005.00373.x

Gelman, A (2006). Prior distributions for variance parameters in hierarchical models. Bayesian Analysis, 1(3), 515-533. DOI: 10.1214/06-BA117A

Gilmour, H. (2012). Social participation and the health and well-being of Canadian seniors. Health Reports, 23(4), 23-32.

Goffe, A. S., Zinner, D., \& Fischer, J. (2016). Sex and friendship in a multilevel society: behavioural patterns and associations between female and male Guinea baboons. Behavioral Ecology and Sociobiology, 70(3), 323-336. doi: 10.1007/s00265-015-2050-6

Gomes, C. M., Mundry, R., \& Boesch, C. (2009). Long-term reciprocation of grooming in wild west african chimpanzees. Proceedings of the Royal Society of London B: Biological Sciences, 276(1657), 699-706. doi: 10.1098/rspb.2008.1324

Graney, M. J. (1975). Happiness and social participation in aging. Journal of Gerontology, 30(6), 701-706.

Gust, D. A., Gordon, T. P., Hambright, M. K., \& Wilson, M. E. (1993). Relationship between social factors and pituitary-adrenocortical activity in female rhesus monkeys (Macaca mulatta). Hormones and Behavior, 27(3), 318-331. doi: 10.1006/hbeh.1993.1024

Hamilton, W. D. (1966). The moulding of senescence by natural selection. Journal of Theoretical Biology, 12(1), 12-45.

Hammerschmidt, K., \& Fischer, J. (1998). Maternal discrimination of offspring vocalizations in Barbary macaques (Macaca sylvanus). Primates, 39(2), 231236. doi: 10.1007/BF02557735 
Hammerschmidt, K., \& Todt, D. (1995). Individual differences in vocalizations of young Barbary macaques (Macaca sylvanus) - A multi-parametric analysis to identify critical cues in acoustic signaling. Behaviour, 132, 381-399. doi: $10.1163 / 156853995 \times 00621$

Hartup, W. W., \& Stevens, N. (1997). Friendships and adaptation in the life course. Psychological Bulletin, 121(3), 355-370.

Haunhorst, C. B., Schülke, O., \& Ostner, J. (2016). Opposite-sex social bonding in wild Assamese macaques. American Journal of Primatology, 78(8), 872-882. doi: 10.1002/ajp.22554

Hauser, M. D., \& Tyrrell, G. (1984). Old age and its behavioral manifestations - A study on 2 species of macaque. Folia Primatologica, 43(1), 24-35. doi: $10.1159 / 000156168$

Havighurst, R. J. (1961). Successful aging. Gerontologist, 1(1), 8-13. doi: 10.1093/geront/1.1.8.

Heckhausen, J., \& Schulz, R. (1995). A life-span theory of control. Psychological Review, 102(2), 284-304.

Hendricks, J., \& Cutler, S. J. (2004). Volunteerism and socioemotional selectivity in later life. The Journals of Gerontology Series B: Psychological Sciences and Social Sciences, 59(5), 251-257. doi: 10.1093/geronb/59.5.S251

Henkel, S. (2008). Social dominance, male-infant interactions and grooming and their influence on glucocorticoid levels in male Barbary macaques (Macaca sylvanus). Diploma Thesis, Georg-August-Universität, Göttingen.

Henkel, S., Heistermann, M., \& Fischer, J. (2010). Infants as costly social tools in male Barbary macaque networks. Animal Behaviour, 79(6), 1199-1204. doi: 10.1016/j.anbehav.2010.02.005

Herndon, J. G., Moss, M. B., Rosene, D. L., \& Killiany, R. J. (1997). Patterns of cognitive decline in aged rhesus monkeys. Behavioural Brain Research, 87(1), 25-34. doi: 10.1016/s0166-4328(96)02256-5

Hesler, N., \& Fischer, J. (2007). Gestural communication in Barbary macaques (Macaca sylvanus): An overview. In J. Call \& M. Tomasello (Eds.), The gestural communication in apes and monkeys (pp. 159-196). New Jersey: Lawrence Erlbaum Associates.

Hobfoll, S. E. (1989). Conservation of resources: A new attempt at conceptualizing stress. American Psychologist, 44(3), 513-524. doi: 10.1037/0003066X.44.3.513

Hoffman, C. L., Higham, J. P., Mas-Rivera, A., Ayala, J. E., \& Maestripieri, D. (2010). Terminal investment and senescence in rhesus macaques (Macaca mulatta) on Cayo Santiago. Behavioral Ecology, 21(5), 972-978. doi: 10.1093/beheco/arq098 
Holt-Lunstad, J., Smith, T. B., \& Layton, J. B. (2010). Social relationships and mortality risk: a meta-analytic review. PLoS Medicine, 7(7), e1000316. doi: 10.1371/journal.pmed.1000316.

Hosaka, K., \& Huffman, M. (2015). Gerontology. In M. Nakamura, K. Hosaka, N. Itoh, \& K. Zamma (Eds.), Mahale Chimpanzees: 50 Years of Research (pp. 313-325). Cambridge: Cambridge University Press.

Hothorn, T., Bretz, F., Westfall, P., \& Heiberger, R. M. (2008). Multcomp: simultaneous inference in general parametric models. $R$ package version 1.0-0: $R$ Foundation for Statistical Computing Vienna, Austria.

Huffman, M. A. (1990). Some socio-behavioral manifestations of old age. In T. Nishida (Ed.), The chimpanzees of the Mahale Mountains - Sexual and Life History Strategies (pp. 237-255). Tokyo: University of Tokyo Press.

Jensen, G. D., Blanton, F., \& Gribble, D. H. (1980). Older monkeys'(Macaca radiata) response to new group formation: Behavior, reproduction and mortality. Experimental Gerontology, 15(5), 399-406.

Jones, O. R., Scheuerlein, A., Salguero-Gómez, R., Camarda, C. G., Schaible, R., Casper, B. B., ... Menges, E. S. (2014). Diversity of ageing across the tree of life. Nature, 505(7482), 169-173. doi: 10.1038/nature12789

Kahneman, D., \& Tversky, A. (1979). Prospect theory: an analysis of decision under risk. Econometrica, 47(2), 263-291. doi: 10.2307/1914185

Kappeler, P. M., \& van Schaik, C. P. (1992). Methodological and evolutionary aspects of reconciliation among primates. Ethology, 92(1), 51-69. doi: 10.1111/j.14390310.1992.tb00948.x

Kato, E. (1999). Effects of age, dominance, and seasonal changes on proximity relationships in female Japanese macaques (Macaca fuscata) in a free-ranging group at Katsuyama. Primates, 40(2), 291-300. doi: 10.1007/bf02557553

Keene, A. C., \& Joiner, W. J. (2015). Neurodegeneration: paying it off with sleep. Current Biology, 25(6), 234-236. doi: 10.1016/j.cub.2015.02.003

Keverne, E. B., Martensz, N. D., \& Tuite, B. (1989). Beta-endorphin concentrations in cerebrospinal-fluid of monkeys are influenced by grooming relationships. Psychoneuroendocrinology, 14(1-2), 155-161. doi: 10.1016/03064530(89)90065-6

Kirkwood, T. B., \& Austad, S. N. (2000). Why do we age? Nature, 408(6809), 233-238. doi: $10.1038 / 35041682$

Klein, N., Kneib, T., Lang, S., \& Sohn, A. (2015). Bayesian structured additive distributional regression with an application to regional income inequality in Germany. The Annals of Applied Statistics, 2(9), 1024-1052. doi: 10.1214/15AOAS823 
Knapp, J. (2009). Disengagement theory. In C.B. Bryant \& D.L. Peck (Eds.), Encyclopedia of Death and the Human Experience (pp. 382-383). Thousand Oaks, California: SAGE Publications, Inc.

Koski, S. E., Koops, K., \& Sterck, E. H. (2007). Reconciliation, relationship quality, and postconflict anxiety: Testing the integrated hypothesis in captive chimpanzees. American Journal of Primatology, 69(2), 158-172. doi: 10.1002/ajp.20338

Kuester, J., \& Paul, A. (1999). Male migration in Barbary macaques (Macaca sylvanus) at Affenberg Salem. International Journal of Primatology, 20(1), 85-106. doi: 10.1023/a:1020536317646

Kumar, S., \& Hedges, S. B. (1998). A molecular timescale for vertebrate evolution. Nature, 392(6679), 917-920. doi: 10.1038/31927

Kuznetsova, A., Brockhoff, P. B., \& Christensen, R. H. B. (2015). ImerTest: Tests in linear mixed effects models. R package version 2.0-25. URL http://CRAN.Rproject.org/package $=$ ImerTest.

Lang, F. R. (2000). Endings and continuity of social relationships: Maximizing intrinsic benefits within personal networks when feeling near to death. Journal of Social and Personal Relationships, 17(2), 155-182. doi: 10.1177/0265407500172001

Lang, F. R., \& Carstensen, L. L. (1994). Close emotional relationships in late life: further support for proactive aging in the social domain. Psychology and Aging, 9(2), 315. doi: 10.1037/0882-7974.9.2.315

Lang, F. R., Staudinger, U. M., \& Carstensen, L. L. (1998). Perspectives on socioemotional selectivity in late life: how personality and social context do (and do not) make a difference. The Journals of Gerontology Series B: Psychological Sciences and Social Sciences, 53(1), 21-30. doi: 10.1093/geronb/53B.1.

Lansford, J. E., Sherman, A. M., \& Antonucci, T. C. (1998). Satisfaction with social networks: An examination of socioemotional selectivity theory across cohorts. Psychology and Aging, 13(4), 544-552. doi: 10.1037/0882-7974.13.4.544

Lemaître, J.-F., Berger, V., Bonenfant, C., Douhard, M., Gamelon, M., Plard, F., \& Gaillard, J.-M. (2015). Early-late life trade-offs and the evolution of ageing in the wild. Proceedings of the Royal Society B Biological Sciences, 282, 2015020920150209. doi: 10.1098/rspb.2015.0209

Lemasson, A., Palombit, R. A., \& Jubin, R. (2008). Friendships between males and lactating females in a free-ranging group of olive baboons (Papio hamadryas anubis): evidence from playback experiments. Behavioral Ecology and Sociobiology, 62(6), 1027-1035. doi: 10.1007/s00265-007-0530-z

Lemon, B. W., Bengtson, V. L., \& Peterson, J. A. (1972). Exploration of activity theory of aging - Activity types and life satisfaction among in-movers to a retirement community. Journals of Gerontology, 27(4), 511-523.

Lett, H. S., Blumenthal, J. A., Babyak, M. A., Strauman, T. J., Robins, C., \& Sherwood, A. (2005). Social support and coronary heart disease: epidemiologic evidence 
and implications for treatment. Psychosomatic Medicine, 67(6), 869-878. doi: 10.1097/01.psy.0000188393.73571.0a

Li, K.Z.H., Lindenberger U., Freund A. M., \& Baltes, B. P. (2001). Walking while memorizing: Age-related differences in compensatory behavior. Psychological Science, 12(3), 230-237. doi: 10.1111/1467-9280.00341.

Lucas, R. E., \& Donnellan, M. B. (2011). Personality development across the life span: Longitudinal analyses with a national sample from Germany. Journal of Personality and Social Psychology, 101, 847-861. doi: 10.1037/a0024298

Maddox, G. L., Jr. (1964). Disengagement theory: A critical evaluation. The Gerontologist, 57, 80-82.

Maestripieri, D., \& Hoffman, C. L. (2012). Behavior and social dynamics of rhesus macaques on Cayo Santiago. In Q. Wang (Ed.), Bones, genetics, and behavior of rhesus macaques (pp. 247-262). Springer.

Maestripieri, D., \& Roney, J. R. (2006). Evolutionary developmental psychology: Contributions from comparative research with nonhuman primates. Developmental Review, 26(2), 120-137. doi:10.1016/j.dr.2006.02.006

Magariños, M., Milo, M., \& Varela-Nieto, I. (2015). Editorial: Aging, neurogenesis and neuroinflammation in hearing loss and protection. Frontiers in Aging Neuroscience, 7(183). doi: 10.3389/fnagi.2015.00138

Maier, H., \& Klumb, P. L. (2005). Social participation and survival at older ages: Is the effect driven by activity content or context? European Journal of Ageing, 2, 3139.

Manrique, H. M., \& Call, J. (2015). Age-dependent cognitive inflexibility in great apes. Animal Behaviour, 102, 1-6. doi. 10.1016/j.anbehav.2015.01.002

Massen, J. J., Antonides, A., Arnold, A. M. K., Bionda, T., \& Koski, S. E. (2013). A behavioral view on chimpanzee personality: exploration tendency, persistence, boldness, and tool-orientation measured with group experiments. American Journal of Primatology, 75(9), 947-958. doi. 10.1002/ajp.20338

Mata, R., Josef, A. K., Samanez-Larkin, G. R., \& Hertwig, R. (2011). Age differences in risky choice: A meta-analysis. Annals of the New York Academy of Sciences, 1235(1), 18-29. doi: 10.1111/j.1749-6632.2011.06200.x

McDonald, R. (2014). Biology of aging. Garland science: Taylor \& Francis Group, LLC.

Menard, N., \& Vallet, D. (1993). Population dynamics of Macaca sylvanus in Algeria: A 8-year study. American Journal of Primatology, 30(2), 101-118. doi: 10.1002/ajp.1350300203

Micheletta, J., Waller, B. M., Panggur, M. R., Neumann, C., Duboscq, J., Agil, M., \& Engelhardt, A. (2012). Social bonds affect anti-predator behaviour in a tolerant species of macaque, Macaca nigra. Proceedings of the Royal Society of London B: Biological Sciences, 279(1744), 4042-4050. doi: 10.1098/rspb.2012.1470 
Müller, N., Heistermann, M., Strube, C., Schülke, O., \& Ostner, J. (2017). Age, but not anthelmintic treatment, is associated with urinary neopterin levels in semi-free ranging Barbary macaques. Scientific Reports, 7, 2045-2322, DOI: 10.1038/srep41973.

Nakamichi, M. (1984). Behavioral characteristics of old female Japanese monkeys in a free-ranging group. Primates, 25(2), 192-203. doi: 10.1007/BF02382391

Nakamichi, M. (2003). Age-related differences in social grooming among adult female Japanese monkeys (Macaca fuscata). Primates, 44(3), 239-246. doi: 10.1007/s10329-003-0036-x

Nakamura, T. M., Morin, G. B., Chapman, K. B., Weinrich, S. L., Andrews, W. H., Lingner, J., ... Cech, T. R. (1997). Telomerase catalytic subunit homologs from fission yeast and human. Science, 277(5328), 955-959. doi: 10.1126/science.277.5328.955

Nikitin, J., Burgermeister, L. C., \& Freund, A. M. (2012). The role of age and social motivation in developmental transitions in young and old adulthood. Frontiers in Psychology, 3, 1-14. doi: 0.3389/fpsyg.2012.00366

Nikitin, J., \& Freund, A. M. (2011). Age and motivation predict gaze behavior for facial expressions. Psychology and Aging, 26(3), 695-700. doi: 10.1037/a0023281.

Nikitin, J., Schoch, S., \& Freund, A. M. (2014). The role of age and motivation for the experience of social acceptance and rejection. Developmental Psychology, 50(7), 1943-1950. doi: 10.1037/a0036979

O'Toole, P. W., \& Jeffery, I. B. (2015). Gut microbiota and aging. Science, 350(6265), 1214-1215. doi: 10.1126/science.aac8469

Ostner, J., \& Schülke, O. (2014). The evolution of social bonds in primate males. Behaviour, 151(7), 871-906. doi: 10.1163/1568539X-00003191

Ostner, J., Vigilant, L., Bhagavatula, J., Franz, M., \& Schülke, O. (2013). Stable heterosexual associations in a promiscuous primate. Animal Behaviour, 86(3), 623-631. doi: 10.1016/j.anbehav.2013.07.004

Otte, C., Hart, S., Neylan, T. C., Marmar, C. R., Yaffe, K., \& Mohr, D. C. (2005) A metaanalysis of cortisol response to challenge in human aging: importance of gender. Psychoneuroendocrinology, 30(1), 80-91. doi: 10.1016/j.psyneuen.2004.06.002

Park, J. S., Lee, S. H., Na, H. J., Pyo, J. H., Kim, Y. S., \& Yoo, M. A. (2012). Age- and oxidative stress-induced DNA damage in Drosophila intestinal stem cells as marked by Gamma-H2AX. Experimental Gerontology, 47(5), 401-405. doi: 10.1016/j.exger.2012.02.007

Patzelt, A. (2006). Versöhnungsverhalten bei Berberaffen (Macaca sylvanus). (Diploma Thesis), Georg-August-Universität, Göttingen.

Patzelt, A., Pirow, R., \& Fischer, J. (2009). Post-conflict affiliation in Barbary macaques is influenced by conflict characteristics and relationship quality, but does not 
diminish short-term renewed aggression. Ethology, 115(7), 658-670. doi: 10.1111/j.1439-0310.2009.01649.x

Paul, A., \& Kuester, J. (1985). Intergroup transfer and incest avoidance in semifreeranging Barbary macaques (Macaca sylvanus) at Salem. American Journal of Primatology, 8(4), 317-322. DOI: 10.1002/ajp.1350080407

Paul, A., \& Kuester, J. (1987). Dominance, kinship and reproductive value in female Barbary macaques (Macaca sylvanus) at Affenberg Salem. Behavioral Ecology and Sociobiology, 21(5), 323-331. doi: 10.1007/BF00299970

Paul, A., Kuester, J., \& Podzuweit, D. (1993). Reproductive senescence and terminal investment in female Barbary macaques (Macaca sylvanus) at Salem. International Journal of Primatology, 14(1), 105-124. doi: 10.1007/bf02196506

Pavelka, M. S. M. (1990). Do old female monkeys have a specific social role. Primates, 31(3), 363-373. doi: 10.1007/bf02381107

Pavelka, M. S. M. (1991). Sociability in old female Japanes monkeys: human versus nonhuman primate aging. American Anthropologist, 93(3), 588-598. doi: 10.1525/aa.1991.93.3.02a00030

Perlman, D., \& Peplau, L. A. (1981). Toward a social psychology of loneliness. In R. Gilmour, \& S. Duck (Eds.), Personal Relationships: 3. Relationships in Disorder (pp. 31-56). London: Academic Press.

Peters, A., Rosene, D. L., Moss, M. B., Kemper, T. L., Abraham, C. R., Tigges, J., \& Albert, M. S. (1996). Neurobiological bases of age-related cognitive decline in the rhesus monkey. Journal of Neuropathology \& Experimental Neurology, 55(8), 861-874. doi: 10.1097/00005072-199608000-00001

Pfefferle, D., Heistermann, M., Hodges, J. K., \& Fischer, J. (2008). Male Barbary macaques eavesdrop on mating outcome: A playback study. Animal Behaviour, 75, 1885-1891. doi: 10.1016/j.anbehav.2007.12.003

Picq, J. L. (1992). Aging and social behavior in captivity in Microcebus murinus. Folia Primatologica, 59(4), 217-220. doi: 10.1159/000156664

Ploss, A. (2010). Social network analysis in Barbary macaques (Macaca sylvanus) Evaluation of network metrics. (Diploma Thesis), Georg-August-Universität, Göttingen.

Prettner, K. (2013). Population aging and endogenous economic growth. Journal of Population Economics, 26(2), 811-834. doi: 10.1007/s00148-012-0441-9

Preuschoft, S., Paul, A., \& Kuester, J. (1998). Dominance styles of female and male Barbary macaques (Macaca sylvanus). Behaviour, 135, 731-755.

Rathke, E. M., Berghänel, A., Bissonnette, A., Ostner, J., \& Schülke, O. (2017). Agedependent change of coalitionary strategy in male Barbary macaques. Primate Biology, 4(1), 1-7. doi: 10.5194/pb-4-1-2017 
Ratnayeke, S. (1994). The behavior of postreproductive females in a wild population of toque macaques (Macaca sinica) in Sri-Lanka. International Journal of Primatology, 15(3), 445-469. doi: 10.1007/bf02696103

Raz, N., Gunning-Dixon, F. M., Head, D., Dupuis, J. H., \& Acker, J. D. (1998). Neuroanatomical correlates of cognitive aging: evidence from structural magnetic resonance imaging. Neuropsychology, 12(1), 95-114. doi: 10.1037/0894-4105.12.1.95

R development core team, (2015). R: a language and environment for statistical computing. Vienna, Austria: R Foundation for Statistical Computing. URL http://www.R-project.org/

Reale, D., Reader, S. M., Sol, D., McDougall, P. T., \& Dingemanse, N. J. (2007). Integrating animal temperament within ecology and evolution. Biological Reviews, 82(2), 291-318. doi: 10.1111/j.1469-185X.2007.00010.x

Rhesus macaque genome sequencing and analysis consortium, Gibbs, RA, Rogers, J., Katze, M.G., Burmgarner, R., ... Zwieg, A.S. (2007). The Rhesus macaque genome sequence informs biomedical and evolutionary analyses. Science, 316, 222-234. doi: 10.1126/science.1139247

Rhodes, M. G. (2004). Age-related differences in performance on the Wisconsin card sorting test: a meta-analytic review: American Psychological Association, 19(3), 482-494. doi: 10.1037/0882-7974.19.3.482

Richerson, P. J., \& Boyd, R. (1998). The evolution of human ultrasociality. In I. EiblEibisfeldt \& F. Salter (Eds.), Indoctrinability, ideology, and warfare: Evolutionary perspectives (pp. 71-95). New York: Berghan Books.

Riediger, M., \& Freund, A. M. (2006). Focusing and restricting: Two aspects of motivational selectivity in adulthood. Psychology and Aging, 21, 173-185. doi: 10.1037/0882-7974.21.1.173

Rohleder, N., Beulen, S. E., Chen, E., Wolf, J. M., \& Kirschbaum, C. (2007). Stress on the Dance Floor: The Cortisol Stress Response to Social-Evaluative Threat in Competitive Ballroom Dancers. Personality and Social Psychology Bulletin, 33(1), 69-84. doi: 10.1177/0146167206293986

Rosati, A. G., Arre, A. M., Platt, M. L., \& Santos, L. R. (2016). Rhesus monkeys show human-like changes in gaze following across the lifespan. Proceedings of the Royal Society of London B: Biological Sciences, 283, 20160376. doi: 10.1098/rspb.2016.0376

Rosen, J. L., \& Neugarten, B. L. (1960). Ego functions in the middle and later years: A thematic apperception study of normal adults. Journal of Gerontology, 15, 6267.

Roth, G. S., Mattison, J. A., Ottinger, M. A., Chachich, M. E., Lane, M. A., \& Ingram, D. K. (2004). Aging in rhesus monkeys: Relevance to human health interventions. Science, 305(5689), 1423-1426. doi: 10.1126/science.1102541 
Roubová, V., Konečná, M., Šmilauer, P., \& Wallner, B. (2015). Whom to groom and for what? Patterns of grooming in female Barbary macaques (Macaca sylvanus). Plos One, 10(2), e0117298. doi: 10.1371/journal.pone.0117298

Ryu, H., Graham, K. E., Sakamaki, T., \& Furuichi, T. (2016). Long-sightedness in old wild bonobos during grooming. Current Biology, 26(21), 1131-1132. doi: 10.1016/j.cub.2016.09.019

Sallis, J. F. (2000). Age-related decline in physical activity: a synthesis of human and animal studiesMedicine \& Science in Sports \& Exercise, 32(9), 1598-1600.

Sapolsky, R. M., Alberts, S. C., \& Altmann, J. (1997). Hypercortisolism associated with social subordinance or social isolation among wild baboons. Archives of General Psychiatry, 54(12), 11371143.10.1001/archpsyc.1997.01830240097014

Sapolsky, R. M., \& Altmann, J. (1991). Incidence of hypercortisolism and dexamethasone resistance increases with age among wild baboons. Biological Psychiatry, 30(10), 1008-1016. doi: 10.1016/0006-3223(91)90121-2

Schell, A., Rieck, K., Schell, K., Hammerschmidt, K., \& Fischer, J. (2011). Adult but not juvenile Barbary macaques spontaneously recognize group members from pictures. Animal Cognition, 14(4), 503-509. doi: 10.1007/s10071-011-0383-8

Schino, G., \& Aureli, F. (2009). Reciprocal altruism in primates: partner choice, cognition, and emotions Advances in the Study of Behavior (39), 45-69.

Schino, G., \& Sciarretta, M. (2016). Patterns of Social Attention in Mandrills, Mandrillus sphinx. International Journal of Primatology, 37(6), 752-761. doi: 10.1007/s10764-016-9936-7

Schino, G., Scucchi, S., Maestripieri, D., \& Turillazzi, P. G. (1988). Allogrooming as a tension-reduction mechanism - A behavioral approach. American Journal of Primatology, 16(1), 43-50. doi: 10.1002/ajp.1350160106

Schülke, O., Bhagavatula, J., Vigilant, L., \& Ostner, J. (2010). Social bonds enhance reproductive success in male macaques. Current Biology, 20(24), 2207-2210. doi: 10.1016/j.cub.2010.10.058

Seyfarth, R. M., \& Cheney, D. L. (2012). The evolutionary origins of friendship. Annual Review of Psychology, 63, 153-177. doi: 10.1146/annurev-psych-120710100337

Shutt, K., MacLarnon, A., Heistermann, M., \& Semple, S. (2007). Grooming in Barbary macaques: Better to give than to receive? Biological Letters, 3(3), 231-233. doi: 10.1098/rsbl.2007.0052

Silk, J. B. (2002). Using the'F'-word in primatology. Behaviour, 139(2-3), 421-446. doi: $10.1163 / 156853902760102735$.

Silk, J. B., Alberts, S. C., \& Altmann, J. (2003). Social bonds of female baboons enhance infant survival. Science, 302(5648), 1231-1234. doi: 10.1126/science. 1088580 
Silk, J. B., Beehner, J. C., Bergman, T. J., Crockford, C., Engh, A. L., Moscovice, L. R., ... Cheney, D. L. (2010). Strong and consistent social bonds enhance the longevity of female baboons. Current Biology, 20(15), 1359-1361. doi: 10.1016/j.cub.2010.05.067

Slessor, G., Venturini, C., Bonny, E. J., Insch, P. M., Rokaszewicz, A., \& Finnerty, A. N. (2016). Specificity of age-related differences in eye-gaze following: evidence from social and nonsocial stimuli. The Journals of Gerontology Series B: Psychological Sciences and Social Sciences, 71(1), 11-22. doi: 10.1093/geronb/gbu088

Small, M. F. (1990a). Alloparental behavior in Barbary macaques (Macaca sylvanus). Animal Behaviour, 39, 297-306. doi: 10.1016/s0003-3472(05)80874-7

Small, M. F. (1990b). Promiscuity in Barbary macaques (Macaca sylvanus). American Journal of Primatology, 20(4), 267-282. doi: 10.1002/ajp.1350200403

Sosa, S. O. (2016). The influence of gender, age, matriline and hierarchical rank on individual social position, role and interactional patterns in Macaca sylvanus at 'La Forêt des singes': A multilevel social network approach. Frontiers in Psychology, 7, 529. doi: 10.3389/fpsyg.2016.00529

Spear, L.-P. (2004). Adolescent brain development and animal models. Annals of the New York Academy of Science, 1021(1), 23-26. doi: 10.1196/annals.1308.002

Staudinger, U. M., Smith, J., \& Baltes, P. B. (1992). Wisdom-related knowledge in a life review task: age differences and the role of professional specialization. Psychology and Aging, 7(2), 271-281. doi: 10.1037/0882-7974.7.2.271

Stawski, R. S., Cichy, K. E., Piazza, J. R., \& Almeida, D. M. (2013). Associations among Daily Stressors and Salivary Cortisol: Findings from the National Study of Daily Experiences. Psychoneuroendocrinology, 38(11), 2654-2665. doi: 10.1016/j.psyneuen.2013.06.023

Suomi, S. J., Novak, M. A., \& Well, A. (1996). Aging in rhesus monkeys: Different windows on behavioral continuity and change. Developmental Psychology, 32(6), 1116-1128. doi: 10.1037//0012-1649.32.6.1116

Tarou, L. R., Bloomsmith, M. A., Hoff, M. P., Erwin, J. M., \& Maple, T. L. (2002). The behavior of aged great apes. In J. M. Erwin \& P. R. Hof (Eds.), Aging in Nonhuman Primates (Vol. 31, pp. 209-231). Basel: Karger.

Taub, D. M. (1980). Testing the agonistic buffering hypothesis . I. Dynamics of participation in the triadic interaction. Behavioral Ecology and Sociobiology, 6(3), 187-197. doi: 10.1007/bf00569200

Thierry, B. (2000a). Covariation of conflict management patterns across macaque species. In F. Aureli \& F. B. M. de Waal (Eds.), Natural conflict resolution (pp. 106-128). Berkeley: University of California Press. 
Thierry, B. (2000b). Social epigenisis. In B. S. Thierry, M. Kaumanns, W. (Eds.), Macaque societies: A model for the study of social organisation (pp. 267-289). Cambridge: Cambridge University Press.

Thierry, B., Iwaniuk, A. N., \& Pellis, S. M. (2000). The influence of phylogeny on the social behaviour of macaques (Primates: Cercopithecidae, genus Macaca). Ethology, 106(8), 713-728.

Thomas, P. D., Goodwin, J. M., \& Goodwin, J. S. (1985). Effect of social support on stress-related changes in cholesterol level, uric acid level, and immune function in an elderly sample. American Journal of Psychiatry, 142(6), 735-737. doi: 10.1176/ajp.142.6.735

Tiddi, B., Aureli, F., di Sorrentino, E. P., Janson, C. H., \& Schino, G. (2011). Grooming for tolerance? Two mechanisms of exchange in wild tufted capuchin monkeys. Behavioral Ecology, 22(3), 663-669. doi: 10.1093/beheco/arr028

Tobin, S. S., \& Neugarten, B. L. (1961). Life satisfaction and social interaction in the aging. Journal of Gerontology, 16, 344-346. doi: 10.1093/geronj/16.4.344

Torre, P., \& Fowler, C. G. (2000). Age-related changes in auditory function of rhesus monkeys (Macaca mulatta). Hearing Research, 142(1-2), 131-140. doi: 10.1016/S0378-5955(00)00025-3

Turckheim, G., \& Merz, E. (1984). Breeding Barbary macaques in outdoor open enclosures. In J.E. Fa, (Ed.). The Barbary macaque: A case study in conservation (pp. 241-261). New York: Plenum Press.

Uchino, B. N., Cawthon, R. M., Smith, T. W., Light, K. C., McKenzie, J., Carlisle, M., ... Bowen, K. (2012). Social relationships and health: Is feeling positive, negative, or both (ambivalent) about your social ties related to telomeres? Health Psychology, 31(6), 789-796. doi: 10.1037/a0026836

Uchino, B. N., Holt-Lunstad, J., Uno, D., \& Flinders, J. B. (2001). Heterogeneity in the social networks of young and older adults: Prediction of mental health and cardiovascular reactivity during acute stress. Journal of Behavioral Medicine, 24(4), 361-382. doi: 10.1023/A:1010634902498

United Nations Report. Department of Economic and Social Affairs Population Division. (2015). World Population Ageing 2015 - Highlights (ST/ESA/SER.A/368).

Veenema, H. C., Spruijt, B. M., Gispen, W. H., \& van Hooff, J. (1997). Aging, dominance history, and social behavior in Java-monkeys (Macaca fascicularis). Neurobiology of Aging, 18(5), 509-515. doi: 10.1016/s0197-4580(97)00107-3

Veenema, H. C., van Hooff, J., Gispen, W. H., \& Spruijt, B. M. (2001). Increased rigidity with age in social behavior of Java-monkeys (Macaca fascicularis). Neurobiology of Aging, 22(2), 273-281. doi: 10.1016/s0197-4580(00)00204-9

Verbrugge, L. M., Gruber-Baldini, A. L., \& Fozard, J. L. (1996). Age differences and age changes in activities: Baltimore longitudinal study of aging. Journals of Gerontology Series B-Psychological Sciences and Social Sciences, 51(1), 3041. 
Verdier, J.-M., Acquatella, I., Lautier, C., Devau, G., Trouche, S., Lasbleiz, C., \& Mestre-Francés, N. (2015). Lessons from the analysis of nonhuman primates for understanding human aging and neurodegenerative diseases. Frontiers in Neuroscience, 9, 64. doi: 10.3389/fnins.2015.00064

Vitzthum, V. J. (2008). Evolutionary models of women's reproductive functioning. Annual Review of Anthropology, 37, 53-73. doi: 10.1146/annurev.anthro.37.081407.085112

Vogel, J. M., Davis, J. W., Nomura, A., Wasnich, R. D., \& Ross, P. D. (1997). The effects of smoking on bone mass and the rates of bone loss among elderly Japanese-American men. Journal of Bone and Mineral Research, 12(9), 14951501.

Wahl, H., \& Rott, C. (2002). Konzepte und Definitionen der Hochaltrigkeit. In Deutsches Zentrum für Altresfragen (Ed.), Expertise im Auftrag der Geschäftsstelle der Sachverständigenkommission für den 4. Altenbericht der Bundesregierung (pp. 5-95). Hannover: Vincentz-Verlag.

Wang, H.-X., Karp, A., Winblad, B., \& Fratiglioni, L. (2002). Late-life engagement in social and leisure activities is associated with a decreased risk of dementia: a longitudinal study from the Kungsholmen project. American Journal of Epidemiology, 155(12), 1081-1087.

Watson, K. K., Li, D., Brent, L. J. N., Horvath, J. E., Gonzalez-Martinez, J., RuízLambides, A. V., ... Platt, M. L. (2015). Genetic influences on social attention in free-ranging rhesus macaques. Animal Behaviour, 103, 267-275. doi: https://doi.org/10.1016/j.anbehav.2015.02.012

Whitten, P. L. (1987). Infants and adult males. In B. B. Smuts, D. L. Cheney, R. M. Seyfarth, R. W. Wrangham, \& T. T. Struhsaker (Eds.), Primate societies. Chicago: University of Chicago.

Williams G. C. (1966). Adaptation and natural selection: a critique of some current evolutionary thought. Princeton, NJ: Princeton University Press.

Winter, D. G. (1994). Manual for scoring motive imagery in running text:(Version 4.2).

Wittig, R. M., Crockford, C., Weltring, A., Deschner, T., \& Zuberbühler, K. (2015). Single aggressive interactions increase urinary glucocorticoid levels in wild male chimpanzees. PLos ONE, 10(2), e0118695. doi: 10.1371/journal.pone.0118695.

Wittig, R. M., Crockford, C., Lehmann, J., Whitten, P. L., Seyfarth, R. M., \& Cheney, D. L. (2008). Focused grooming networks and stress alleviation in wild female baboons. Hormones and Behavior, 54(1), 170-177. doi: 10.1016/j.yhbeh.2008.02.009

Wrangham, R. W. (1980). An ecological model of female-bonded primate groups. Behaviour, 75, 262-300. doi: 10.1163/156853980X00447 
Young, C., Majolo, B., Heistermann, M., Schülke, O., \& Ostner, J. (2014). Responses to social and environmental stress are attenuated by strong male bonds in wild macaques. Proceedings of the National Academy of Sciences, 111(51), 1819518200. doi: 10.1073/pnas.1411450111

Zeileis, A., Kleiber, C., \& Jackman, S. (2008). Regression models for count data in R. Journal of Statistical Software, 27(8), 1-25 DOI: 10.18637/jss.v027.i08. 


\section{Acknowledgements}

First of all, I thank Julia Fischer for giving me the opportunity to work with the monkeys and much more important for supporting me with remarkable scientific and emotional competence continuously since I started as a Bachelor student at her lab. I am really glad and grateful for all your patience and all your help.

Second, I thank the members of my thesis committee, Margarete Boos and Julia Ostner, for valuable input from an interdisciplinary perspective. Particularly Julia Ostner I thank for co-supervising my thesis.

Third, I thank Claudia Fichtel, Tanya Behne and Bernhard Fink, who agreed to be in the examination board.

Moreover, I thank Ellen Merz, Gilbert de Turckheim and Guillaume de Turckheim for permission to conduct the data collection for my dissertation at 'La Forêt des Singes' in Rocamadour. Especially I am grateful to Ellen Merz, who supported me directly at site. I am also grateful to the team at La Forêt des Singes and Xavier Costes in particular, for their eagerness to facilitate our data collection.

I thank Kurt Hammerschmidt for many fruitful discussions and also practical help.

I thank Alexandra M. Freund for all her helpful comments and the discussions we had, for inviting me to spend some time at her lab and encouraging me to write up my thesis.

I thank Holger-Sennhenn Reulen for substantial statistical support.

I thank all my field assistants, Bachelor and Master-students, who were involved in the collection of data or analysis: Elena Jeß, Dominique Treschnak, Laura Tschernek, Heather Sanders, Julia Mörchen, Lisa Wenzel and Annika Huber. Aside from the working aspects: thank you a lot for the funny times we had in the "field".

In addition, I thank Andreas Ploss and Annika Patzelt whose behavioral data on female Barbary macaques I incorporated in my dissertation studies. 
I thank all members of the Cognitive Ethology Lab (current and past) for the great working atmosphere, all the scientific input I got and the fun at the retreats. Especially in the recent time you were especially nice and supportive. Special thanks to Rebecca, who managed to remain such a good friend aside from her role as the program coordinator. Special thanks also to Ludwig Ehrenreich, who was always available to help with all the problems that may occur and Mechthild Pohl and Chris Schloegl for support in administrative issues. Moreover, I thank Friederike Hillemann who helped me with tons of 'small' things since we started long ago to work with the Barbary macaques together as well as Eva-Maria Rathke and Franziska Wegdell, who particularly supported me a lot in the last year.

Moreover, I thank the team of the Life-Management Lab in Zurich for the nice stay and for discussing my project with me.

I thank the Leibniz ScienceCampus for Primate Cognition for funding my stay in Zurich and provisioning of travel support for the IPS in Chicago as well as the Erich Carl Raddatz foundation for funding to take part in the EFP in Rome, which gave me the opportunity to discuss my research with the scientific community.

In addition, I would like to thank Dana Pfefferle, Stefanie Keupp, Kurt Hammerschmidt, Alexandra M. Freund, Greg M. Sax, Friederike Hillemann, Brian Cardini, Nives Vajda, Vanessa Wilson, Eva-Maria Rathke and Franziska Wegdell for comments and corrections on previous versions of the manuscript.

I thank the family Cailles and Valerie in particular, for incorporating me in their family while I stayed at their wonderful Camping les Cigales in Rocamadour.

Finally, I want to thank all my friends and family members for supporting me with my dissertation and especially their constant trying to involve me in leisure time activities and for the great times we had. I am really happy for all of your encouraging messages you have send me recently. 